\title{
Morphological, histological and behavioural change in two species of marine bivalves in response to environmental stress
}

A thesis submitted in partial fulfilment for the requirements for the degree of Master of Science in Marine Biology

Dayanitha Angela Damodaran 2020

School of Biological Sciences

Victoria University of Wellington

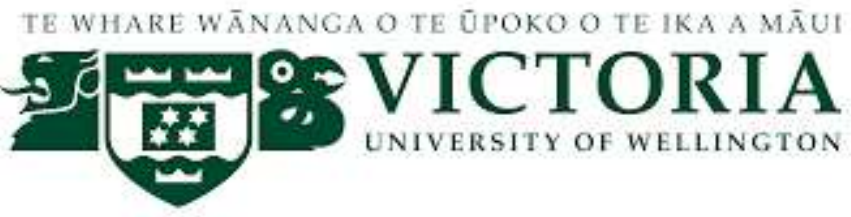




\section{Acknowledgements}

This project was a labour of love and involved a huge team of people to get it over the finish line. I am extremely thankful to everyone that supported me and helped me through this painful and rewarding experience.

Firstly I would like to thank my supervisor Nicole Phillips for her guidance, endless patience and wisdom, without whom I could not produce the quality of work I have managed. Thank you for scraping the anxiety from my skull and always helping me achieve a higher standard.

Thank you to everyone at VUCEL especially the technicians John and Snout for helping me with the logistics of my experiment and always being kind and honest. Special thank you to my personal lab angel, Alison Duncan for always having time to chat with such positivity.

Thank you to the staff at the Bowen Eye Clinic, Reece Hall, Kathryn Hall, Sam Hou and Nicole Paterson for supporting me financially and emotionally to further my education in a well-rounded way.

Thank you to Pisana Rawson, Derek Heath, and Paul Wolf for all your histology help and guidance. Particularly huge thank you to Khoi Phan who single handedly helped me develop my histology technique leaps and bounds and kept me in check with a witty sense of humour. My project would not have been nearly as successful without your guidance.

Thank you to Henry Lane for teaching me the in's and outs of shellfish and helping me interpret my slides.

To the eco pals: Li Yeoh, Brittany Florence-Bennett, Caitlyn Shannon, Baylee Wade, Jenna Mumford and Ronja Hauke, thank you for studying alongside me, keeping a smile on my face, being my personal therapists, living with me, and reminding me there was a world outside this project.

Thank you to all of my friends who listened to me rant and complain about things going wrong and supported me in words of encouragement and field work even though they often had no idea what was going on. Particularly big thank you to Robyn Bryant, Erin Donohue and Olivia Singleton for keeping me grounded and being my eternal cheerleaders. 
To Daniel Falloon, thank you for always supporting me, being more interested than me in my own project, staying up late while I finished writing and getting up at ridiculous hours of the morning to jump into the ocean with me -even in the middle of winter. You are truly a shellfish whisperer.

A particularly special thank you to my sister Vidhiya Damodaran for being the smartest person I know and tearing my drafts to shreds with words of sarcasm and love. You inspire me immensely and I hope to become even half the scientist you are.

Thank you to all of my family: Nini Shridhar, Purnima Damodaran, Nathan Young, Conrad MacCormick, and Damo Damodaran who supported me, watched me draw diagrams at family lunch, and always gave feedback when asked. Special thank you to my mother, Arshini Damodaran for always believing in me and helping me through the hardest parts. She is my rock, my inspiration and the most resilient woman I know. Without her I would not be the person I am today.

To my nieces and nephew, Maya Damodaran Young, Tyler Damodaran MacCormick and the new baby to come. I hope you grow up to see an ocean full of life and biodiversity.

Finally, thank you to all the shellfish that had the unfortunate luck of being discovered by me one fine day. I hope by sacrificing your bodies to science those that come after you will live healthier and more respected lives.

"O Oysters, come and walk with us!'

The Walrus did beseech.

A pleasant walk, a pleasant talk,

Along the briny beach:

We cannot do with more than four, To give a hand to each.'

The eldest Oyster looked at him,

But never a word he said:

The eldest Oyster winked his eye, And shook his heavy head -

Meaning to say he did not choose

To leave the oyster-bed."

-Verse 6 \& 7

The Walrus and the Carpenter

Lewis Carroll 


\section{Table of Contents}

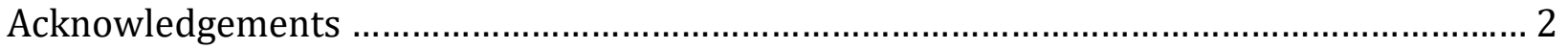

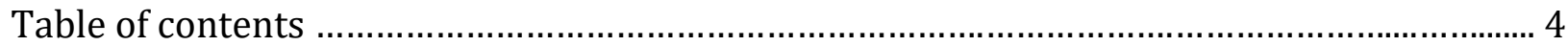

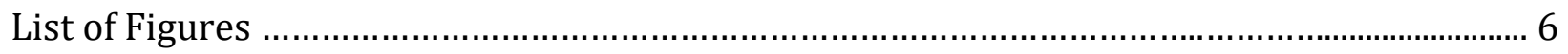

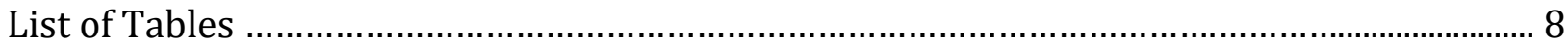

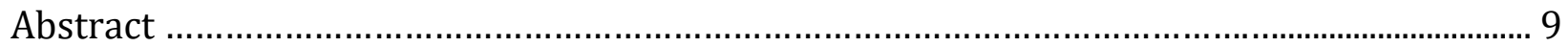

\section{Chapter 1: Introduction and Methods}

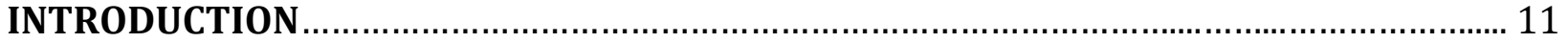

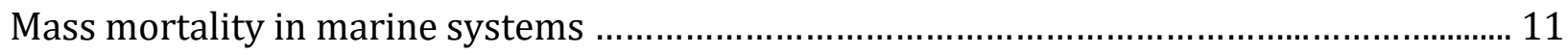

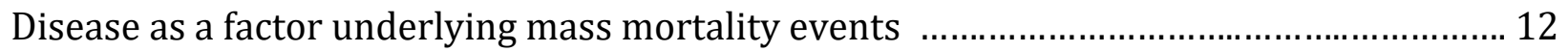

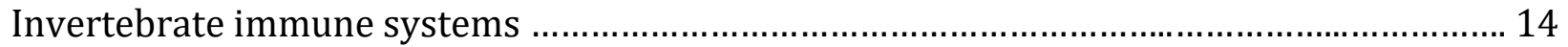

Environmental stressors as factors underlying MMEs ................................................. 15

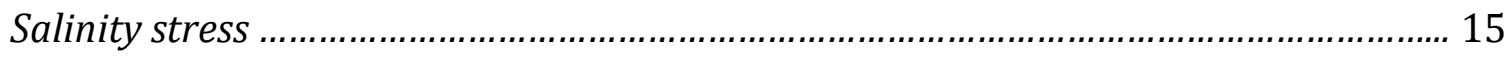

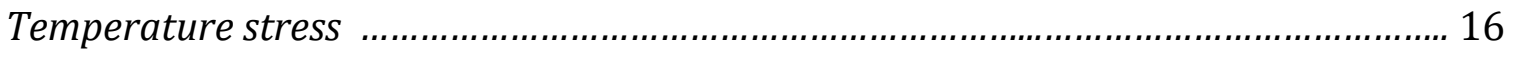

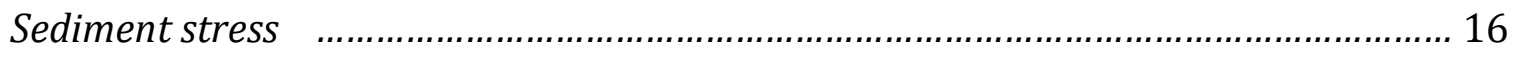

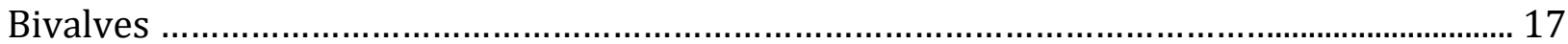

Mass mortality events in New Zealand bivalves .......................................................... 18

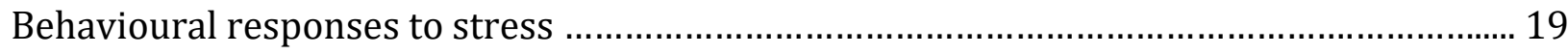

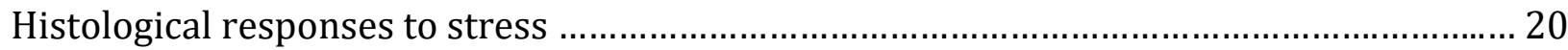

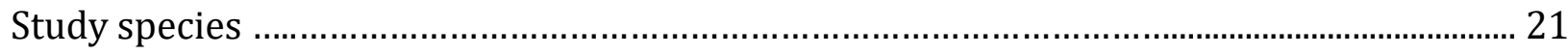

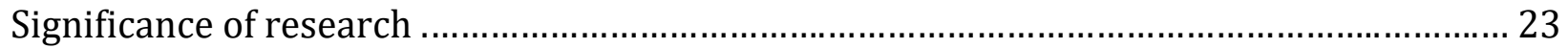

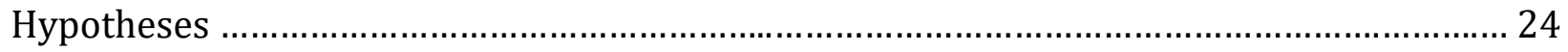

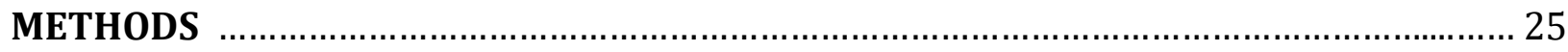

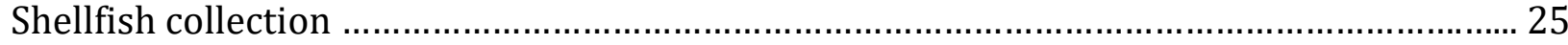

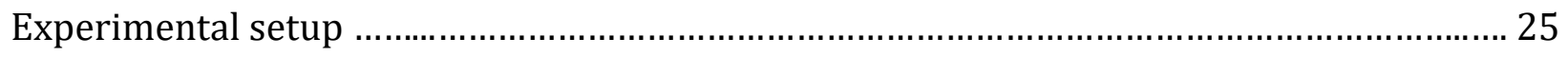

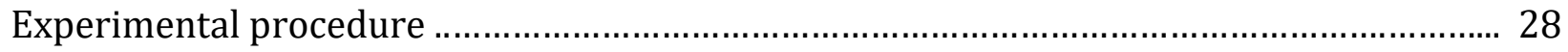

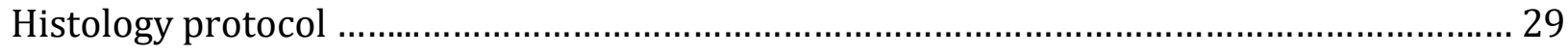

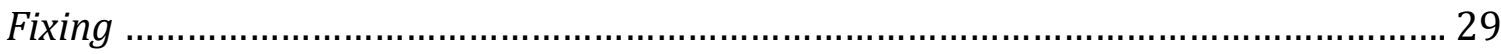

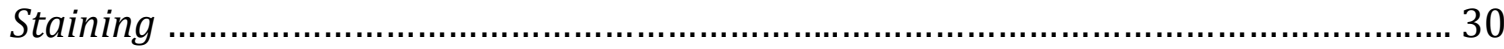

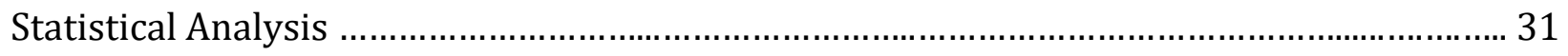




\section{Chapter 2: Results and Discussion}

RESULTS 32

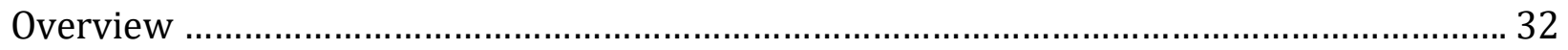

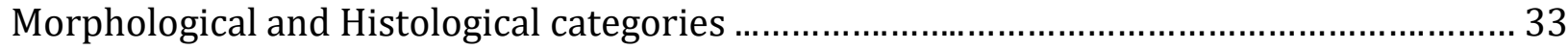

Morphological responses ................................................................................. 33

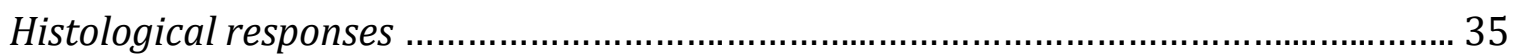

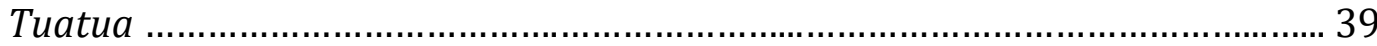

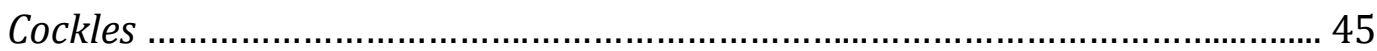

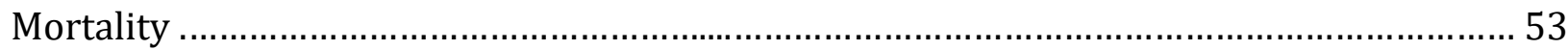

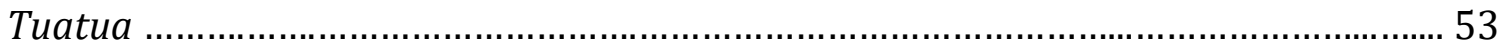

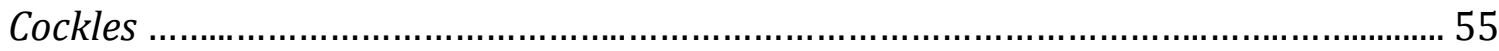

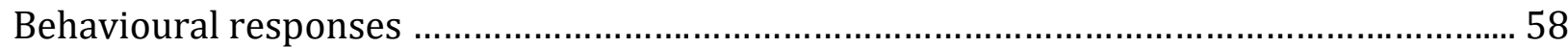

Analysis of treatment effects on histological and morphological categories ....................... 62

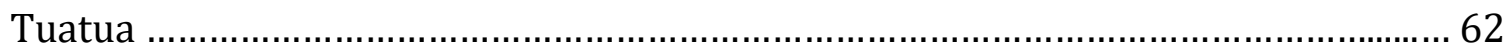

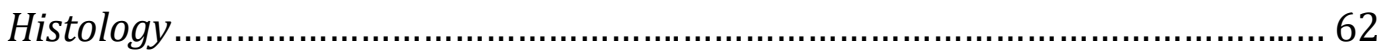

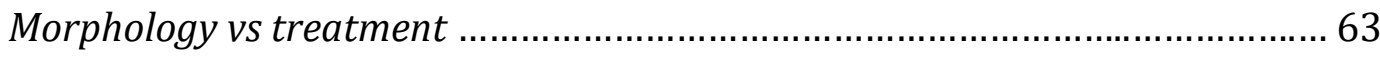

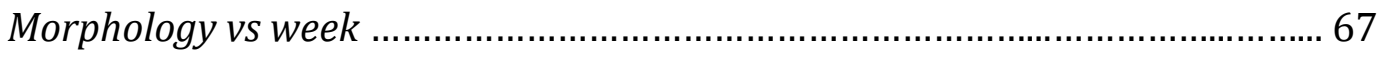

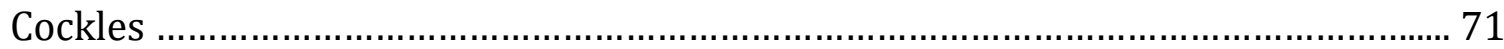

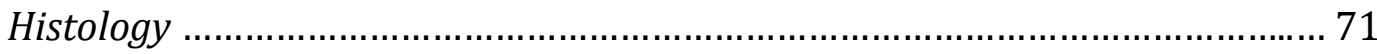

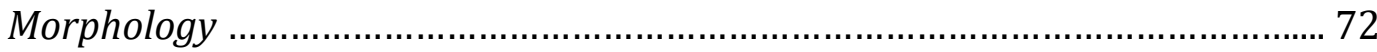

DISCUSSION

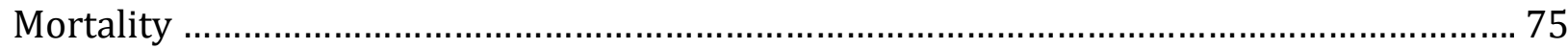

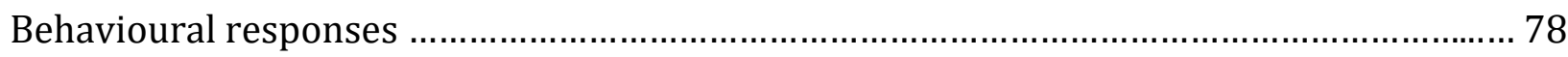

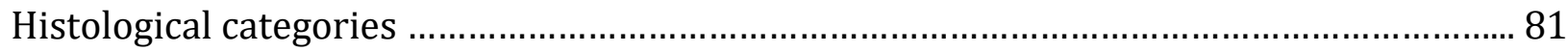

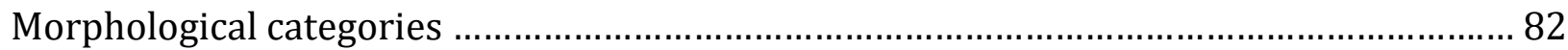

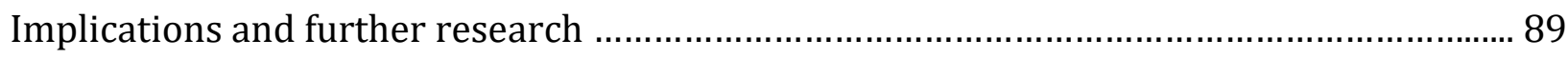

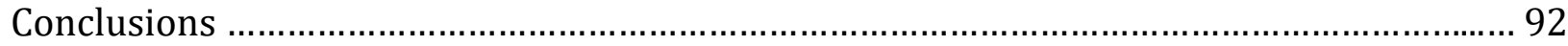

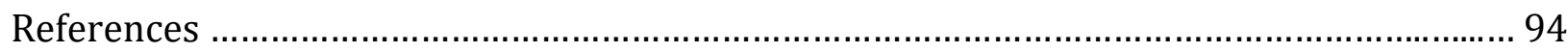

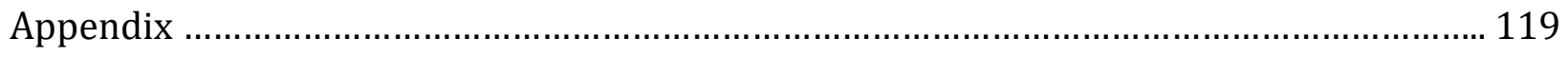




\section{List of Figures}

Figure 1. Magnitude and causes of mass mortality events across a number of taxa over time and with highlighted significant temporal trends. Sourced from Fey et al. (2014).

Figure 2.Photograph of aquaria with sea water hose supply set up. Photographed by Dayanitha Damodaran.

Figure 3. Photograph inhalant and exhalant siphon of tuatua. Photographed by Dayanitha Damodaran.

Figure 4. Photograph of unburied tuatua with foot extruding. Photographed by Dayanitha Damodaran.

Figure 5. Photograph of inhalant and exhalant siphon of cockles. Photographed by Dayanitha Damodaran.

Figure 6. Photograph of unburied cockle. Photographed by Dayanitha Damodaran.

Figure 7. Morphological response traits and categories in tuatua, where 1 is the least severe and 3 is the most severe.

Figure 8. Morphological response traits and categories in cockles, where 1 is the least severe and 3 is the most severe.

Figure 9. Histological structure of the digestive gland in the grooved carpet shell (Ruditapes decussatus). Showing a range of digestive cells from normal to necrotic cells. Sourced from Costa et al. (2012).

Figure 10. Histological structure of gill tissue in sand clam (Gomphina veneriformis). Images A \& C show tissue in the control treatment, while images B \& D show tissue exposed to tributyltin (TBT) for 28 days. Sourced from Park et al. (2012).

Figure 11. Histological view of male and female sex cells in the grooved carpet shell (Ruditapes decussatus) throughout development. Female: $2 \mathrm{a}$ : initiation of gametogenesis $2 \mathrm{~b}$ : Advanced gametogenesis 2c: Reproduction period. Male: 2d: initiation of gametogenesis 2e: Advanced gametogenesis 2f: Reproduction period. Sourced from Delgado \& Camacho (2005).

Figure 12. Tuatua digestive glands histological categories.

Figure 13. Tuatua gill histological categories.

Figure 14. Tuatua gonad histological categories.

Figure 15. Cockle digestive glands histological categories.

Figure 16. Cockle gill histological categories.

Figure 17. Cockle gonad histological categories.

Figure 18. Cockle foot edge histological categories.

Figure 19. Stacked bar chart showing the percentage of total death in tuatua that occurred in each treatment within each experiment.

Figure 20. Bar chart showing tuatua mortality change across time (weeks) when combined over experiments.

Figure 21. Stacked bar chart showing the percentage of total death in cockles that occurred in each treatment within each experiment.

Figure 22. Bar chart showing cockle mortality change across time (weeks) when combined over experiments. 
Figure 23. Stacked bar chart showing number of tuatua individuals from each treatment that reacted when removed from aquaria.

Figure 24. Bar chart showing mean reaction times of tuatua individuals in seconds across treatments. Data was combined over days and error bars show standard error.

Figure 25. Stacked bar chart showing the percentage of tuatua in digestive gland histology categories over exposure time (weeks) combined over all treatments.

Figure 26. Stacked bar charts showing morphological category change for tuatua over treatment. Where, $\mathrm{A}=$ Gill erosion vs treatment, $\mathrm{B}=$ Gill colour vs treatment, $\mathrm{C}=$ Body colour vs treatment, and $\mathrm{D}=$ Body consistency vs treatment.

Figure 27. Stacked bar chart showing the percentage of tuatua in each body consistency category over exposure time (weeks), combined over treatments.

Figure 28. Stacked bar chart showing the number of individuals in each body consistency category over time (weeks), broken down by treatment. Where, $\mathrm{C}=\mathrm{Control}, \mathrm{H}=\mathrm{Heat}, \mathrm{S}=$ Salinity, and $\mathrm{Se}=$ Sediment.

Figure 29. Stacked bar chart showing the percentage of tuatua in each category for the red mark trait over time (weeks), combined over treatments.

Figure 30. Stacked bar chart showing the percentage of cockles in gill histology categories over exposure time (weeks), combined over treatments.

Figure 31. Stacked bar chart showing the percentage of cockles in gill colour categories over exposure time (weeks), combined over treatments

Figure 32. Stacked bar chart showing the percentage of cockles gill erosion categories over exposure time (weeks), combined over treatments

Figure 33. Stacked bar chart showing the percentage of cockles in body colour categories over exposure time (weeks), combined over treatments. 


\section{List of Tables}

Table 1: Percentage of total death that occurred in each experiment for each species

Table 2: Chi-squared tests for differences in mortality of tuatua between experiments. Statistically significant results $\mathrm{p}<0.0083$ indicated by*. Cut offs are variable due to bonferroni correction.

Table 3: Chi-squared or fisher's tests for differences in mortality of tuatua between treatments. Statistically significant results $\mathrm{p}<0.0083$ indicated by*. Cut offs are variable due to bonferroni correction.

Table 4: Fisher's tests for differences in mortality of cockles between experiments. Statistically significant results $\mathrm{p}<0.0083$ indicated by*. Cut offs are variable due to bonferroni correction.

Table 5. Overview of results from general mixed effect logistic regression for reaction time in tuatua. Statistically significant results $\mathrm{p}<0.05$ indicated by*.

Table 6. Overview of results from two-way ANOVA for reaction time in tuatua. Statistically significant results $\mathrm{p}<0.05$ indicated by*

Table 7. Tukey test for differences between experiments for reaction time in tuatua

Table 8. Chi-squared tests for variation in morphological categories across treatments in tuatua. Statistically significant results $\mathrm{p}<0.05$ indicated by*.

Table 9. All significant chi-squared comparisons within traits compared by treatment. p values showing statistical significance indicated by*. Cut offs are variable due to bonferroni correction. Table 10. Chi- squared comparisons of traits with time of death (TOD). Statistically significant results $\mathrm{p}<0.05$ indicated by*.

Table 11. Significant results from fisher's pairwise comparisons between trait categories compared to time of death (TOD). $p$ values showing statistical significance indicated by*. Cut offs are variable due to bonferroni correction. 


\section{Abstract}

Mass mortality events (MMEs) occur when a disproportionate part of a population dies in a single event. The frequency of MMEs is increasing globally. In the past, MMEs have been linked to starvation, changes in environmental conditions and disease outbreaks. However, it is often unclear what the underlying cause of these events are. In New Zealand several MMEs have occurred in the bivalve species Austrovenus stutchburyi (Wood 1828) and Paphies subtriangulata (Wood 1828) with little known about the cause. Both of these species are recreationally harvested for consumption in New Zealand and have cultural significance.

In order to better understand MMEs in these species we must first gain a better understanding of stress expression. Bivalves have few observable features and it is difficult to classify them as healthy or stressed without investigating immune change which can be quite costly. Some research has looked into how different cell types change in response to pollutants but few studies have researched how cell types change in response to environmental conditions. The aim of this research was to find novel ways of assessing if shellfish were healthy or stressed. Little is known about how shellfish respond to environmental stressors and this is the first study to look at several novel stress expressions simultaneously, in New Zealand shellfish.

Histological, morphological and behavioural responses were measured in both $A$. stutchburyi and $P$. subtriangulata after treatment with increased temperature, lowered salinity and increased fine sediment input for up to 5 weeks. Temperature stress was the main stressor for $P$. subtriangulata (85\% of overall mortality occurred in the heat treatment), salinity was the main stressor for A. stutchburyi ( $46 \%$ of overall mortality occurred in the salinity treatment), and fine sediment stress did not seem to have an effect on either species in this study. Overall, $A$. stutchburyi were more robust to the treatments, but low mortality occurred in both species $(\leq 8 \%)$. Mortality correlated with time of year and was believed to be related to spawning in P. subtriangulata (48\% of overall mortality occurred from October-November). Both species had a single histological marker, in $A$. stutchburyi this was change in gill morphology, and in $P$. subtriangulata this was change in 
digestive gland morphology. Several individual morphological features were identified as potential stress markers in A. stutchburyi and P. subtriangulata. Additionally, when removed from aquaria $P$. subtriangulata had impeded foot retraction time in the salinity treatment $(\mathrm{p}<.0001)$. The differences in stress markers shows the diversity of reactions to stressors even within New Zealand bivalves. This study provides a useful baseline in investigating how $P$. subtriangulata and $A$. stutchburyi respond to environmental stress. The histological slides produced during this investigation are an invaluable resource that can be used in future studies and in comparisons with archived specimens from known MMEs. Knowing how to detect signs of stress in these bivalves will help to predict MMEs in the future and aid in implementing processes to combat these events. 


\section{Introduction}

\section{Chapter 1: Introduction and Methods}

Mass mortality events in marine systems

Anthropogenic change is an increasingly important issue in the current environment. In marine systems ocean acidification, temperature increase, fluctuating oxygen levels and changes in sediment input influenced by human actions are all factors of increasing concern. The effects of these factors on marine systems are most notable at the poles which are at risk of sea ice retreat, and in the tropics where corals are particularly sensitive to temperature shifts (Doney et al. 2012). However, the effects of anthropogenic change in marine systems are felt globally. In New Zealand, the reef, sand and mud habitats along shallow coastlines and estuaries are considered to be the most at risk environments to anthropogenic change (DOC 2011). The threats to these environments are wide-ranging and caused by a number of recreational and commercial activities (MacDiarmid et al. 2012). As we see the frequency of abnormal environmental conditions increase, we also see changes in ecosystem stability, including population changes within species, community composition changes between species, and increasing mortality events. How organisms adapt to, and tolerate, this human-accelerated environmental change will determine the survival of many species worldwide (Harvell et al. 1999).

Mass mortality events (MMEs) are catastrophic death rates that affect one or all life stages of an organism and remove a significant proportion of the population in a short amount of time relative to the lifespan of the organism (Fey et al. 2014). They are an increasing global issue from an aquaculture, wild fishery and human health point of view and disproportionately affect benthic species (Ereskovsky et al. 2019). MMEs are a naturally occurring phenomenon, however, in recent

years the frequency of these events has greatly increased. Climate change has aided this through intensification of environmental stressors, which can lower immunity and increase disease transmission (Thieltges \& Rick 2006, Ereskovsky et al. 2019). MMEs with the largest magnitude of deaths are correlated with starvation, multiple stressors and disease (Figure 1.) (Fey et al. 2014). However, the majority of MMEs are poorly understood because of the number of interconnected stress factors, which make it hard to isolate the specific cause in many cases. 


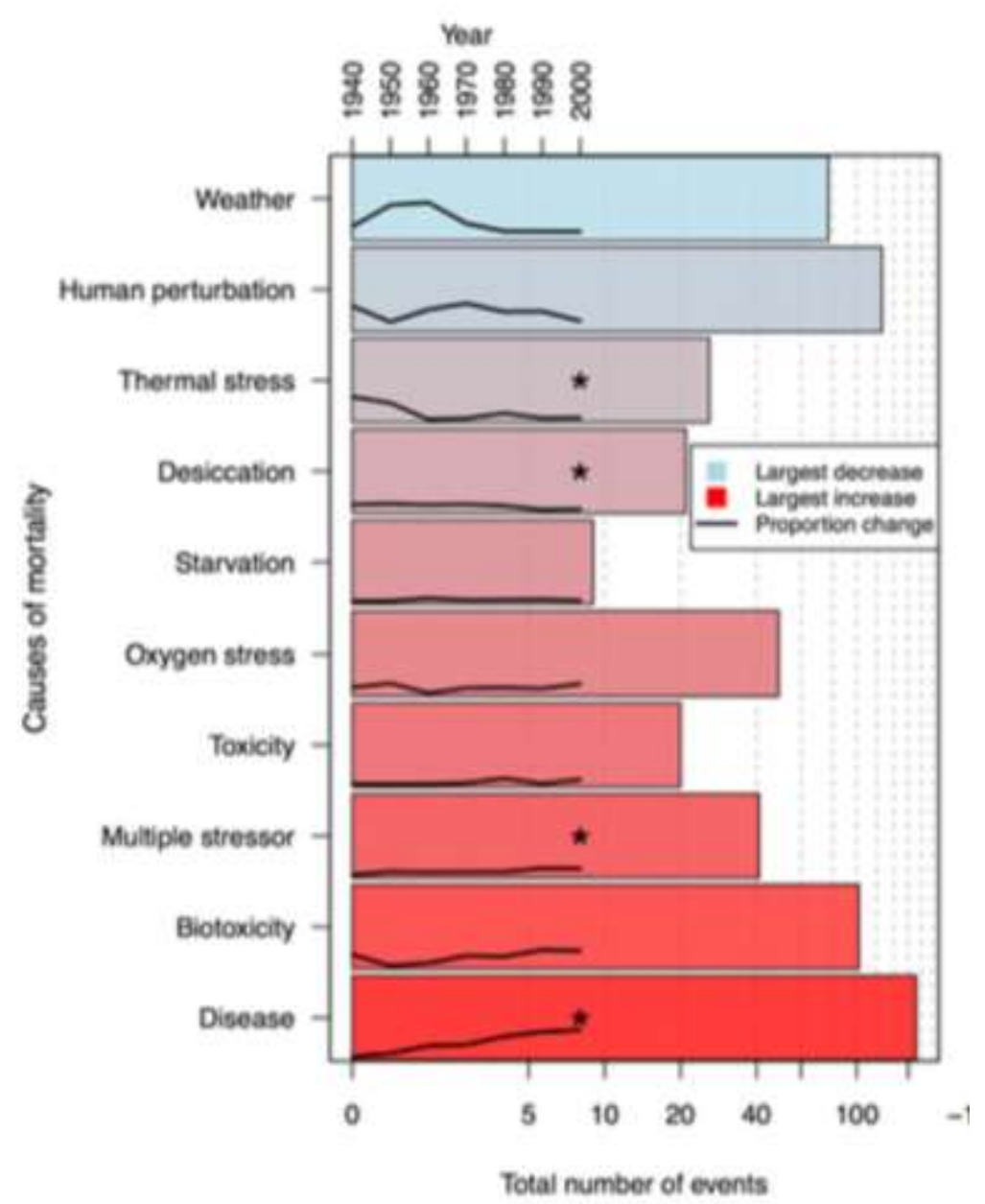

Figure 1. Magnitude and causes of mass mortality events in fish, invertebrates, amphibians, reptiles, birds and mammals. Bars show total number of mortality events, while lines show change in occurrence over time and stars show significant temporal trends (Fey et al. 2014).

\section{Disease as a factor underlying Mass Mortality Events}

Many MMEs have been linked to disease. Understanding why and how these MMEs are occurring is of central importance to conservation and management of marine resources, as disease outbreaks have increased globally over the last 50 years. Disease in marine invertebrates first appeared in published literature and became a subject of research in the 1960s (Vago 1966, Johnson 1984). However, the range of studies has been largely organism biased. For example, in the tropics, most research has focused on coral diseases due to the importance of coral reef based ecosystems in supporting both biodiversity and marine tourism (Diedrich 2007, Jones et al. 2004). The fragility of these organisms likely also fuels this research. Temperate disease research is mainly focused on keystone species (for example the effects of sea star wasting syndrome on Pisaster ochraceus) and 
commercially important species (for example withering syndrome in Haliotis sp.) (Haaaker et al. 1992, Hewson et al. 2014, Flegel et al. 2008). The nature of MMEs and disease outbreaks means they can easily be missed or go unstudied depending on the monitoring and visibility of the species they affect. To learn how to navigate and reduce these events, we need to understand the individual causes, and combination of causes leading to species stress and eventually MMEs.

Disease outbreaks that lead to MMEs can have significant long-term effects on population and community dynamics (Allam \& Espinosa 2016). In 2012 there was an outbreak of sea star associated densovirus in P. ochraceus on the Pacific coast of the United States of America. Over the next three years $81 \%$ of the P. ochraceus populations in northern California died (Rodgers et al. 2018, Moritsch \& Raimondi 2018, Menge et al. 2016). In 1983 the black sea urchin (Diadema antillarum) population in the Atlantic Ocean had a 93\% population reduction due to an unknown pathogen. Research showed that the population still had not recovered 20 years later, despite $D$. antillarum's high fecundity (Lessios 1995, 2005). In 1980, on the Atlantic coast of Nova Scotia, green urchins (Strongylocentrotus droebachiensis) were infected by the marine amoeba Paramoeba invadens causing a 3 year MME (Scheibling \& Hennigar 1997).

Bacterial infections that wipe out populations and cause MMEs are also implicated in more controlled settings like aquaculture. Disease outbreaks in aquaculture are also of serious concern as individuals of the same species are often kept in close proximity and at a high density. Diseases spread quickly in this environment and can kill whole stocks of organisms. Even if a disease does not result in death, it can still cause a change in fecundity and growth rates (Shirakashi \& ElMatbouli 2009). Roseovarius oyster disease (ROD) (formerly known as juvenile oyster disease) affects farmed Crassostrea virginica and can cause seasonal die off of up to $90 \%$ of the affected population (Boettcher et al. 2000). Shrimp ponds also spread bacteria extremely quickly, resulting in a boom and bust cycle of infection due to the impacts of disease at such high densities. White spot syndrome virus (WSSV) is the most lethal virus affecting shrimp farms (Nakano et al. 1993). Strains of WSSV can be highly lethal, reaching a 100\% mortality rate of infected individuals within 3-10 days in some cases (Chang et al. 1996). 


\section{Invertebrate immune systems}

In order to prevent disease events and make predictions about how disease mortalities may change in the future for invertebrates; we must first understand how invertebrates respond to infections, species immunocompetence and how immunity shifts with changing abiotic conditions. Invertebrate immunity is extremely variable and has different degrees of sophistication (Rowley \& Powell 2007, Wotton et al. 2003). Sea urchins have some of the most complex immune systems of marine invertebrates, and dedicate $4-5 \%$ of their genes to immune response (Rast et al. 2006). At minimum, most invertebrates have a basic cellular and humoral response system.

Coral immune responses are complex and still not well understood. The surface mucopolysaccharide layer in coral is a physical barrier to pathogens, but the primary immune defences are cellular. Amebocytes absorb invading threats and increase in numbers during a pathogen attack, much like white blood cells (Ritchie 2006, Mullen et al. 2004). In tandem, there is also an enzymatic response and production of antimicrobial chemicals by the mucopolysaccharide layer (Ritchie 2006, Mullen et al. 2004). Similarly, the sea star immune system is made up of signalling molecules, coelomocytes, specialised phagocytotic cells, antimicrobial enzymes and melanisation responses (Franco et al. 2011). Coelomocytes are the innate immune response and have an important role in regeneration (Cervello et al. 1996). Like sea stars, sea urchins also use coelomocytes as part of their innate immune reaction. The function of coelomocytes in urchins is to secrete antibacterial chemicals, increase mobility, and phagocytose foreign bodies (Smith et al. 1996).

Bivalves have an open circulatory system with hemolymph. They lack an adaptive immune system, and instead their innate immune system is made up of humoral and haemocyte-bound (cellular) defences. Hemocytes make up the majority of the immune response in bivalves with a range of physiological and immune roles including phagocytosis, encapsulation, healing. Hemocytes can also cross epithelial membranes. In molluscs, the gill and the digestive glands are the most hemocyterich tissues (Allam \& Raftos 2015, Canesi \& Pruzzo 2016). The immune response in molluscs is made up of sensing and responding arms. Sensing happens through host recognition of pathogenassociated molecular patterns (PAMPs). After recognition, molecules are deployed to bind to the pathogen (cytokines) and emit the relevant immune response (Allam \& Raftos 2015, Pruzzo et al. 2005). One type of immune response is antimicrobial factors neutralising the pathogen by causing lysis or disrupting the metabolism (Ellis et al. 2011). Another part of the immune response is the 
mucus interface. The mucus interface in bivalves is a barrier to microbes and contains immune cells such as neutrophils and dendritic cells. How the mucus interface functions is largely understudied at this stage (Lau et al. 2017).

Bivalves have different types of haemocytes meaning their immune response can be extremely specific to infection types. However, not all haemocytes are the same across species and infection can go unrecognised by the immune system (Fryer \& Bayne 1996). Different combinations of disease and immune response will result in different outcomes between species when subjected to abiotic stress. For example, even different species of the bacteria genus Vibrio can cause low level stress or be lethal depending on the species. The effectiveness of depuration of shellfish to remove bacteria can also vary greatly depending on the bacterial species (Tokarskyy et al. 2018). The complexity of disease agents can vary greatly and coupled with environmental stressors, can overload the immune system and change organism response to mild stress.

\section{Environmental stressors as a factor underlying MMEs}

Environmental stress is a driving influence behind marine MMEs globally and can interact with other important factors. For example, abiotic stress affects disease transmission through changing pathogen development, transmission, life cycles, and host susceptibility (Mydlarz et al. 2006, Harvell et al. 2002). Environmental stress is particularly intense in the intertidal zone where conditions are highly variable. Intertidal stressors can include increased and variable temperature, increased desiccation, decreased salinity, and changes in pH (Harvell et al. 2007, Miner et al. 2018, Moore \& Robbins 2000, Mydlarz et al. 2006, Harvell et al. 2002).

\section{Salinity stress}

Salinity stress can have a variety of negative effects on marine invertebrates. Low salinity can directly and indirectly cause negative effects on the individual and their offspring by impeding metamorphosis, depleting larval reserves and impacting growth rates (Thiyagarajan et al. 2007). In marine species that hold embryos in brood chambers, salinity fluctuations cause chambers to become hypoxic and increase ammonia concentration, impacting long term shell formation (Chapparro et al. 2009). Salinity stress can also activate an immune response, increasing phagocytosis (Wang et al. 2008). The response of individuals to salinity stress changes over the time exposed, and the intensity of exposure. 


\section{Temperature stress}

In the literature there is a major focus on how water temperature increases the intensity and severity of disease outbreaks in marine populations (Harvell et al. 2007, Miner et al. 2018, Moore \& Robbins 2000, Fey et al. 2014, Ereskovsky et al. 2019). As sea surface temperatures rise, thermal tolerances of different species become increasingly important. Above average sea surface temperatures have been recorded to increase the frequency of infection in corals (Harvell et al. 2007). Several coral diseases and marine fungi, including Vibrio shiloi and white pox disease have been shown to thrive closer to the coral heat stress zone as they grow better under increased temperatures (Harvell et al. 2002, Patterson et al. 2001). Increased temperatures can also hinder viral capabilities. The frequency of mortality of kuruma shrimp (Marsupenaeus japonicus) infected with the white spot syndrome virus is significantly reduced at higher temperatures, as the increased temperature reduces the ability of the virus to replicate (You et al. 2010, Moser et al. 2012).

Global temperature rise is also increasing the frequency of parasites in the benthic community, through increased hatching, increased transmission and an extended transmission season (Poulin \& Mouritsen 2006, Studer \& Poulin 2013, Ford \& Chintala 2006). The thermal tolerance of parasites, can be higher than their hosts, but still has clear upper limits (Thieltges \& Rick 2006). Parasitism is important in shaping benthic communities, which are often intermediate hosts.

\section{Sediment stress}

Increasing sediment input is becoming more common in the marine environment due to factors such as agricultural run-off, and marine drilling (Kennicutt et al. 1983, Jordan et al. 2003). While a degree of sedimentation naturally occurs in coastal ecosystems due to storms and natural run-off, the scale sediment loading occurs at has significantly increased in many systems with changes in land use. This is increasingly concerning for organisms living in these habitats, but particularly for filter feeders and benthic organisms as it can affect feeding and respiration. For example, the horse mussel (Atrina zelandica) loses biomass after sediment influx, regardless of food availability (Ellis et al. 2002, Covault et al. 2013, Thrush et al. 2004). Minute changes in sediment can cause significant changes in ecosystems. Sedimentation levels as low as $100 \mathrm{mg} / \mathrm{L}$ have been observed to have effects on bivalve activity, while concentrations of $44 \mathrm{mg} / \mathrm{L}$ inhibit growth (Ellis et al. 2002). Fine clay deposits on New Zealand sandflats that were $3 \mathrm{~cm}$ deep led to a $90 \%$ decrease in macrofauna in 10 days (Norkko 2002). 
Temperature, salinity and sediment are all important stressors for bivalves and invertebrates globally. Exposure to these stressors can drastically change growth and respiration and can lead to death. There is a lack of information available on how responses to different stressors are exhibited in different species of bivalve, and the magnitude of their effect. There is also little understanding of how these stressors work in a New Zealand context.

\section{$\underline{\text { Bivalves }}$}

Bivalves are molluscs that are of huge ecological importance in New Zealand and the world. They are usually found in brackish waters with high nutrient levels. High aggregations of bivalves cause changes in sediment accumulation, temperature and light (Sousa et al. 2009, Newell \& Koch 2004, Ajonina et al. 2005). Burrowing bivalves, which live in soft sediment habitats make up a large portion of bivalves worldwide. When high volumes of bivalves are present in an environment they can have a huge impact on water quality, including changing concentrations of phytoplankton, organic detritus, and bacteria in the water column (Vaughn \& Hakenkamp 2001). Marine bivalves are particularly important as they filter two to eight times more water than freshwater bivalves of comparable size. In some systems, marine bivalves filter $100 \%$ of the water in the water column every day (Strayer et al. 1999, Kryger \& Riisgard 1988).

Movement of bivalves can also have a significant effect on environmental conditions. Bioturbation are the movement processes of organisms that indirectly or directly affect sediment matrices, including particle reworking and burrow ventilation (Kristensen et al. 2012). Bioturbation of bivalves plays a key role in releasing nitrogenous compounds from soil, increasing ammonium uptake and increasing primary production (Jones et al. 2011, Sandwell et al. 2009, Yamada \& Kayama 1987). This movement through sediment also influences water quality, decreases water transparency and influences infaunal sediment composition (Matzusaki et al. 2007). Bioturbation can homogenize sediments and change community structure. This has been observed in the presence of the bivalve Austrovenus stutchburyi, where sediment homogeneity and porosity was reported to be higher with increasing shellfish densities (Sandwell et al. 2009).

Most bivalves are edible and have been used as a food source for centuries, dating back to the Roman Empire. Bivalves are farmed as part of both recreational and commercial fisheries. Small scale fisheries are incredibly important for food security, sustainable livelihoods and poverty alleviation globally. Production of bivalves for human consumption exceeds 15 million tonnes annually (Staples et al. 2004, Wijsman et al. 2019). Bivalves are a staple in supporting rural deltaic communities. It is estimated that traditionally, 11-90\% of Maori food energy was derived from 
consuming shellfish, depending on the tribe (Shawcross 1970, Paulin 2007). Thus, preservation of bivalve stocks is of cultural, economic and global significance.

The modality of filter feeding, and commonality as food items, make molluscs the most common source of seafood-related illness worldwide (Pruzzo et al. 2005). Shellfish consumption can transfer a number of enteric viruses, including typhoid, polio and Hepatitis A. Shellfish-related viruses are generally non-toxic to humans with the exception of Vibrio vulnificus that can have a mortality rate of $50 \%$ in susceptible people when exposed. Oysters cause the majority of shellfish poisoning, followed by clams and mussels (Chuang et al. 1992, Chiang \& Chuang 2003, Atmar et al. 1993). Due to the high infection rate, understanding shellfish health can also have positive impacts on human health.

\section{Mass mortality events in New Zealand Bivalves}

Since the early 1980s, marine MMEs have been occurring in New Zealand with increasing frequency and magnitude (Fey et al. 2014). These events have caused substantial reduction in flora and fauna around the country. For example, between 1986 and 1992, the dredge oyster (Ostrea chilensis) suffered several MMEs resulting in 91\% mortality of the population. Mortality was attributed to the parasite Bonamia exitiosa, in tandem with other factors (Cranfield et al. 2005). In 2005, the mussels Perna canaliculus and Mytilus galloprovincialis faced a MME in the South Island due to a high aerial temperature event. P. canaliculus had a higher mortality rate because they were living closer to the edge of their thermal tolerance range (Petes et al. 2007). In 2006, Austrovenus strutchburyi had an MME in Whangateau Harbour resulting in a 60\% death rate. This event was attributed to higher than average water temperatures combined with high parasite infection rates (Jones et al. 2016). In New Zealand, there have been several bivalve MMEs in the past few years with little known about the underlying causes or consequences for populations and community dynamics. At least six of these were associated with rickettsia like organisms (RLOs) (Ross et al. 2017).

A common theme in the literature is that MMEs are attributed to one factor, usually pathogens, but it is difficult to separate external factors in order to definitively attribute cause to a singular factor. For example, farmed Crassostrea gigas had a large mortality event in the summer of 2010 from a herpes-like virus Ostreid herpesvirus-1 (OsHV-1 Var). Mortality quickly reached 83-100\% of oyster spat (Keeling et al. 2014). This event then moved across the Tasman to Australia affecting C. gigas in New South Wales. It is theorised that increasing water temperature influenced the onset of these events however it is difficult to prove this (Paul-Point et al. 2014). Additionally, MMEs caused by OsHV-1 Var are often associated with other microbes, especially of the Vibrio species (Degremont 
2011). Bacteria and parasites are always present in the water column and have the potential for infection. A bacteria or parasite overload resulting in a MME is likely to have some other trigger that lowers population immunity.

Understanding MMEs is a priority for marine resource management in New Zealand and is being actively investigated by the Ministry for Primary Industries (MPI) and the National Institute of Water and Atmospheric Research (NIWA). In order to investigate these events in wild species, MPI tests deceased individuals using PCR, bacterial culture and histopathology (Ministry of Prime industries 2019). In farmed species mass mortalities are quickly discovered and reported, however, even in these cases, it can be hard to tell the cause of mortality (Norman et al. 2013). In Foveaux Strait, the bonamia (Bonamia exitiosa) infection levels in oysters (Ostrea chilensis) are frequently monitored to help predict MMEs (Michael et al. 2012). MPI takes management of these events seriously and can close recreational fishing grounds during and after MMEs to allow time for species recovery (Ministry of Prime industries 2015a, 2015b). How stressors affect species that have MMEs is being actively studied by MPI to better understand when these mortality events might occur (Jones et al. 2015).

\section{Behavioural responses to stress}

Behavioural patterns can be useful tools in assessing stress, however this can be difficult, particularly in infaunal species. Despite this difficulty, behavioural change should not be overlooked as it can be an easy and quick way to assess organism health. In bivalves, siphon presence and absence directly relate to food uptake and respiration. Reduced siphoning behaviour is believed to be a self-protection mechanism that increases the concentration of antioxidant response enzymes in the bivalve by reducing water filtration. However, extended valve closure in bivalves leads to death (Anestis et al. 2007).

When exposed to salinities below 15ppt the marine bivalves, Venerupis corrugata, Ruditapes decussatus and Ruditapes philippinarum reduced burrowing, faecal deposition and siphon presence. However, V. corrugata and R. philippainarum increased siphon presence at salinities equal to or above 20ppt (Woodin et al. 2020). In Corbicula fluminea, siphoning behaviour increased for the first 3 days when exposed to both aluminum coagulants and increased acidity. After the initial 3 days, siphoning behaviour decreased steadily, and after 7 days of exposure the health declines were significant (Wu et al. 2019). Reduced movement, and siphon changes may be a sign of bivalve exposure to stress. When $C$. fluminea were exposed to imidacloprid, as well as an inhibition of siphoning behaviour, a reduction of burrowing behaviour was observed (Shan et al. 2020). A 
similar response was observed in the freshwater bivalves Lamellidens jenkinsianus obsea and Parreysia corrugata. Reduced movement and siphon extension was observed in these bivalves with exposure to increasing lead pollution. At high lead concentrations no foot or siphon extensions were observed (Brahma \& Gupta 2020). If behavioural patterns can be used to detect stress then this is an easy way for local communities to monitor the health of shellfish in their area. These communities are both the most common harvesters and have the most vested interest in the shellfish health.

\section{$\underline{\text { Histological responses to stress }}$}

Another way to monitor shellfish health is through the use of histological slides. Histology is the study of biological microscopic structures using light microscopy to examine a thin slice or section of tissue. Histopathology is using these tissues to note anomalies that could be the cause or outcome of disease. The technique was initially used in clinical medicine to examine biopsies, however it is now widely applicable to a number of biological fields. In order to prepare tissue for examination, tissue must first be fixed, embedded, sectioned, and then stained. Hematoxylin and eosin (H \& E stain) is the most common stain used in light microscopy and was first described in 1875. It is a permanent stain and stains the cytoplasm pink and the nuclei purple (Musumeci 2014). Using histology to diagnose and recognise signs of stress in organisms is a relatively novel field of biology. With increases in environmental stressors and MMEs, histology is an effective and reliable tool for assessing the condition of individuals and the surrounding environment, but there are still vast areas of untapped potential (McElwain \& Bullard 2014, Costa et al. 2013). At this stage, the majority of published literature that utilises histological techniques looks at different parts of organisms when exposed to a stressor and a control, however, there is no clear "baseline" for how variable organism tissue is without any stress input (Costa et al. 2012, Park et al. 2012, Cao et al. 2017).

The appearance of bivalve gills and digestive glands can be used to assess health in histopathology. Gills and digestive glands are target areas for contaminants and they conduct key physiological processes. The gills and digestive glands are known to be affected by nanoparticles in the water column and can also be contaminated by metals (Trombini et al. 2019, Khan et al. 2019). Digestive glands are responsible for the elimination of foreign material and metabolism, while gills are responsible for water pumping, filtration and the transport of particulate matter to the mouth (Jorgensen 1996, Wu et al. 2019). 
Beyond assessing individual condition, histology has many other uses. In South America, histological techniques were used to assess the reproductive cycle of the invasive bivalve $C$. fluminea to identify the spawning cycle and help prevent spread (Cao et al. 2017). Jemaa et al. (2014) used histology to better understand the immune system of bivalves by confirming cells differentiate into hemocytes in the gills of Crassostrea gigas. In New Zealand, MPI has archived slides from past Paphies subtriangulata MMEs. The research undertaken in the current study aims to create a "baseline" of histological slides illustrating variation of healthy P. subtriangulata and $A$. stutchburyi. These histological slides can then be used as a reference for comparison to slides of individuals under different stress conditions.

\section{$\underline{\text { Study Species }}$}

The highly abundant Paphies subtriangulata and Austrovenus stutchburyi are the focus of the present research. Both P. subtriangulata and A. stutchburyi are in the Veneridae family and are prominent shellfish on New Zealand's west coast. A. stutchburyi and P. subtriangulata are important species in New Zealand and are traditionally harvested by tangata whenua. Historical translocations by Maori can be used to explain the distribution of Paphies spp. around the country. Depending on if populations occur naturally or were seeded, shellfish beds depleted by MMEs or overfishing may not recover (Ross et al. 2018).

Tuatua (Paphies subtriangulata) occupy the sublittoral zone of fine sand beaches in harbours and on the open coast. Paphies spp. are one of the most common infaunal bivalve living in these habitats around New Zealand (Redfearn, 1987). There are four species of Paphies in New Zealand: Paphies ventricosa, (toheroa) Paphies subtriangulata (tuatua), Paphies donacina (deep water tuatua) and Paphies australis (pipi) (Hooker 1997). Generally, the habitat area differs between species, however, in Otaki, P. donacia can co-occur in beds with P. subtriangulata. While the species can interbreed, this does not occur with high success (Richardson et al. 1982, Grant et al. 1998). P. subtriangulata are found dispersed throughout the country but are more commonly found in the North Island. Within $P$. subtriangulata, there are at least three genetically distinct groups. These are referred to as North, Central and Chatham Islands (Smith et al. 1989).

When extended, the foot of $P$. subtriangulata is a broad oval shape that can be anchored into the sand to facilitate movement. P. subtriangulata settle in $3-5 \mathrm{~cm}$ of sand but can occur at depths of up to $4 \mathrm{~m}$. They can tolerate some salinity fluctuation but have no tolerance to silt so are usually found in areas with clean sand (Morton \& Miller 1968). Tuatua have no minimum shell size for harvest and are caught recreationally around the country. The mean density of aggregations is $5.5 \mathrm{~m}^{2}$. There 
is no reliable harvest data for recreational fishing and illegal catch is poorly monitored (Cranfield et al. 2002, MPI Fisheries). Reproduction occurs via broadcast spawning of separate sexes. This occurs twice annually, between September and November, and February and April. Larvae are planktonic and take 2-3 weeks to settle. They live for about 5 years and can grow up to $80 \mathrm{~mm}$ in width (Smith et al. 1989). Tuatua populations are largely understudied.

Cockles (Austrovenus stutchburyi) are a native New Zealand bivalve that inhabit lower estuarine soft mudflats. Estuaries are semi-enclosed bodies of water that have a connection to both the ocean and a fresh water source from land drainage (Prichard 1967). They are highly productive environments, rich in biodiversity and are also subject to large variability in salinity, temperature and turbidity (Dallarés et al. 2018). Estuarine species tend to have a higher tolerance to change in environmental features due to the larger fluctuation of environmental factors. Cockles are shallow burrowers, often found between 5-10 cm depth due to their short siphons. They occur abundantly throughout the subtidal to mid-tidal areas and are the dominant species in many ecosystems, because of this, they have a strong effect on ecosystem processes (Morton \& Miller 1968).

A. stutchburyi reaches sexual maturity at approximately $18 \mathrm{~mm}$. They grow at a rate of about $10 \mathrm{~mm}$ per year until they reach $30 \mathrm{~mm}$, which is when their growth rate slows down. Individuals can move up to $1.5 \mathrm{~m}$ between tides. Their lifespan reaches $20+$ years with the number of bands on their shell correlating with their age (Adkins et al. 2014, Mouritsen 2001, Morton \& Miller 1968). Densities of cockles vary from $100-3,500$ individuals $/ \mathrm{m}^{2}$ and recruitment of new cockles to the ecosystem varies from year to year. Cockle shells are an important source of hard substrate within the system, which in turn provides habitat for other benthic species (Yakovis \& Artemieva 2017). Commercial cockle farms have been established in Nelson since the 1970's (Fisheries NZ 2018). Harvesting by humans changes community dynamics in cockles by reducing intraspecific competition and therefore increasing individual growth rates (Wells et al. 2018). Alterations in cockle assemblages cause both flow down and flow up effects due to their biomass. Patterns of population density and structure in cockles were previously attributed to biological interactions (Hewitt et al. 1996). More recently, multiple stressors in ecosystems have been observed to be the primary cause of differences in population density and structures (Adkins et al. 2014). Cockle growth rates are affected by environmental change and have been declining significantly since Maori settlement in the late 1300 's. This has lowered the mean adult size and reduced water filtration as smaller cockles cannot filter water as efficiently (Wells et al. 2018). 
It is important to note that cockles are commonly infected with parasites, particularly the trematode parasite, Curtuteria australis. C. australis infects the foot of cockles as a secondary host, encysting in the tip, reducing the ability of the cockles to bury themselves. This is to increase their vulnerability to avian predators who are the primary host of this parasite. However, encysting in the foot tip leaves $C$. australis exposed and more likely to be damaged from foot cropping from the fish Notolabrus celidotus (Mouritsen \& Poulin 2004, Mouritsen 2002, Mouritsen \& Poulin 2003a, Mouritsen \& Poulin 2003b). In the current study, it is expected that some individuals will be stressed due to the presence of parasites.

What is the significance of this research?

The New Zealand bivalves Paphies subtriangulata (tuatua) and Austrovenus stutchburyi (cockles) both experience MMEs. Like with other bivalve MMEs the causes are unknown, but thought to include stress and disease, although it is not possible to disentangle the contributions of those factors. There is a large hole in the literature surrounding what markers of stress are in invertebrates, and for bivalves in particular because they have few charismatic features, there is currently no way to tell whether individuals are stressed or not. Further, it is not known whether different stressors may result in different responses. By looking at morphological, histological and behavioural responses to different common stressors it is hoped that signs of stress can be identified. If so, signs of stress could be used to predict the likelihood of MMEs before they happen. Knowing if shellfish are stressed is a vital step toward mass mortality prevention. If shellfish stress can be predicted, then harvesting of shellfish at times of high stress can be avoided to allow species numbers time to recover. Beyond this, the slides created from these experiments can serve as a library of tissue condition of shellfish at different times of year and under different stressors. This is helpful for future histological comparisons to existing archived samples from previous MMEs. 


\section{Aims of this research is to:}

- Define signs of stress in two species of marine bivalves in order to aid health monitoring.

- Determine signs of stress that can be observed behaviourally, morphologically and histologically.

- Determine if stress expression changes based on the stressor.

- Determine if stress tolerance changes with size.

- Create a reference of stressed and healthy histological slides that can then be compared to archived specimens from MMEs. Additionally, create a reference of stressed and healthy histological blocks that can be used to make more slides in the future.

\section{Hypotheses}

- Indicators of stress will be detectable concurrently across behavioural, morphological, and histological categories.

- Increased temperature will have the biggest negative effect on shellfish.

$\circ$ Damage to tissue condition will be expressed similarly across species and will be most clear in the digestive glands and gills.

- Larger individuals will have a higher stress tolerance.

- More stressed individuals will have slower reactions. 


\section{Methods}

\section{Shellfish collection:}

All specimens were collected by hand at low tide from coastal sites in the Wellington region. Tuatua (P. subtriangulata and P. donacia) were collected from Otaki beach ( $\mathrm{n}=65$ per experiment), an open shore beach on the Kapiti coast $70 \mathrm{~km}$ North of Wellington $\left(40.7413^{\circ} \mathrm{S}, 175.1170^{\circ} \mathrm{E}\right)$ (DOC, 2009). For the purposes of this study the two Paphies species could not be definitively distinguished, however, due to the slight habitat differentiation the majority of individuals were P. subtriangulata and will be grouped as Paphies subtriangulata. Cockles (A. stutchburyi) were collected from Pauatahanui inlet ( $n=65$ per experiment), a section of the Porirua Harbour estuarine catchment on the west coast of New Zealand $\left(41^{\circ} 07^{\prime} \mathrm{S} 174^{\circ} 55^{\prime} \mathrm{E}\right)$. The inlet is contaminated with heavy metals. This is at a safe consumption level for humans, but effect on fauna is not fully understood yet (Swales et al. 2005, Blaschke et al. 2010).

Four collections were made between April and November 2019. Shellfish were transported to the Coastal Ecology Laboratory, at Victoria University of Wellington in 5L buckets half filled with seawater. Sand was also collected at this time from the water's edge in separate 5L buckets. Any leftover sand was stored for later use. Shellfish were placed directly into aquaria with flowing seawater when they arrived at the laboratory then given a 3-5 day acclimation period.

After the acclimation period, individuals were measured and tagged. A permanent marker covered with clear nail polish to seal, was used to number the shells of tuatua individuals. Super Glue was used to attach numbered tags to the outer edge of the cockle shells which could not be tagged with a marker because they are highly ridged. Any animals on the shells were removed.

\section{Experimental setup:}

Twenty-four 12L plastic aquaria were set up in a large sea-table. Each had a hose to supply raw seawater. Aquaria contained two $8 \mathrm{~mm}$ holes on either side approximately $2 \mathrm{~cm}$ from the top for drainage (Figure 2). 12 aquaria were for tuatua and 12 for cockles. Aquaria were filled with unfiltered sand from the collection sites at a depth of $4 \mathrm{~cm}$, and $7 \mathrm{~cm}$ of seawater. If the sand had been stored it was rinsed in freshwater and then saltwater before being added to the aquaria. Five cockles and five tuatua were placed in each aquarium. Tuatua were sorted by size and 5 individuals were placed into each aquaria so that each aquaria had a diverse range of sizes of individuals in 
order to investigate size tolerance $(25-77 \mathrm{~mm}$ width). Cockles were closer in size range and were assigned randomly with no differentiation (13-41mm width).

Three different stress treatments plus a control were used in the experiment:

1. Increased water temperature $(\mathrm{H})$

2. Lowered salinity (S)

3. Addition of fine sediment (Se)

4. Control (C)

For each species there were three replicate aquaria for each treatment, including controls. Treatments were applied overnight (15-20 hours), for 5 nights a week for a minimum of 4 weeks. During the treatments seawater flow was stopped to the aquaria. At the end of each treatment night, running seawater was resupplied to each aquarium. Due to logistical constraints, occasionally experiments ran for up to 23 hours a night or ran 4 nights a week, but this was rare and did not occur in a consistent way across treatments, so is unlikely to have introduced bias. This experiment was replicated four times over the period of the 28th of April to the 11th of November 2019. After each collection 5 individuals from each species were immediately dissected and preserved in order to assess conditions straight from the field. These were labelled as baseline treatment (B). Treatment application is described below:

1. To increase the water temperature, $50 \mathrm{~W}$ aquarium heaters set to $32^{\circ} \mathrm{C}$ were used (one in each of three replicate aquaria). This produced temperatures $\sim 10{ }^{\circ} \mathrm{C}$ warmer than ambient seawater, ranging from $19^{\circ} \mathrm{C}$ in the winter to $28^{\circ} \mathrm{C}$ in the summer, across experiments. Ambient seawater ranged from $8^{\circ} \mathrm{C}$ in the winter to $18^{\circ} \mathrm{C}$ in the summer across experiments.

2. Salinity was lowered to $9-12$ ppt by decanting seawater from the aquaria and then adding seawater and freshwater until a salinity refractometer confirmed salinity was within the desired range.

3. For the fine sediment treatment, $80 \mathrm{~g}$ of bentonite clay (particle size ranges from 0.03-20 microns) were added to each aquarium, and stirred daily to keep particles suspended in the water column before settling (settlement time = 2-3 hours) (Al-Homadhi 2009). Concentration of sediment within aquaria was roughly $8 \mathrm{~g} / \mathrm{L}$. Weekly, $20 \mathrm{~g}$ of extra sediment was added to each sediment treatment to account for sediment loss through water flow or 
shellfish excretion and keep concentration stable (Cranford \& Gordon 1992, Smit et al. 2008). Sediment depth in each aquarium was roughly $1 \mathrm{~cm}$.

4. Control aquariums had the seawater supply turned off and on at the same time as the treatment aquariums.

Raw seawater was the sole source of food to the individual aquaria. Sand was topped up to all aquariums as needed throughout the experiment. Pilot experiments were initially run in March 2019 to determine appropriate treatment levels that were likely to cause stress, but not immediate death (Appendix E).

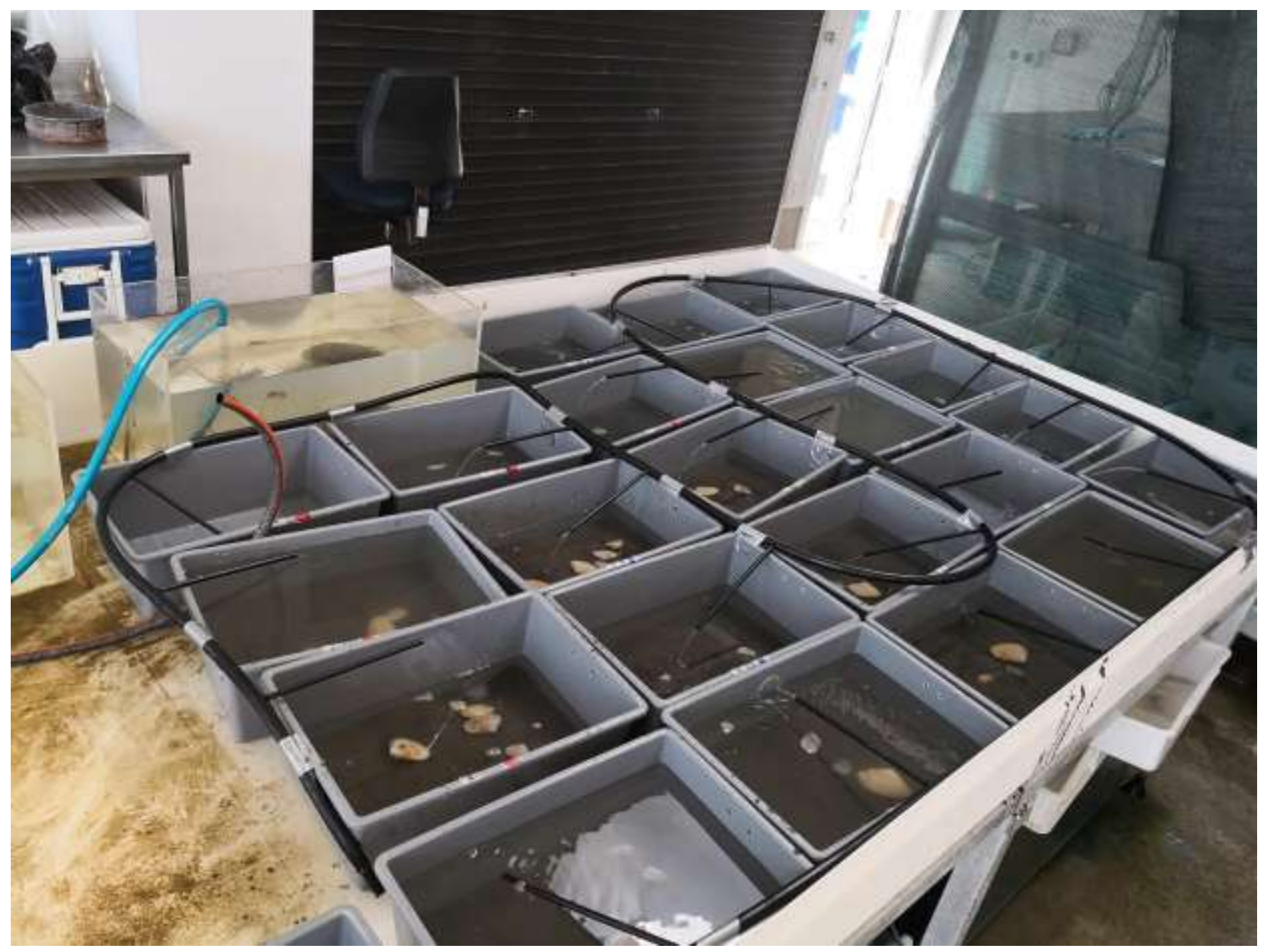

Figure 2. Aquarium set up for experiments with shellfish placed into treatments 


\section{Experimental procedure:}

At the end of each day (from 3pm-6pm), the sea water supply was turned off. The time was noted, and each aquarium was checked for the number of visible siphons at the surface and the number of individuals unburied. A siphon was considered "visible" if any part of either the inhalant or exhalant siphon was visible at the surface (Figure $3 \& 5$ ). An individual was considered "unburied" when enough of the shell was visible at the surface to determine the orientation of the individual (Figure $4 \& 6)$. After this assessment of individuals, the treatments as described above, began.
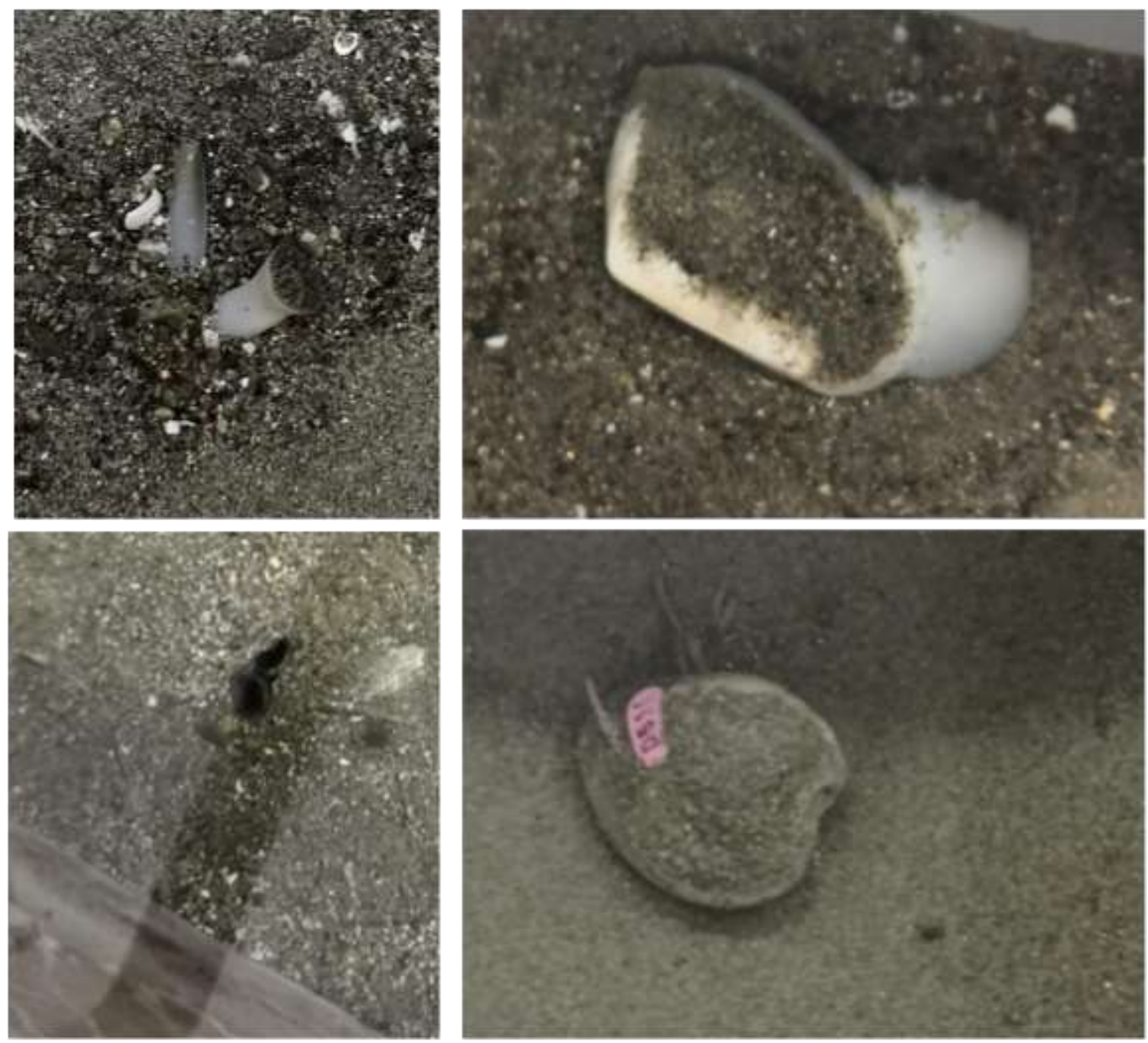

Figure 3. (Top left) Tuatua inhalant and exhalant siphon

Figure 4. (Top right) Unburied tuatua foot extruding

Figure 5. (Bottom left) Cockle inhalant and exhalant siphon 
Figure 6. (Bottom right) Unburied cockle

Treatments were stopped the following morning from 7-10am. Each aquarium was assessed, and individuals again noted if they had visible siphons or were unburied. In addition, for tuatua behavioral responses were examined. Reaction time was checked by removing 3 individuals from each aquaria and holding them for 15 seconds while they retracted. The time taken for the foot and siphons to fully retract back into the shell was measured (in seconds). Any other reactions (e.g. "spitting" - water forcefully ejected from the shell as foot retracts) were also recorded. If the individual did not fully retract, or did not respond to being removed from the treatment, it was recorded as the maximum of 15 seconds. Individuals were then placed back into their aquaria. Dead animals that retained enough intact tissue were preserved in Davidson's fixative for 48-72 hours and then moved into 70\% ethanol (histology protocol described below).

One individual from each aquarium was chosen haphazardly each week, and was dissected to look for any morphological and histological responses to the stress treatments. For the dissection, abductor muscles were severed and the internal structure photographed. Weekly dissections combined with natural mortality caused some treatments to end earlier than others. All treatments were run for at least 4 weeks. All experiments ended when at least one treatment (15 individuals total at the start) had $\leq 3$ individuals left.

\section{$\underline{\text { Histology protocol }}$}

Each week histology was carried out on the individuals that were randomly selected from each treatment (12 individuals per species). Samples were fixed in Davidson's solution and stained with Gill's hematoxylin and eosin Y working solution (0.25\%).

\section{Fixing:}

After dissection, the whole animal was fixed in Davidson's fixative for 48-72 hours before being moved to $70 \%$ ethanol until ready for tissue processing. Individuals were then cross-sectioned and placed into cassettes for tissue processing. The tissue processor machine ran cross-sections (held within cassettes) through a number of chemical baths to dehydrate and fix tissue for wax embedding. The tissue processor used was the TP1020 Lecia P6. The cycle ran: 60 mins 70\% ethanol, 60 mins 70\% ethanol, 60 mins 95\% ethanol, 60 mins 100\% ethanol, 60 mins 100\% ethanol, 80 mins 50:50 xylene: ethanol, 45 mins xylene, 45 mins xylene vacuum, 80 mins paraffin 
vacuum, 80 mins paraffin vacuum. Specimens were then embedded in paraffin wax and stored at $2^{\circ} \mathrm{C}$ until ready for sectioning.

For sectioning, blocks were placed on ice before excess wax was cut off using a microtome blade. When the tissue section was exposed, blocks were placed back on ice for another 5 minutes before sectioning with a fresh section of blade. Individuals were sectioned at $5 \mu \mathrm{m}$ intervals into ribbons that were transferred to $40^{\circ} \mathrm{C}$ water bath. Ribbons were then transferred to slides and allowed to dry at $2^{\circ} \mathrm{C}$ overnight before staining. A fresh blade was used after every $2-3$ individuals.

\section{Staining:}

For staining, a haematoxylin \& eosin protocol provided by Khoi Phan, an histology expert at Wellington Southern Community Laboratories (SCL) was modified. Modifications were based on trial and error during experiment 1 . Slides were baked in an oven at $62^{\circ} \mathrm{C}$ for 20 minutes before staining. Chemicals used in staining are further explained in Appendix A.

The following staining protocol was used:

Wax was removed from the slide using the following process: 5 min histoclear, 1 min histoclear, 1 min histoclear, 1 min absolute ethanol, 1 min absolute ethanol, 30 seconds 95\% ethanol, 20 seconds $70 \%$ ethanol, 2 minutes running tap water.

Then dewaxed slides were stained using the following process: 15 min gill's III haematoxylin, running tap water until clear, 30 seconds $1 \%$ acid alcohol, running tap water until clear, 3 minutes Scott's tap water, 1 minute 95\% ethanol, 10 minutes 1\% alcoholic eosin, running tap water until clear.

Slides were then dehydrated, cleared and mounted in the following cycle:

30 seconds 95\% ethanol, 30 seconds absolute ethanol, 10-15 minutes histoclear.

Once slides were dry, dibutylphthalate polystyrene xylene (DPX mounting medium) was placed on a coverslip which was dipped in a small amount of histoclear to spread and placed on the section. Samples were then categorized by week and stress treatment to create a reference table of cell variation under different treatments. 
After the dissection and photography, all shellfish were assigned to categories based on shared visual characteristics in the following traits: gill erosion, gill coloration, body consistency and, in tuatua, additionally the presence or absence of red marks on exterior tissue near the stomach.

\section{Statistical Analysis:}

All statistical analyses were carried out in R studio (Version 64-bit, R-3.6.2). The R packages used were lme4, afex and lmerTest. Differences in morphological or histological categories and mortality for each species was compared across treatments and experiments. A separate analysis was carried out for the tuatua behavioural data. All analyses were the same for both species with the exception of behavioural data which was only looked at for tuatua.

Behavioural data was measured by the time taken for the foot to retract into the shell. Due to the high number of zero-second measurements in the data, retraction data was turned into a dichotomous variable: did react (coded as 1) or did not react (coded as 0 ). This was analysed with a mixed effects logistic regression. In the model, the aquarium was the random effect, and treatment, experiment and day were fixed effects. Following this, mean reaction times across experiments were compared using a two-way ANOVA. For each experiment data was pooled across days, and transformed by adding 1 and taking the log of each value. Transformation was necessary because of the high number of zero-second measurements in the data. To determine differences between experiments, a post-hoc Tukey test was run. Control and sediment treatments were removed from the two-way ANOVA due to a lack of values.

Chi squared tests were used to examine whether there were associations between the treatment applied and the morphological traits, histological traits, size of individuals (as a continuous variable), and mortality. If there were any significant associations between treatment and traits, Bonferroni-adjusted pairwise comparisons were run to give conservative estimates of differences between categories within the traits. In some cases, the expected counts were too small, and a Chi squared test was not reliable. When this occurred a Fisher's exact test was used instead. Where values were missing for an individual because of technical difficulties in histology or human error, the individual was removed from the data set. Approximately 15 individuals per species were removed from the data set due to missing values. 


\section{Chapter 2: Results and Discussion}

\section{Results:}

\section{Part 1: Morphological and Histological categories}

\section{Overview:}

A primary goal of this research was to create a reference set of specimens to enable histological comparisons from different stress treatments. This will help ascertain whether shellfish condition can be visually assessed as healthy or unhealthy and whether different stresses result in different histological responses. To accomplish this, roughly 250 histological blocks per species were created from preserved shellfish (3 individuals per treatment, per week from each of the 4 experiments). The majority of these could be used again to produce more slides in the future as they remain in good condition. Approximately 169 slides per species were successfully created out of these blocks to assess as part of the present research and make preliminary comparisons with the control shellfish. These slides will be given to the Ministry of Primary Industries (MPI) at the completion of this work. Preliminary morphological and histological categories for the different tissue types were created from microscopic assessment of the slides and dissections. Results were interpreted visually, to create the best possible meaningful categories. It is likely that more information can be gained from these slides with expert assessment and interpretation, however, this was not feasible in the time frame of the present research. The results herein should be treated as preliminary and be interpreted with caution.

For the purposes of analysis, the following abbreviations have been applied to graphs and tables: heat $(\mathrm{H})$, salinity $(\mathrm{S})$, sediment (Se), control (C), baseline (B) and time of death (TOD). Experiments were carried out from the 28th of April to the 8th of November 2019. Traits are defined as the overarching groups (e.g. Body consistency, digestive glands) and categories are defined as the levels within these traits (e.g. 1, 2, 3 or A, B, C). The weeks were defined as: week $0=$ all individuals that died before the first dissection, including baseline individuals, week $1=$ all individuals in the first dissection, including those that died before the second dissection, week $2=$ all individuals in the second dissection, including those that died before the third dissection, week $3=$ all individuals in the third dissection, including those that died before the fourth dissection, week $4=$ all individuals in the fourth dissection, (in the case of 5 weeks this includes those that died before the fifth dissection), week $5=$ individuals in the 5 th dissection. 


\section{Morphological responses:}

For tuatua, individuals were placed into one of three categories according to morphological reaction to the treatments, with 1 being the least severe and 3 being the most severe. Five traits were assessed for reactions to the treatment; gill erosion, gill colour, body colour, body consistency and red marks on the body. Each trait was assessed independently of the others (Figure 7). A similar table was created for cockles. The same traits were assessed for cockles, with the exception of red marks which were not present on the cockle bodies (Figure 8).

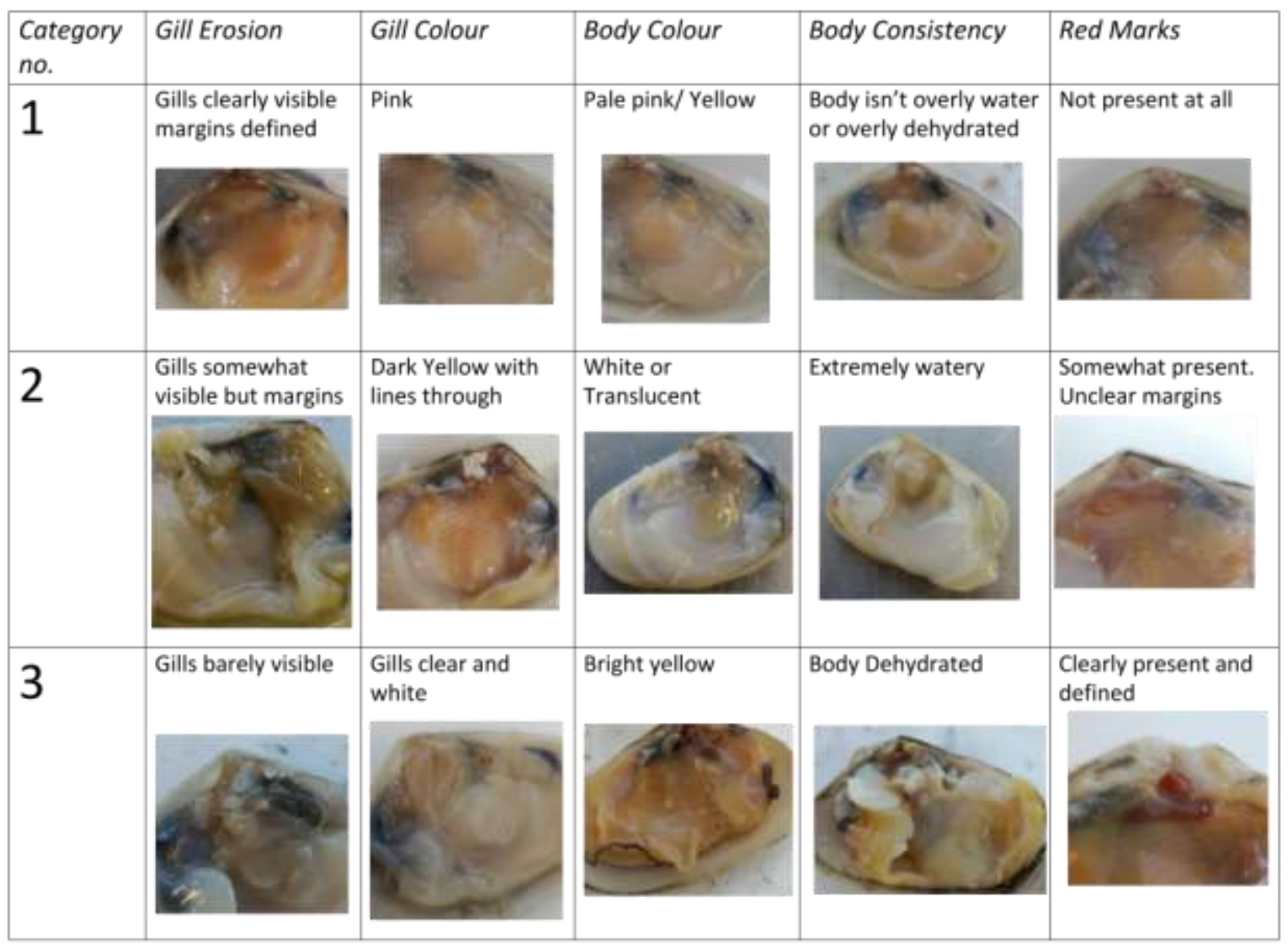

Figure 7. Traits and categories of morphological responses of tuatua, where 1 is the least severe and 3 is the most severe. 


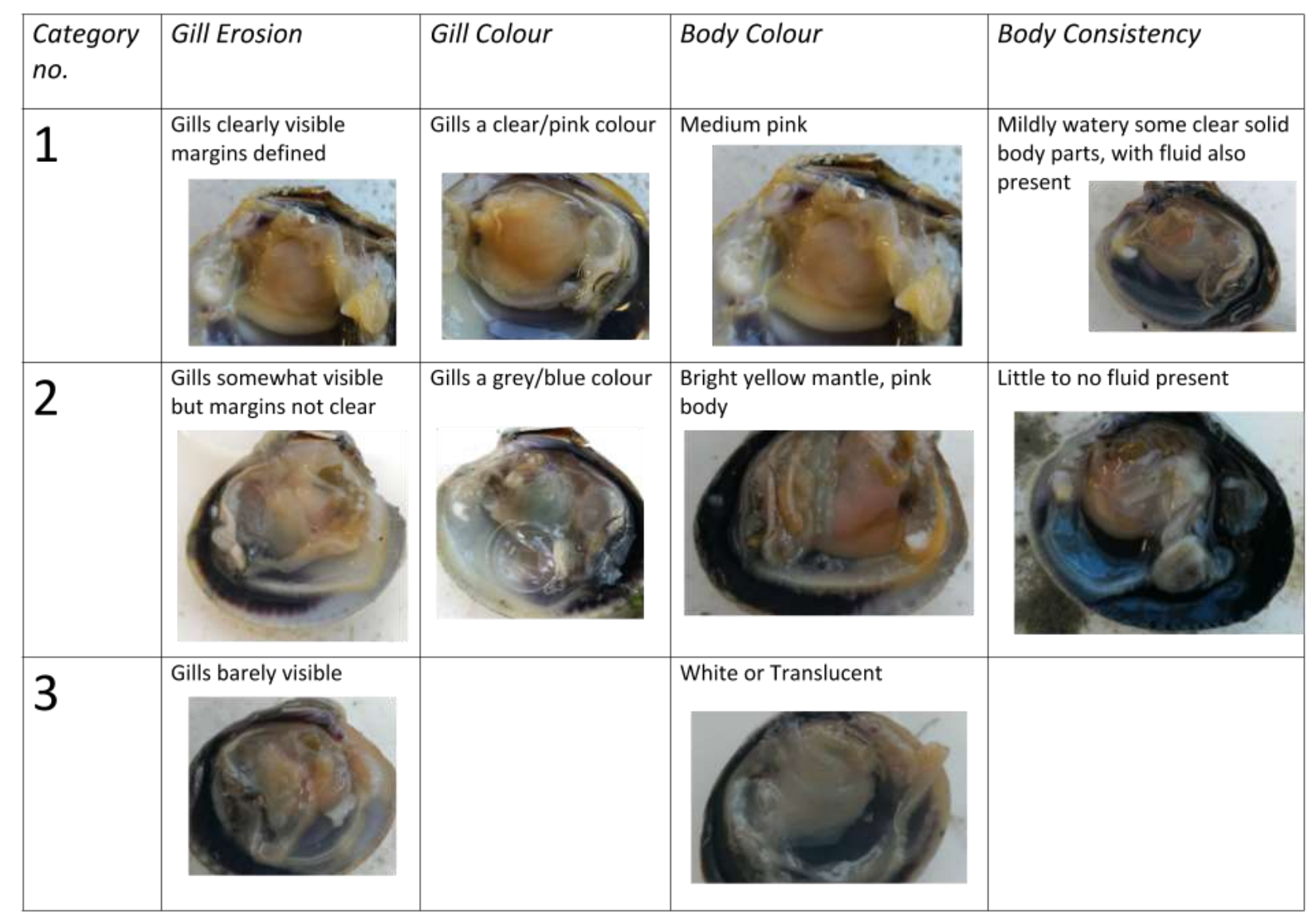

Figure 8. Traits and categories of morphological responses in cockles, where 1 is the least severe and 3 is the most severe.

\section{Histological responses to stress}

Histological categories for tuatua and cockles were created by identifying differences in the same cell types between slides. In both species, the traits, digestive gland, gonad and gill condition were examined separately. For cockles, the bottom edges of the foot were also assessed. The categories were aligned with published histological images (e.g. Figures 9, 10 and 11) and archived MPI slides (Appendix B, Figure 1). All visible categorical differences were added to a reference table and assigned a letter. After all slides were assessed, any categories with less than 5 individuals were removed from the overall reference table. All images of histological slides were taken under 100x magnification with a dissecting microscope. Note: there is no histological assessment of individuals from experiment 1 due to technical issues affecting the quality of slides (Appendix B, Figure 2). 

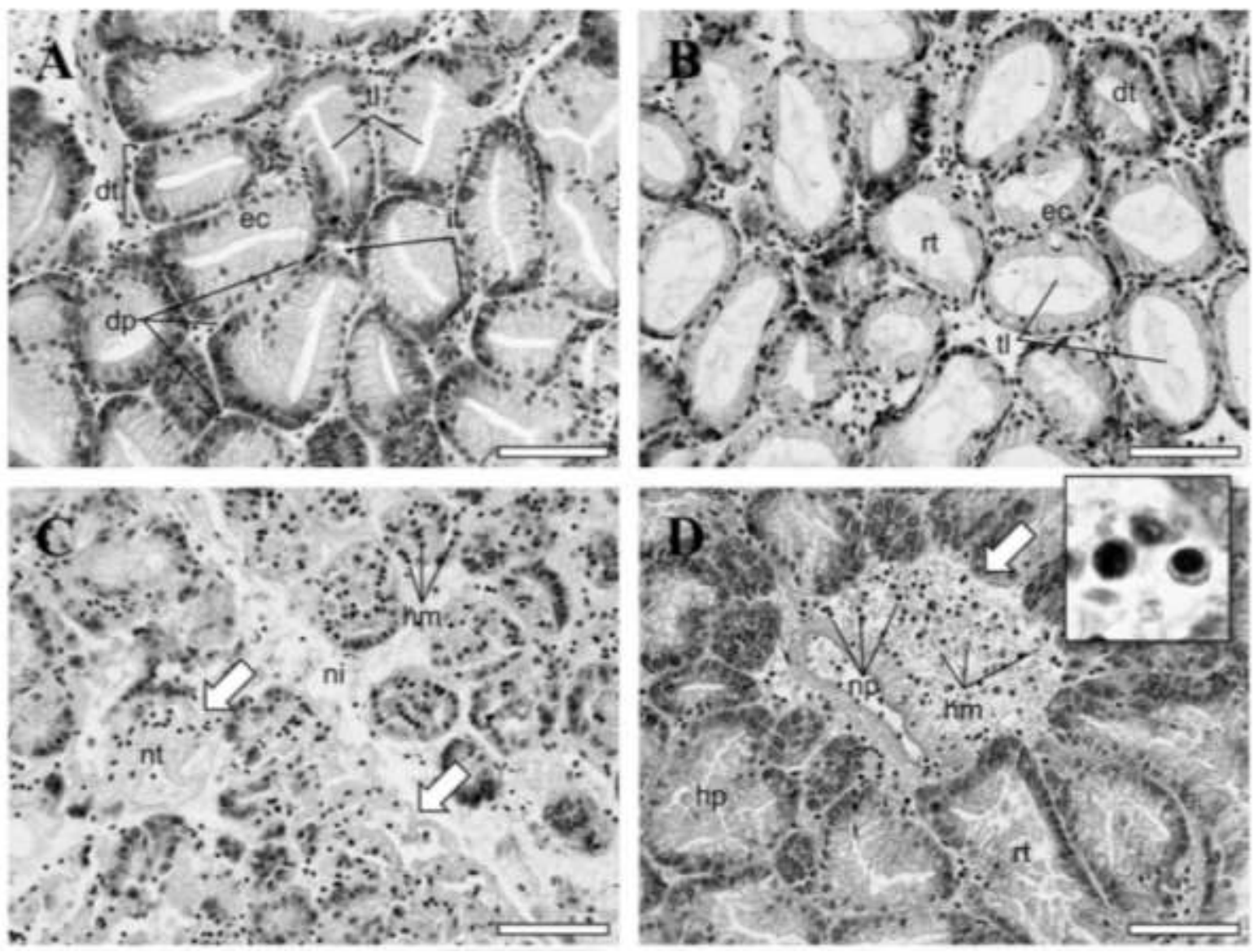

Figure 9. Digestive gland of grooved carpet shell (Ruditapes decussatus). A: normal cells, B: regressing tubules (rt), C: Fibrosis and necrotic tubules (nt), D: Neoplasic haemocytes (np) and necrotic area (shown by arrow) and diffuse epithelial hypoplasia (hp). Diagram abbreviations stand for: Numerous haemocytes (hm), digestive tubules (dt), epithelial cells (ec), tubular lumen (tl), interstitial tissue (it). Scale bar $50 \mu \mathrm{m}$. Sourced from Costa et al. (2012). 

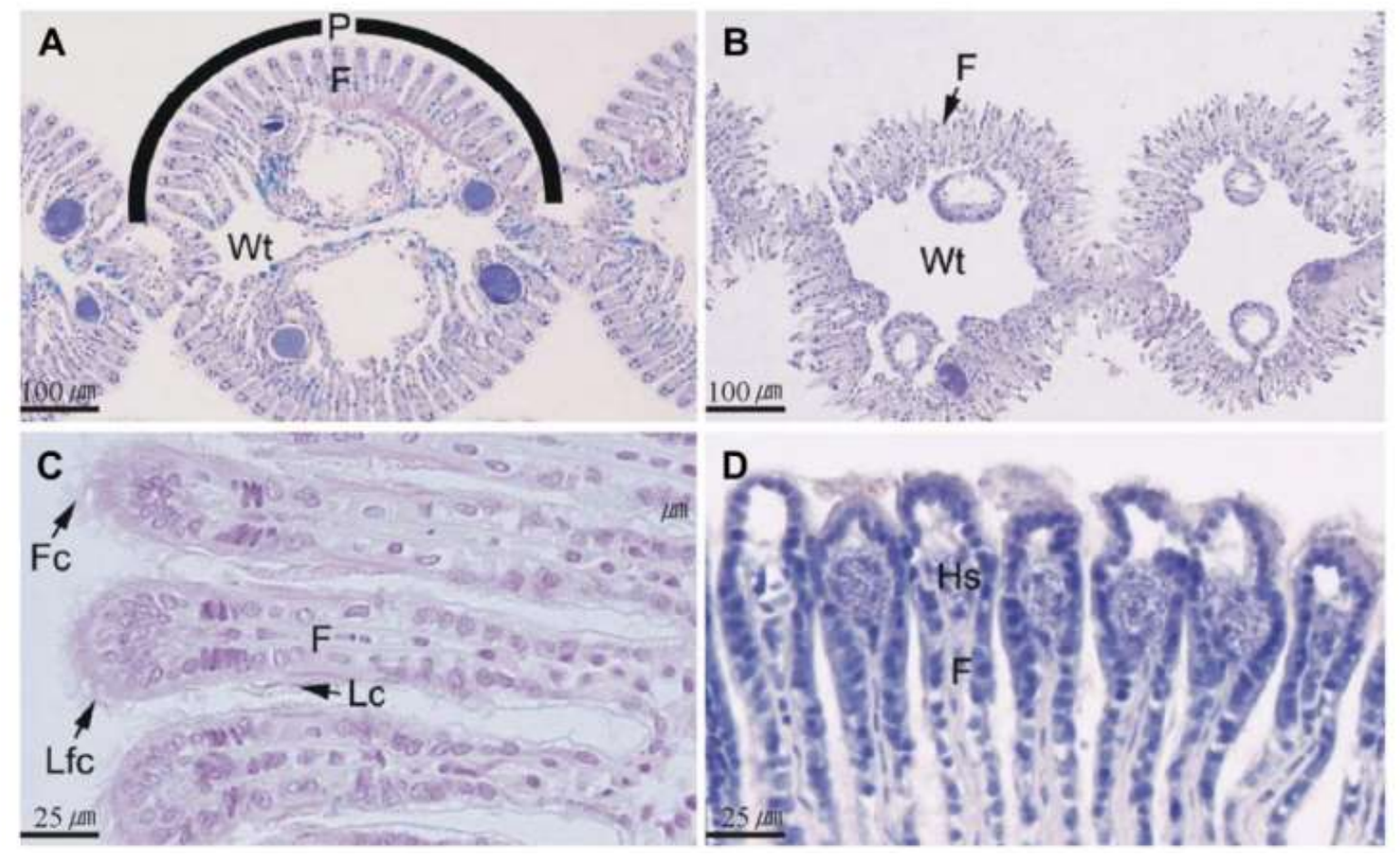

Fig 10. Histological structure of gill tissue in sand clam (Gomphina veneriformis). Images $\mathrm{A} \& \mathrm{C}$ are from a control treatment, images B \& D were exposed to tributyltin (TBT) for 28 days. P= Plica, $\mathrm{F}=$ filaments, $\mathrm{Wt}=\mathrm{Water}$ tubules, $\mathrm{Fc}=$ Front cilia, Lc=Lateral cilia and Lfc=latero-front cilia, Hs=Haemolymph sinus. Sourced from Park et al. (2012). 


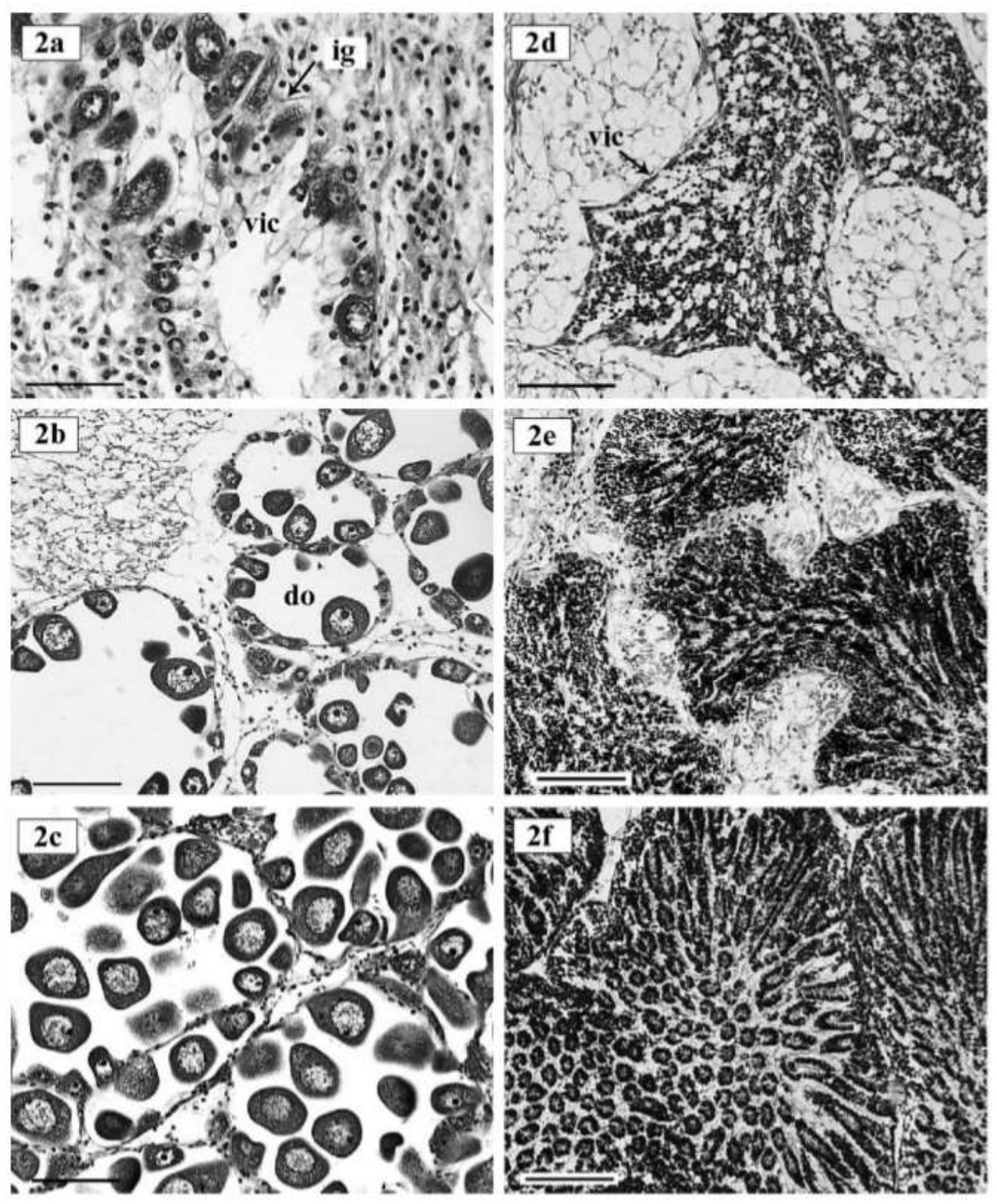

Figure 11. Histological view of male and female sex cells in the grooved carpet shell (Ruditapes decussatus) throughout development. Female: $2 \mathrm{a}$ : initiation of gametogenesis $2 \mathrm{~b}$ : Advanced gametogenesis 2c: Reproduction period. Male: $2 \mathrm{~d}$ : initiation of gametogenesis 2e: Advanced gametogenesis 2f: Reproduction period. IG=immature gametes, $\mathrm{DO}=$ developing oocyte, VIC=vesicular intrafollicular cells. Figures $2 \mathrm{a} \& 2 \mathrm{~d}$ scale bar is $150 \mu \mathrm{m}$. All other figures scale bar is $75 \mu \mathrm{m}$. Sourced from Delgado \& Camacho (2005). 
The histological categories developed for each tissue type of each species are described below, including photographs of examples.

Note: Both species had a number of rickettsia-like organisms (RLOs) that were not able to be distinguished from hemolymph cells at the time of analysis. This should be considered in any interpretation and for future analyses. 


\section{Tuatua}

\section{Digestive glands:}

A: Epithelial hyperplasia, tubular lumen space is reduced, and low to non-existent interstitial tissue. B: Space between cells, interstitial tissue present, and cells layers moderately thick.

C: Cellular infiltration around digestive glands, hypoplasic cells, and undefined lumens. Neoplastic haemocytes and necrotic areas are also present.

D: Large gaps between cells, large cell lumens, cell structure stretched, and cells hypoplasic.

E: Unclear cell outlines, cellular infiltration, large empty spaces, large cell lumens, extremely thin gland epithelium and hypoplasia.
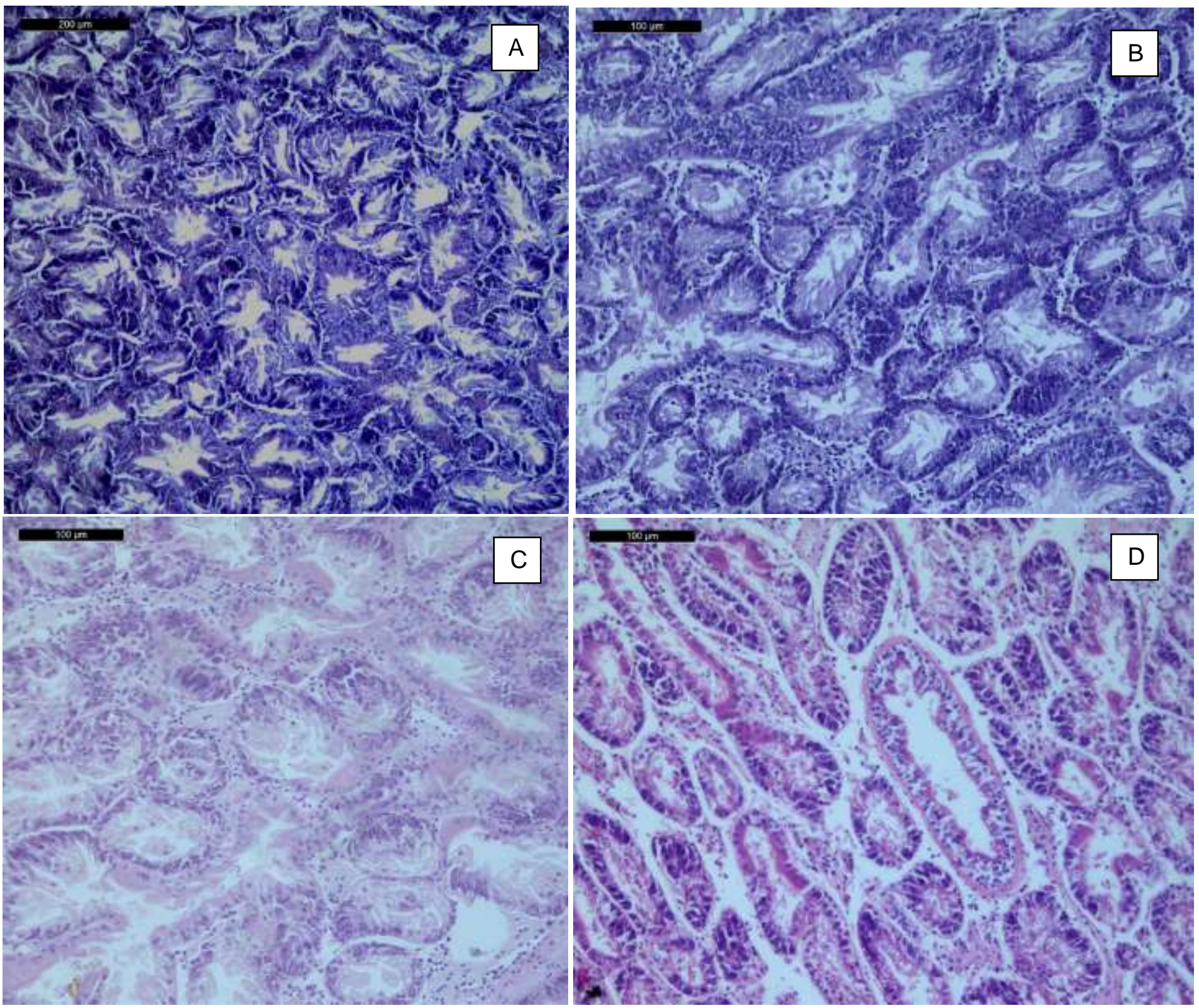


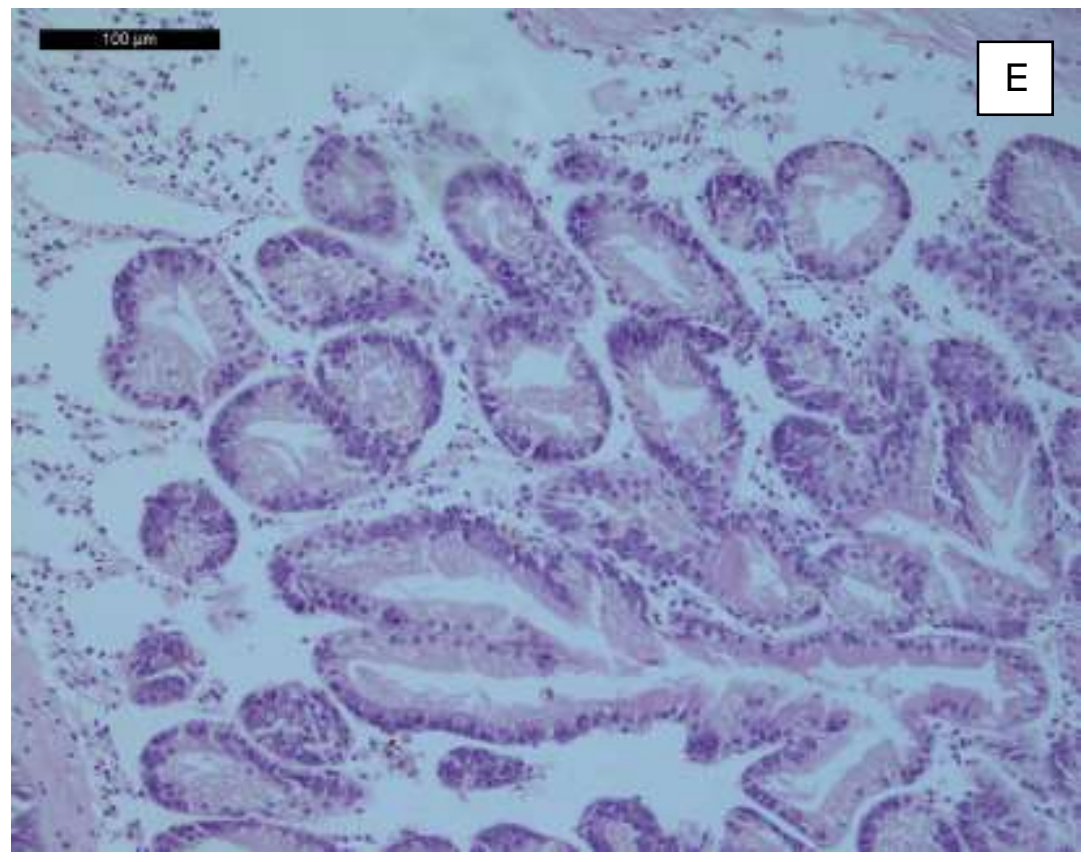

Figure 12. Tuatua digestive glands histological categories. See text for detail. 
Gills:

A: Large gaps between filaments, thin cell epithelium, hypoplasic cells, and open water tubules.

B: Uniform plicae, gaps between filaments, cellular infiltration, and haemolymph sinus moderately full.

C: Filaments occasionally compacted together, water tubules collapsed, plicae straight (nonexistent), and thick haemolymph sinus.

D: Clearly defined plicae, gill lamellae joined together closely in plaques, thick haemolymph sinus, small water tubules, and cellular infiltration. 

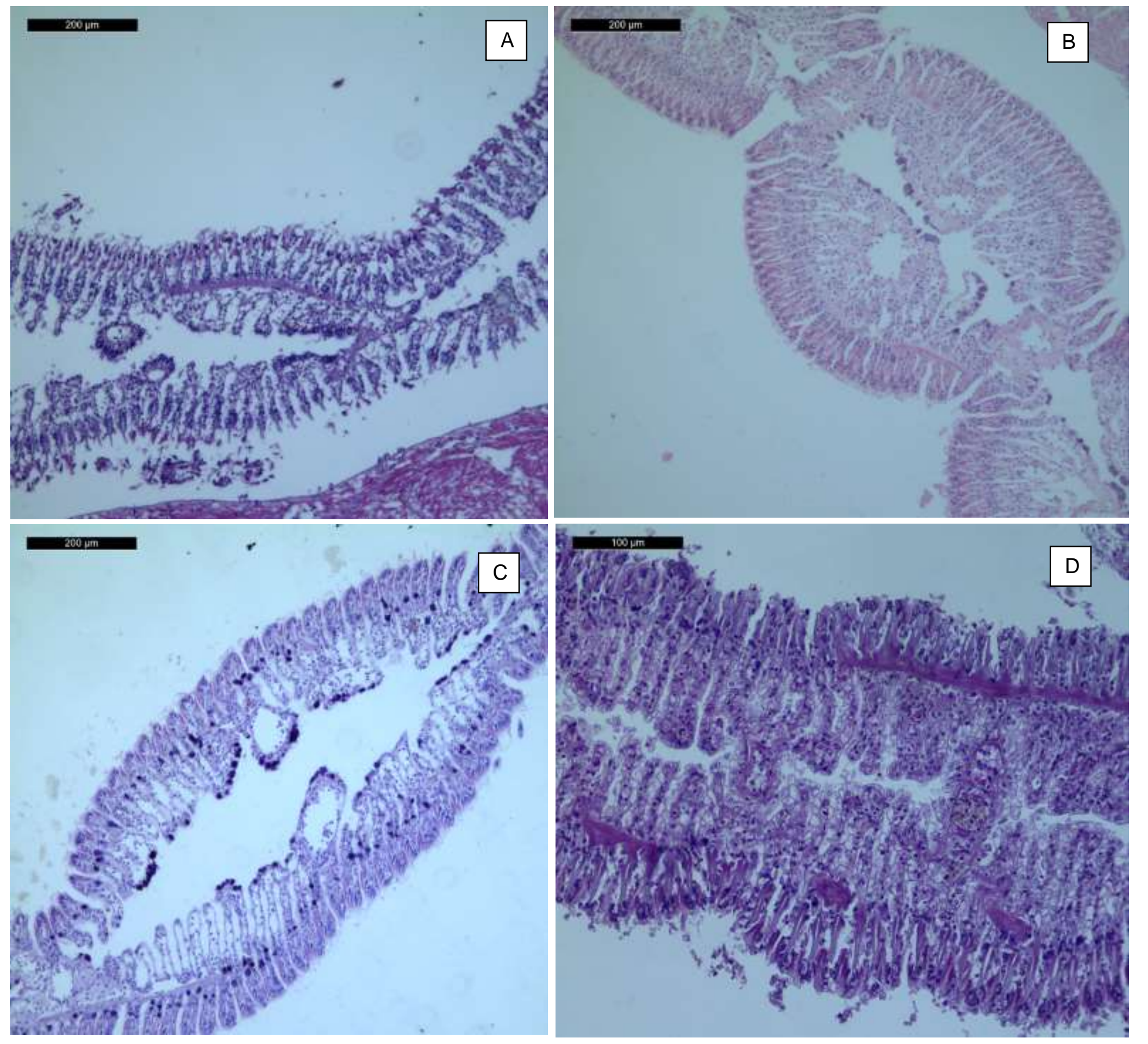

Figure 13. Tuatua gills histological categories. See text for detail. 


\section{Gonad:}

A1: Mature sperm follicles.

A2: Mature oocytes.

B1: Oocytes at mid stages of reabsorption.

B2: Sperm reabsorption.

B3: Oocytes, at end stages of reabsorption.

C: Unknown.
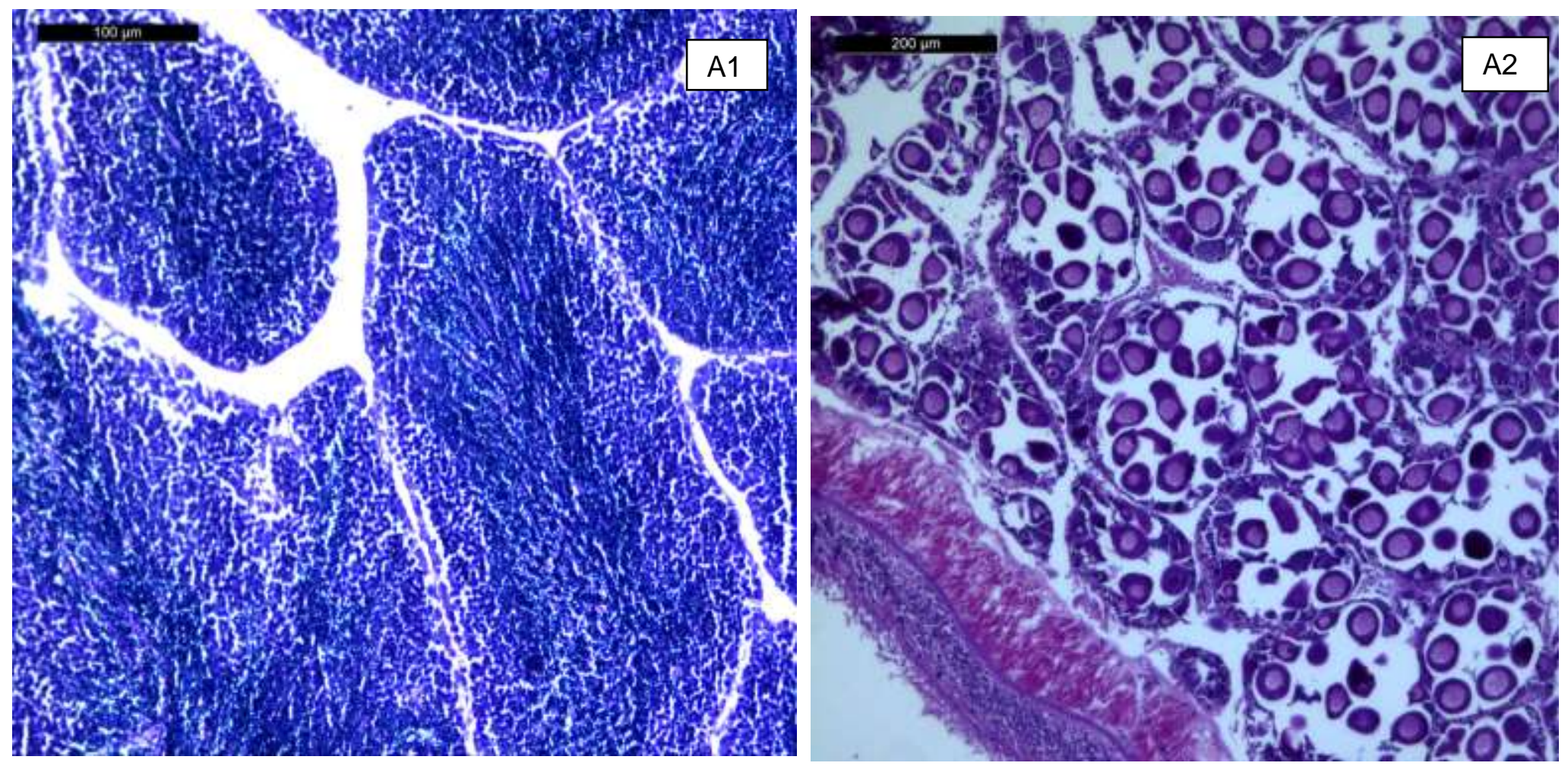

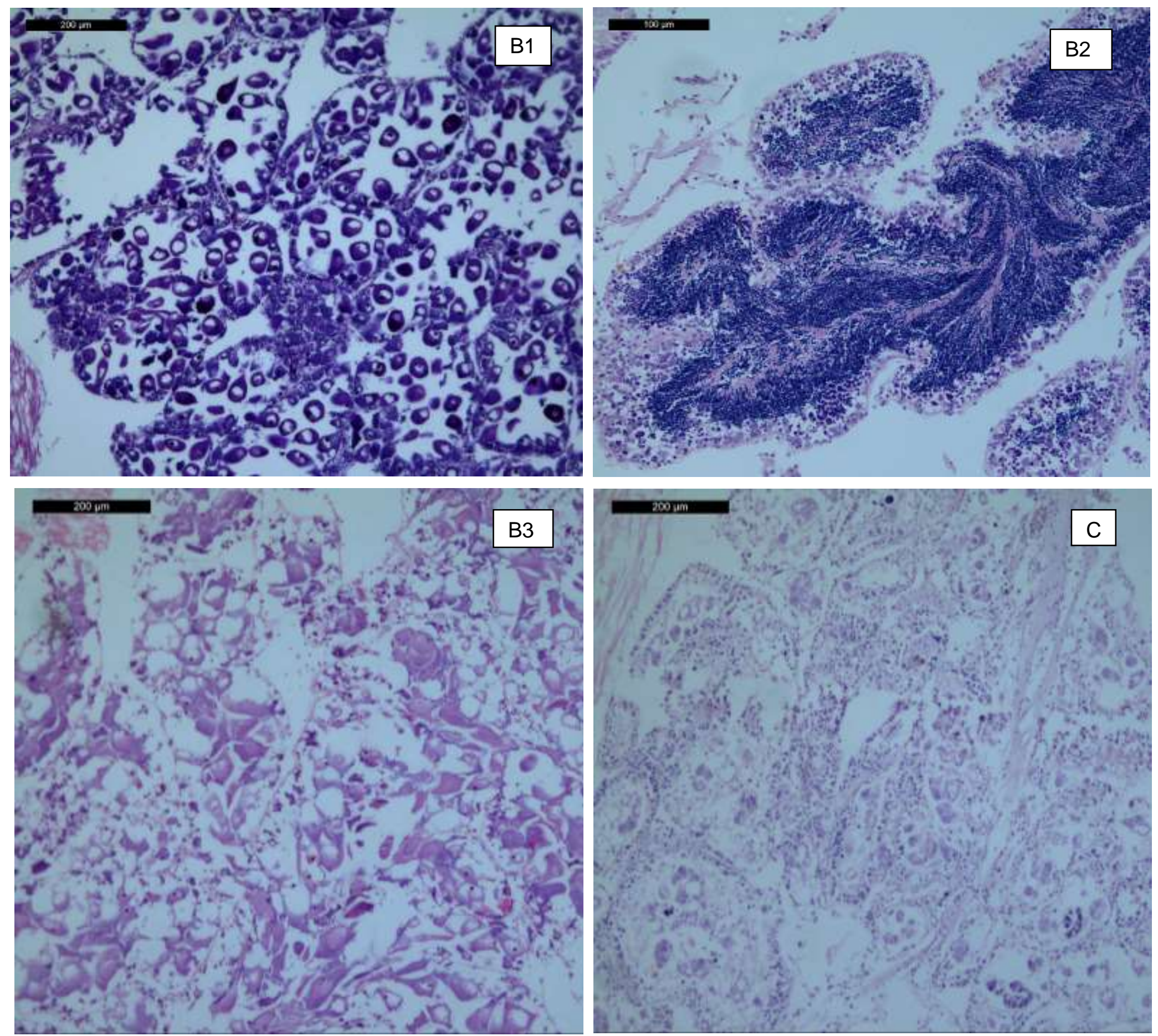

Figure 14. Tuatua gonads histological categories. See text for detail. 


\section{Cockles}

\section{Digestive glands:}

A: Thickening in digestive glands, thickening of the epithelium, clearly defined lumen, no cellular infiltration, and "coffee bean" shape.

B: Cellular infiltration around digestive glands, thickening in glands, thickening of the epithelium, thin but clearly defined lumen, little interstitial tissue, and oval but not always clearly defined cell shapes.

C: Thin digestive cells, hypoplasia, and some space between cells.

D: Hypoplastic cells, majority of the cell made up by the lumen, cellular infiltration between cells, thin epithelium and undefined cell walls.
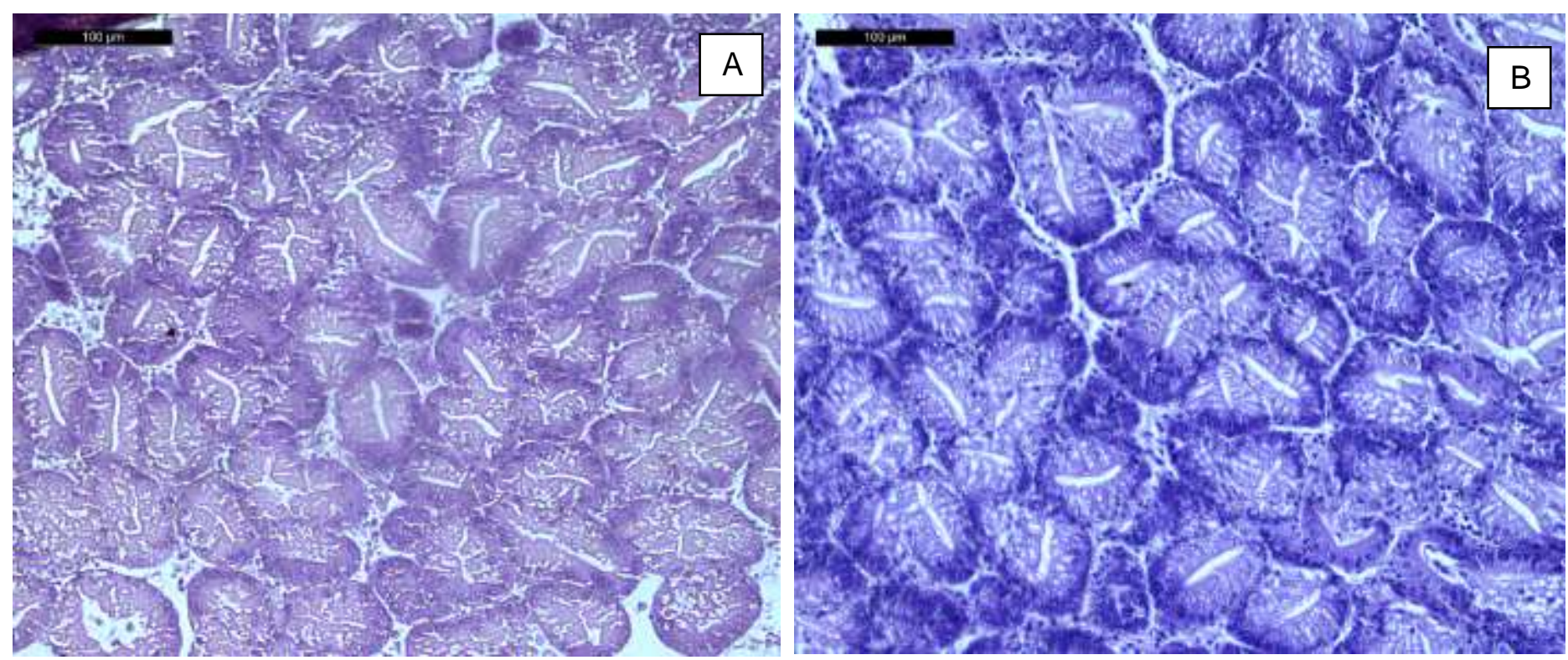

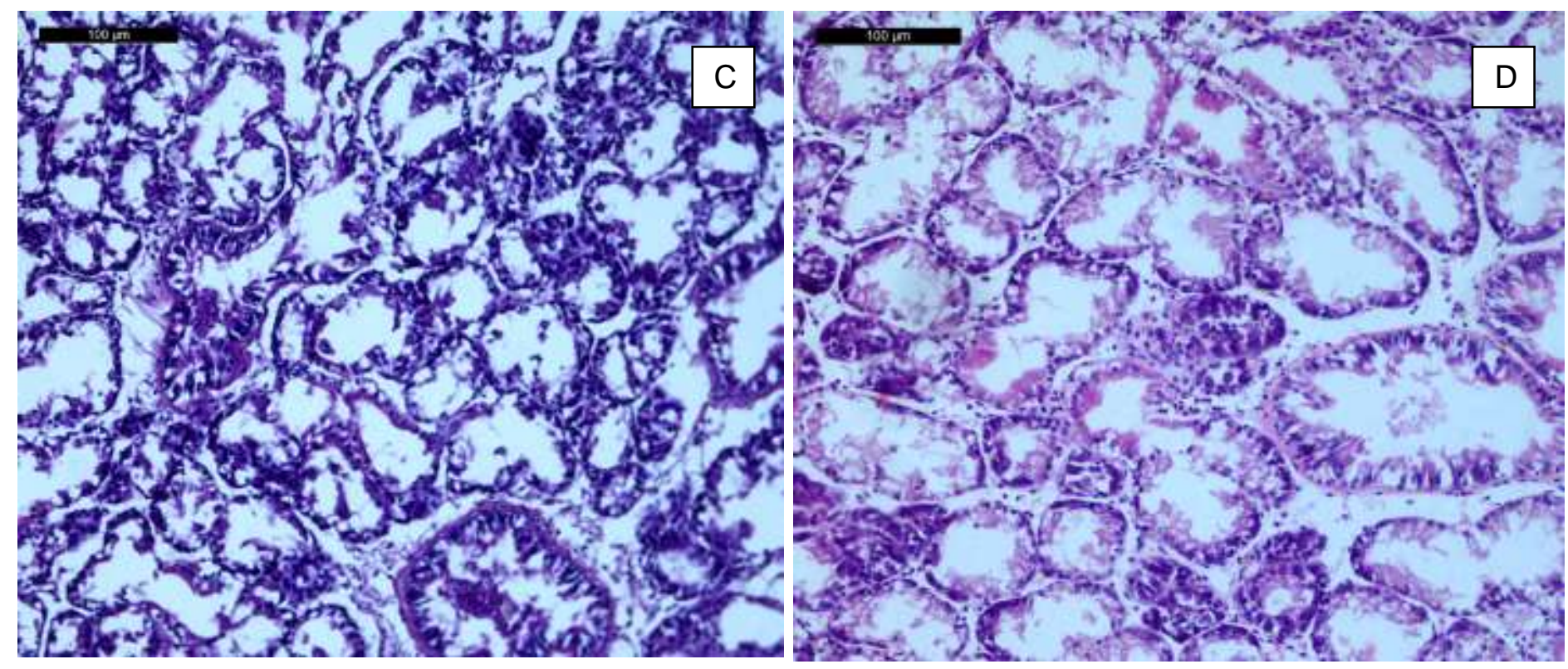

Figure 15. Cockle digestive glands histological categories. See text for detail. 
Gills:

A: Hypoplasia, space between gill filaments, water tubules large and "pinched" horizontally, plicae clear and parabolic.

B: Filaments compacted, water tubules large, gill structure uniform, plicae parabolic and extremely well-articulated.

C: Space between filaments, cellular debris present in water tubules, water tubules parallel and large, plicae not clearly defined, and breaks in cell walls.

D: Cells tightly compacted, hyperplasia, filaments joined closely, water tubules clearly present, gill shape longer vertically, and plicae gently sloping.

E: Gill filaments joined together closely in plaques, cell compacted, water tubules collapsed and barely present, plicae gentle and not well articulated.
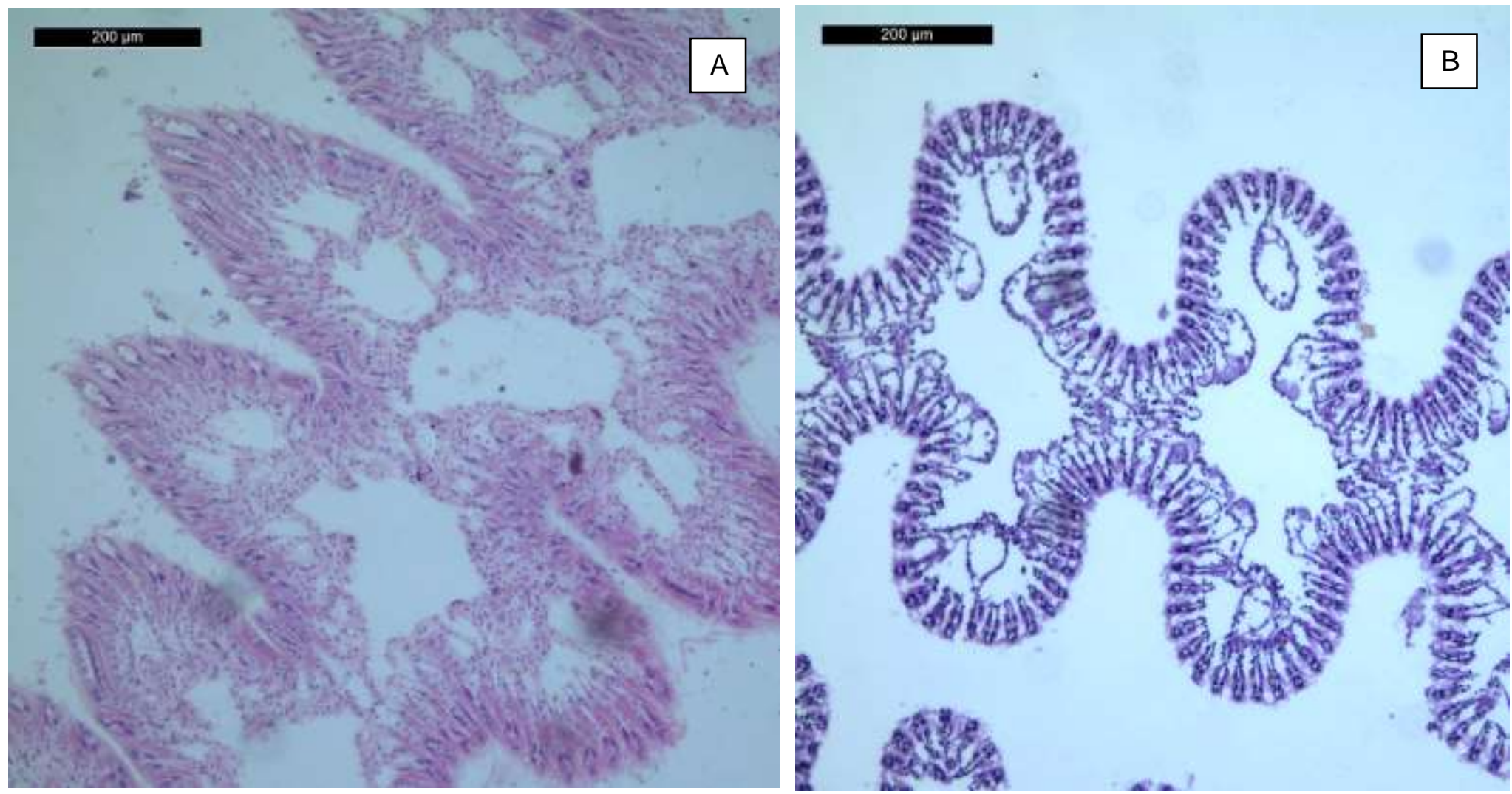

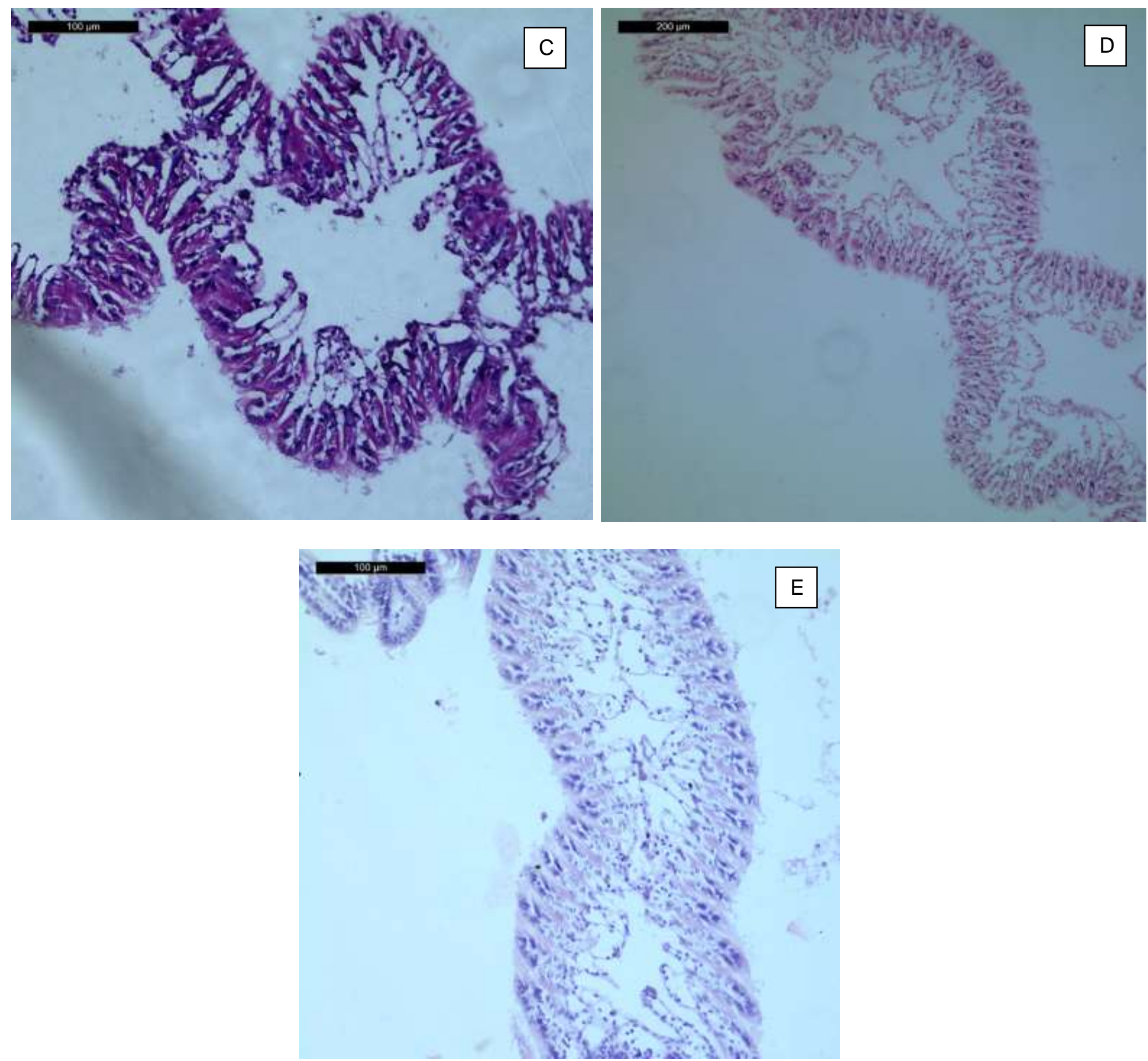

Figure 16. Cockle gills histological categories. See text for detail. 


\section{Gonad:}

A1: Mature sperm follicles.

A2: Mature oocytes.

B1: Oocytes late reabsorption. Parasite visible on left side.

B2: Sperm late reabsorption.
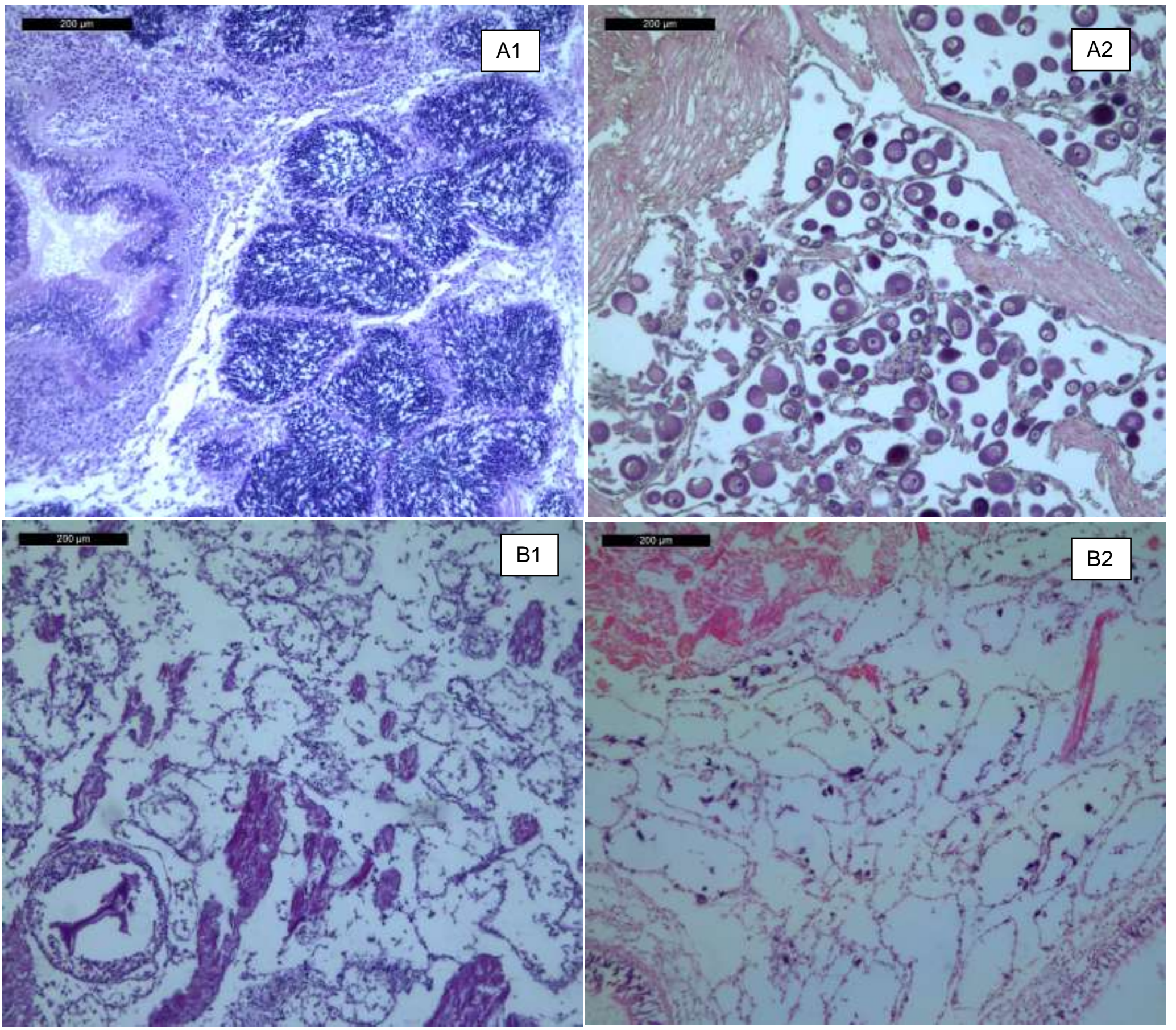

Figure 17. Cockle gonads histological categories. See text for detail. 
Foot Edges: taken from bottom of the foot where possible

A: Low nuclear activity, thin and clearly defined epithelium.

B: Nuclear cells scattered through edges.

C: Pockets of mucus cells.

D: Clear banding of mucus cells (large nuclear concentrations).

E: Large sections of mucus cells spread to the edges of the foot. 

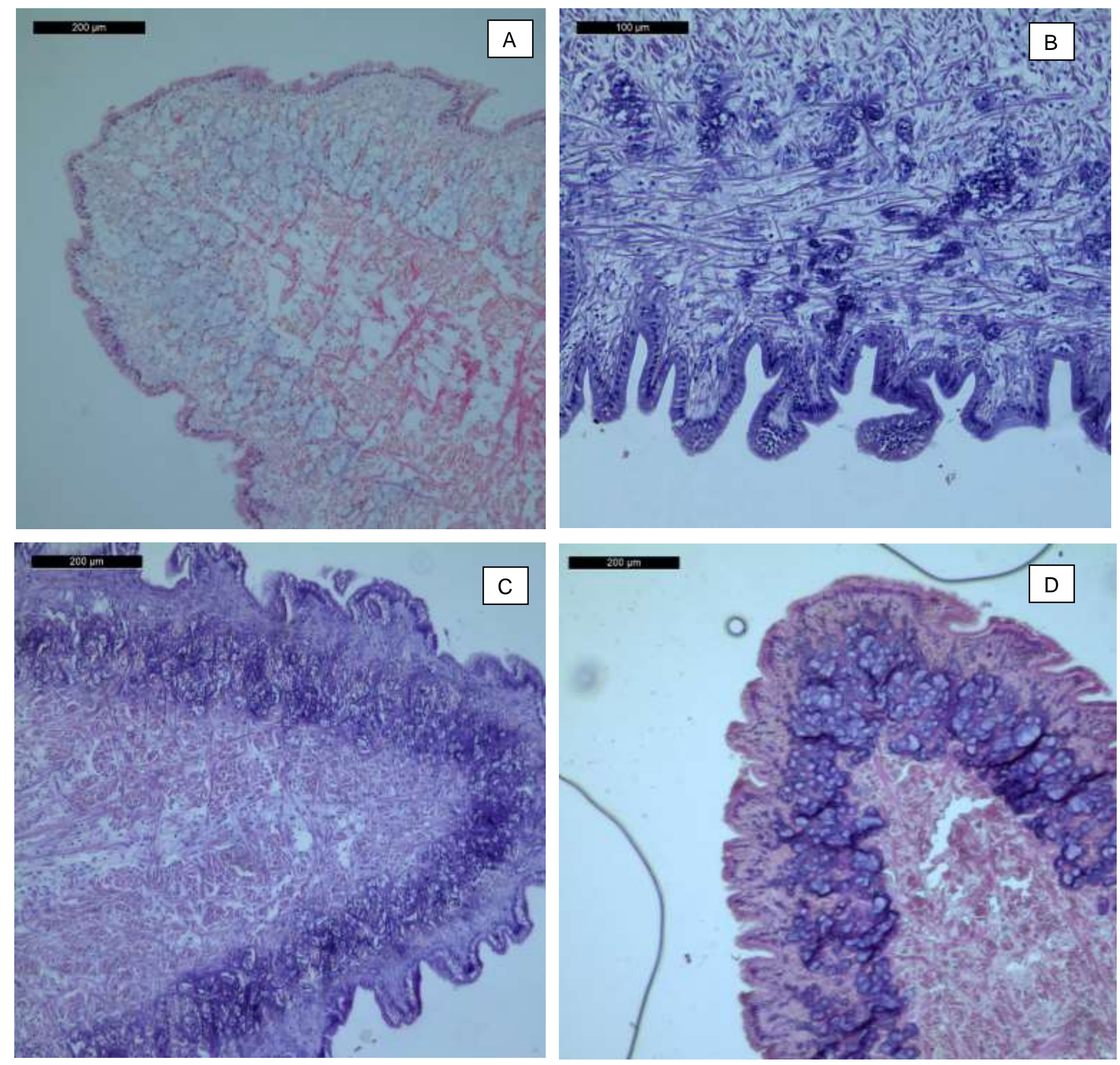


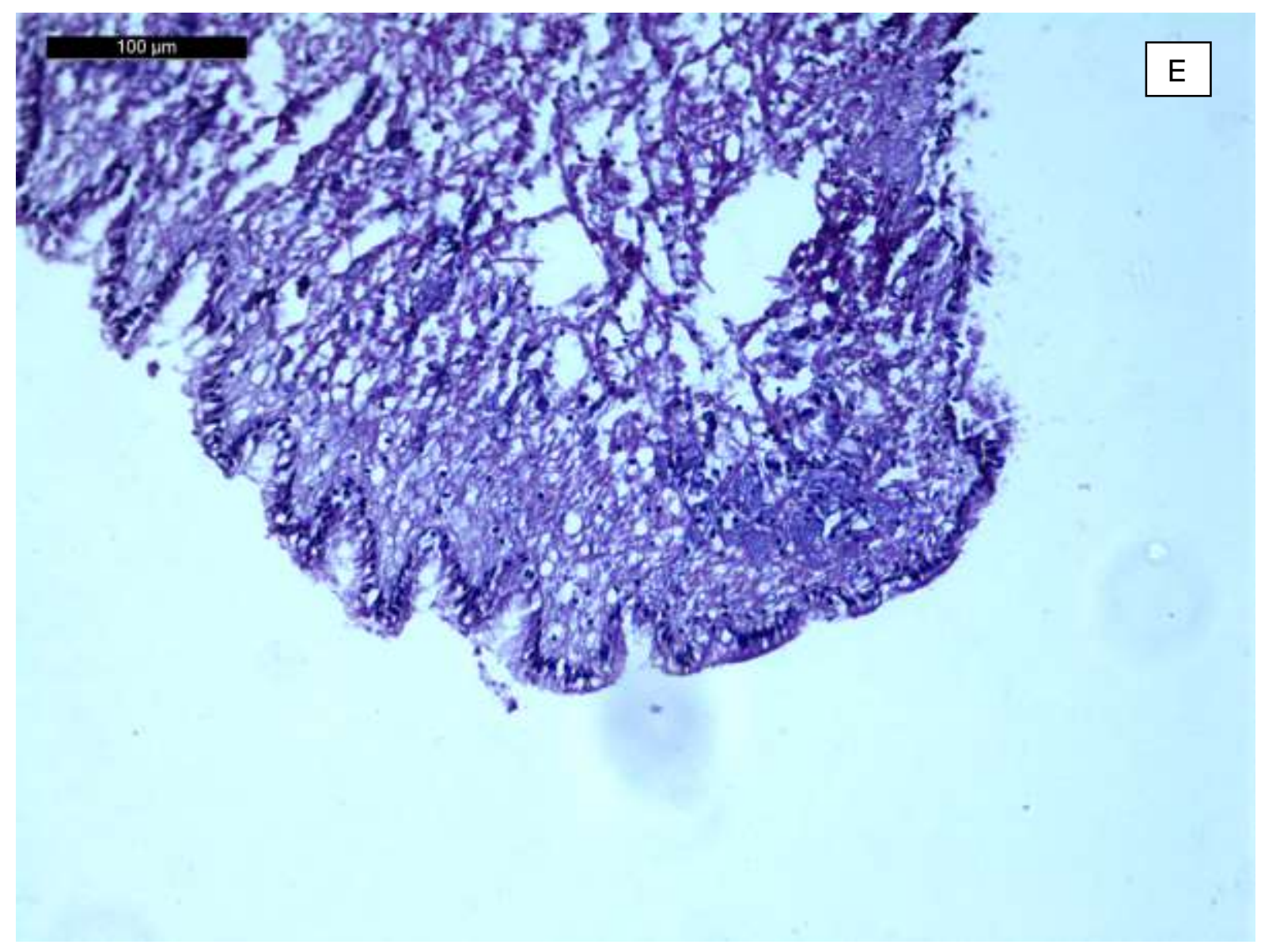

Figure 18. Cockle foot edges histological categories. See text for detail. 


\section{Part 2: Mortality}

\section{Tuatua}

Throughout all 4 experiments 21 tuatua died out of 264 (8\%). The mortality rate varied across experiments $\left(\mathrm{X}^{2}=17.83, \mathrm{df}=3, \mathrm{p}=0.0005\right)$. Of those that died, nearly half were from experiment 4 (Table $1 \& 2$ ), which was also the only experiment where death occurred in the salinity and sediment treatments (Table 3, Figure 19).

Table 1: Percentage of total death that occurred in each experiment for each species

\begin{tabular}{|l|l|l|}
\hline Experiment & Tuatua & Cockles \\
\hline $1(28 / 04 / 19-27 / 05 / 19)$ & $19 \%$ & $92 \%$ \\
\hline $2(29 / 07 / 19-29 / 08 / 19)$ & $14 \%$ & 0 \\
\hline $3(05 / 09 / 19-04 / 10 / 19)$ & $19 \%$ & 0 \\
\hline $4(13 / 10 / 19-08 / 11 / 19)$ & $48 \%$ & $8 \%$ \\
\hline
\end{tabular}

Mortality changed according to the treatment an individual was subjected to $\left(X^{2}=50.6, d f=4, p\right.$ $<.0001)$. Of all the deaths across experiments, $85 \%$ occurred in individuals subjected to the heat treatment (Table 3, Figure 19). 


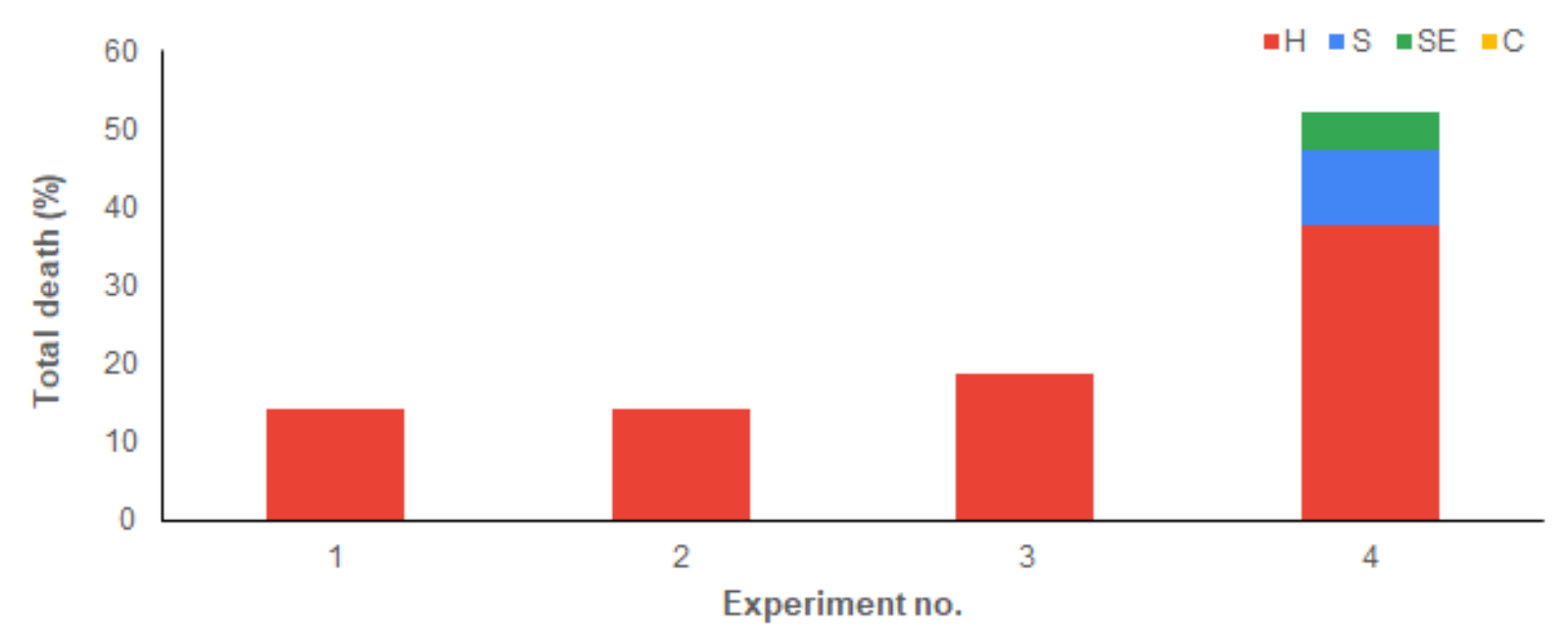

Figure 19. The percentage of total death in tuatua that occurred in each treatment in each experiment, separated by treatment. Where, $\mathrm{H}=$ heat treatment, $\mathrm{S}=$ salinity treatment, $\mathrm{Se}=$ sediment treatment, $\mathrm{C}=$ control.

The overall size range for tuatua across experiments (by width) was $25-77 \mathrm{~mm}$. The tuatua that died had a width range of 31-63mm. Both width $\left(X^{2}=152.01, d f=164, p=0.74\right)$ and height $\left(X^{2}=157.12\right.$, $\mathrm{df}=139, \mathrm{p}=0.14$ ) of the tuatua were not correlated with death.

Table 2: Differences in mortality of tuatua between experiments. Test statistic is $\mathrm{X}^{2}$. Statistically significant results $\mathrm{p}<0.0083$ indicated by*. Cut offs are variable due to bonferroni correction.

\begin{tabular}{|l|l|l|l|}
\hline Experiments & Test statistic & $\mathbf{d f}$ & $\mathbf{p}$ \\
\hline 1,2 & Fisher's & & 0.708 \\
\hline 1,3 & Fisher's & & 1 \\
\hline 1,4 & 5.83 & 1 & 0.016 \\
\hline 2,3 & Fisher's & & 1 \\
\hline 2,4 & 8.63 & 1 & $0.0033^{*}$ \\
\hline 3,4 & 7.11 & 1 & $0.0077^{*}$ \\
\hline
\end{tabular}


Table 3: Differences in mortality of tuatua between treatments. Test statistic is $\mathrm{X}^{2}$. Statistically significant results $\mathrm{p}<0.0083$ indicated by*. Cut offs are variable due to bonferroni correction. Where, $\mathrm{H}=$ heat, $\mathrm{S}=$ salinity, $\mathrm{Se}=$ sediment and $\mathrm{C}=$ control

\begin{tabular}{|l|l|l|l|}
\hline $\begin{array}{l}\text { Treatmen } \\
\text { ts }\end{array}$ & $\begin{array}{l}\text { Test } \\
\text { statistic }\end{array}$ & df & $\mathbf{p}$ \\
\hline C, H & 20.9 & 1 & $<.0001^{*}$ \\
\hline C, S & 8.6 & 1 & $<.0001^{*}$ \\
\hline C, SE & Fisher's & & 1 \\
\hline H, S & 15.1 & 1 & $0.0004^{*}$ \\
\hline H, SE & 18.0 & 1 & $<.0001^{*}$ \\
\hline S, SE & Fisher's & & 0.619 \\
\hline
\end{tabular}

The highest mortality across all experiments occurred in weeks 1 and 2. The majority of mortality, $62 \%$, occurred before the end of the second week. After week 2 , the mortality across experiments dropped to $19 \%$ per week until the end of the experiments (Figure 20).

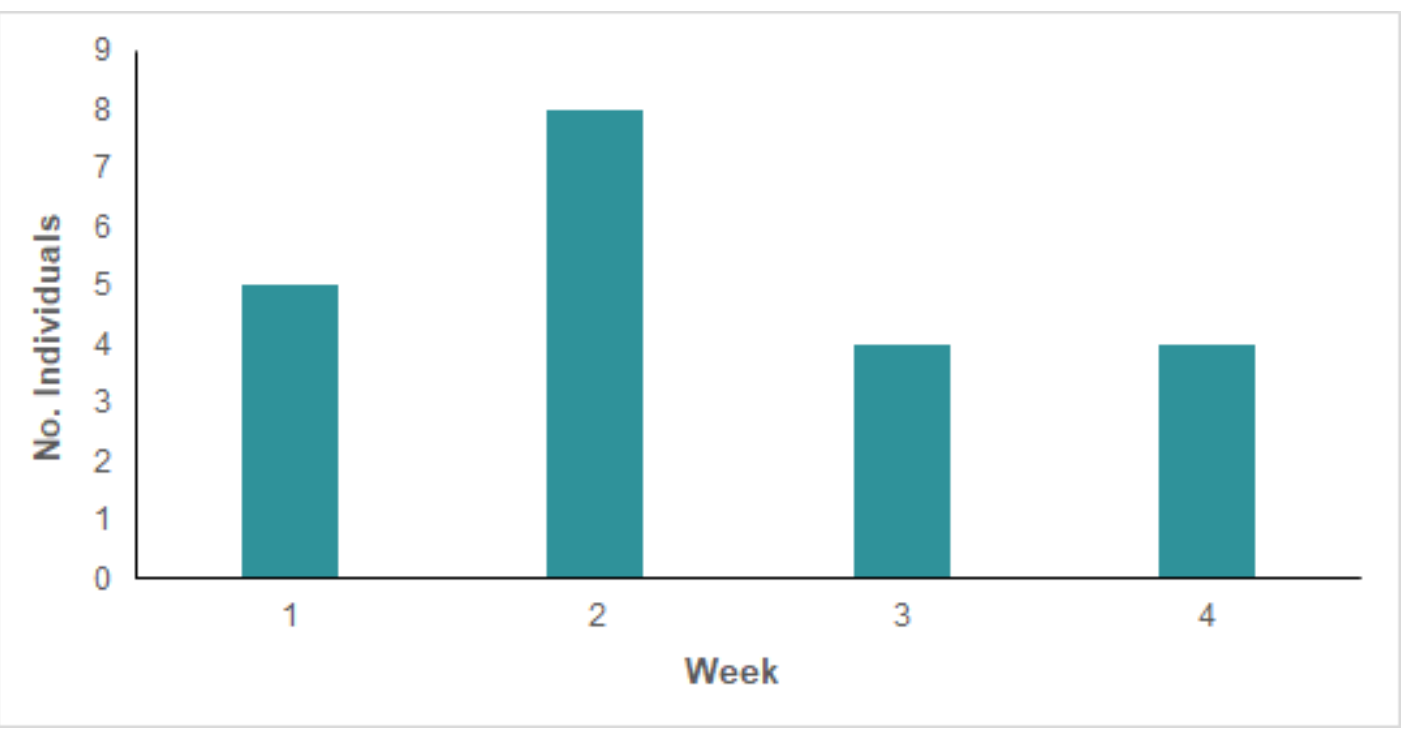

Figure 20. Tuatua mortality over time (weeks) combined across experiments. 


\section{Cockles}

The mortality in cockles varied significantly between experiments $\left(X^{2}=28.43, \mathrm{df}=3\right.$, p-value $<.0001$ ). In experiment 1 , the most deaths of cockles were recorded. Twelve individuals died in experiment 1 , out of the 13 individuals who died across experiments 1 to 4 (Tables $1 \& 4$ ). Of those 12 , six died in the salinity treatment, four died in the heat treatment, one died in the sediment treatment and two died in the control (Figure 21). Across the other three experiments, only one cockle died - a cockle from the control treatment in experiment 4. Non-significant results for pairwise treatment comparisons can be found in Appendix C, Table 1.

There was no relationship between the width $\left(X^{2}=41.96, d f=119, p=1\right)$ or height $\left(X^{2}=63.66, d f=\right.$ $110, p=1$ ) of cockles and their time of death.

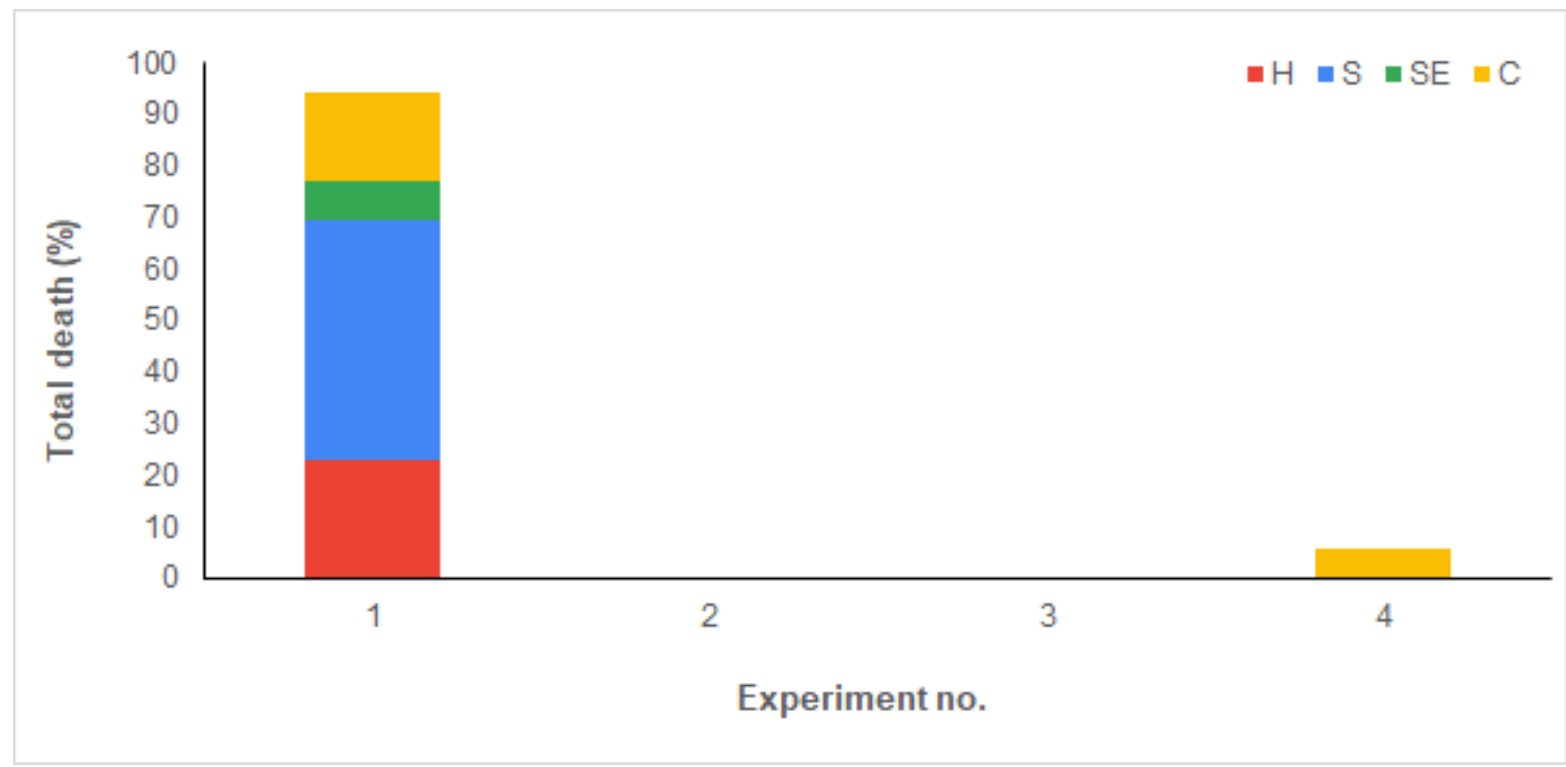

Figure 21. The percentage of total death in cockles that occurred in each experiment broken down by treatment. Where, $\mathrm{H}=$ heat treatment, $\mathrm{S}=$ salinity treatment, $\mathrm{Se}=$ sediment treatment, $\mathrm{C}=$ control. 
Table 4: Differences in mortality of cockles between experiments. $p$ value is from fisher's test. Statistically significant results $\mathrm{p}<0.0083$ indicated by*. Cut offs are variable due to bonferroni correction.

\begin{tabular}{|l|l|}
\hline Experiments & $\mathbf{p}$ \\
\hline 1,2 & $<.0001^{*}$ \\
\hline 1,3 & $<.0001^{*}$ \\
\hline 1,4 & 0.2261 \\
\hline 2,3 & 1 \\
\hline 2,4 & $0.0023^{*}$ \\
\hline 3,4 & $0.0043^{*}$ \\
\hline
\end{tabular}

The highest mortality across all experiments occurred in week 1 (38\%). Mortality steadily declined by approximately $8 \%$ for the next two weeks. Week 4 had the lowest mortality at $8 \%$ (Figure. 22).

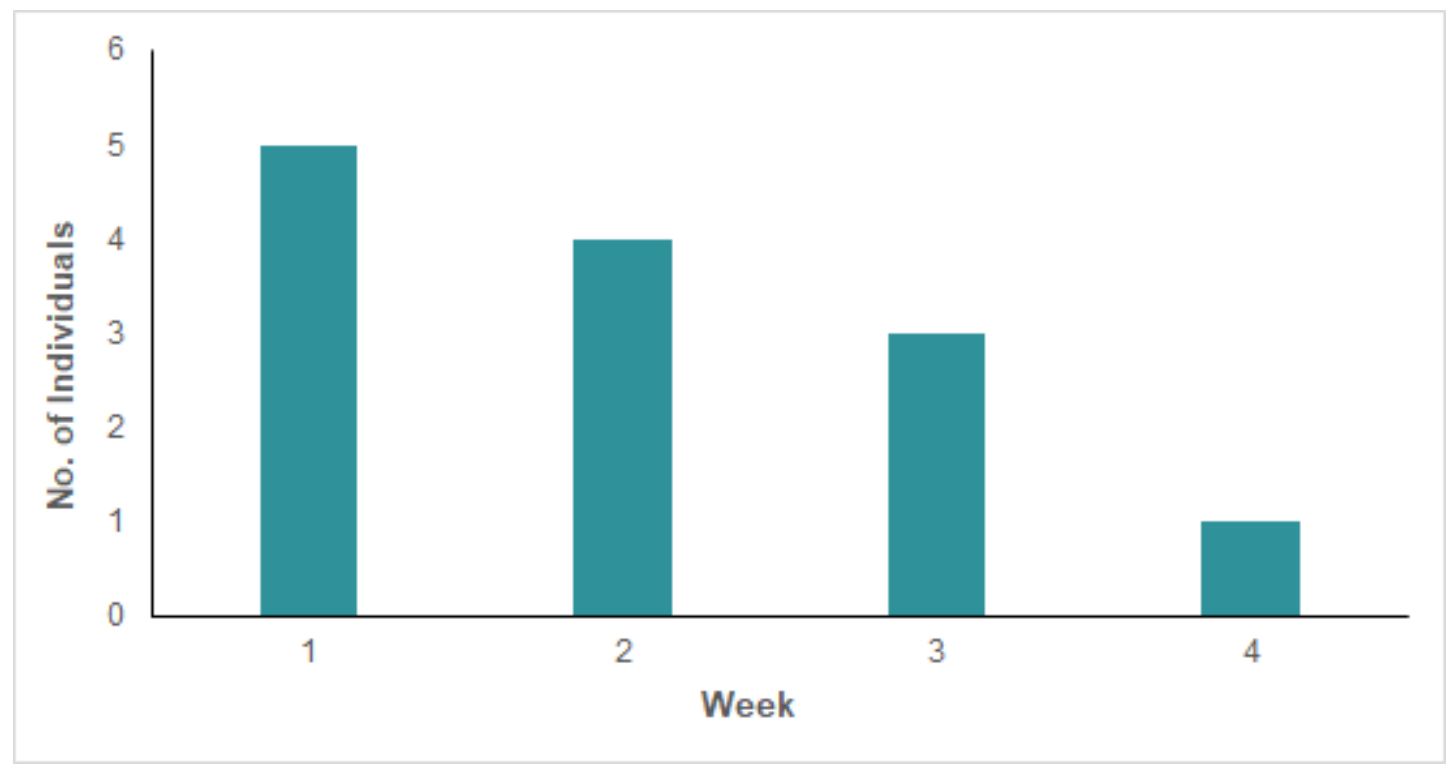

Figure 22. Total cockle mortality across experiments, by week. 


\section{Part 3: Behavioural responses}

\section{Tuatua only}

In tuatua, time taken to retract into their shells (after being lifted out of the aquarium) did not significantly change with treatment, with the exception of the salinity treatment (Table 5). The majority of individuals across all treatments had no measurable retraction time. In the salinity treatment, almost half of the individuals had a noted reaction (Figure 23). The heat treatment also had more reactions than the control and the sediment treatment, but these were not statistically significant. Low numbers of retractions were recorded for individuals where they either retracted so quickly that the reaction could not be recorded, or they were not sitting with their foot anchoring as expected. There were a significant number of these instances so reactions were recorded as "yes" or "no" for initial analysis.

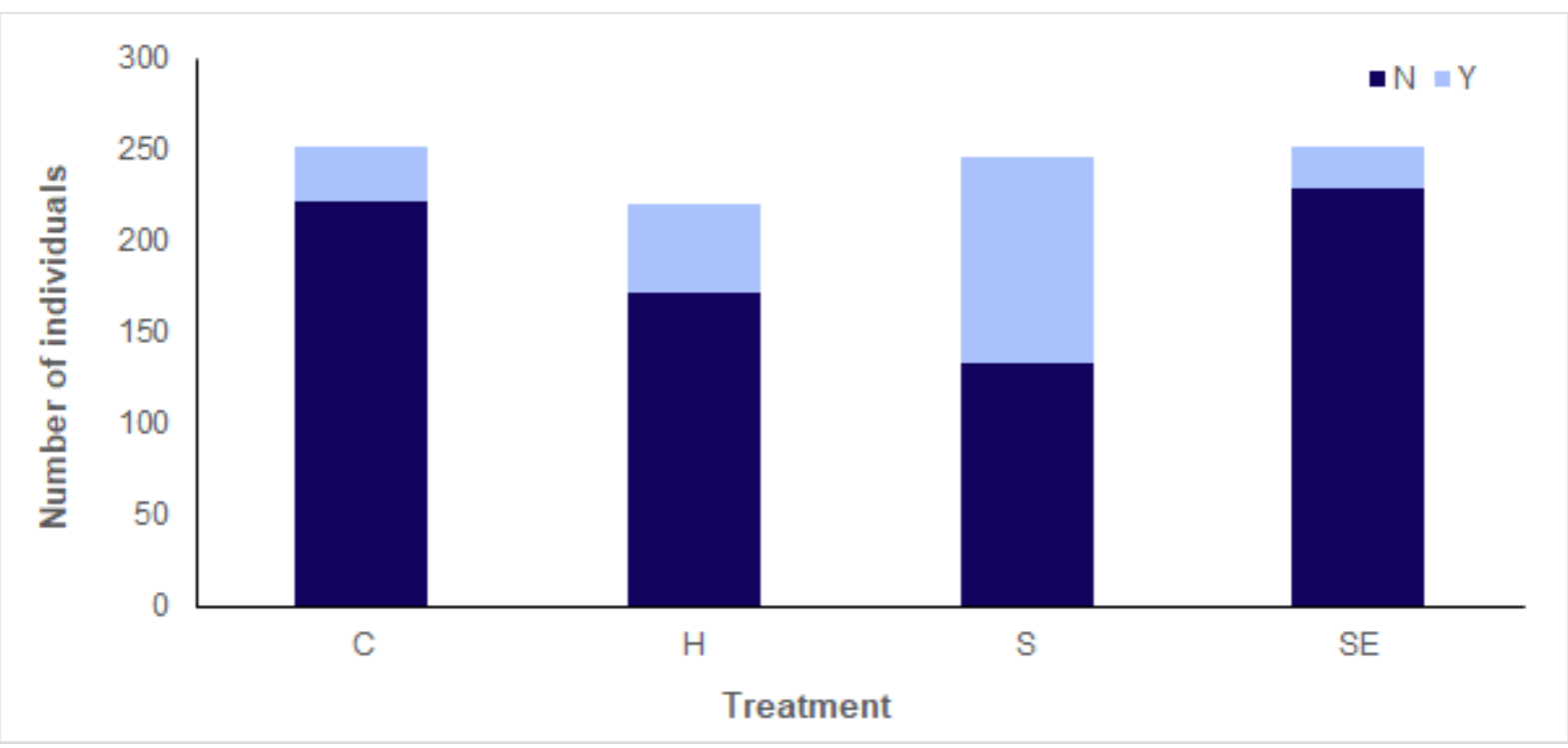

Figure 23. Number of individuals from each treatment that reacted when removed from aquaria. $\mathrm{N}=$ no reaction, $\mathrm{Y}=$ yes reaction. 
The mixed effect logistic regression model showed significant differences in reaction time between experiment 4, salinity treatment, and day, and all other treatments (Table 5). In the post-hoc analysis, differences in reaction time over days could not be found across several different models and it was not explored further.

Table 5. Overview of results from general mixed effect logistic regression for reaction time in tuatua. Statistically significant results $\mathrm{p}<0.05$ indicated by*. Intercept indicated by **.

\begin{tabular}{|l|l|l|l|l|}
\hline & Estimate & Std. Error & $\mathrm{z}$ value & $\operatorname{Pr}(>|\mathrm{z}|)$ \\
\hline (Intercept) & -1.27765 & 0.37414 & -3.415 & $0.0006^{* *}$ \\
\hline Experiment 2 & 0.05810 & 0.23546 & 0.247 & 0.805 \\
\hline Experiment 3 & -0.04859 & 0.23782 & -0.204 & 0.838 \\
\hline Experiment 4 & -0.94299 & 0.27315 & -3.452 & $0.0006^{*}$ \\
\hline Heat Treatment & 0.61190 & 0.44033 & 1.390 & 0.165 \\
\hline $\begin{array}{l}\text { Salinity } \\
\text { Treatment }\end{array}$ & 2.04269 & 0.42465 & 4.810 & $<.0001^{*}$ \\
\hline $\begin{array}{l}\text { Sediment } \\
\text { Treatment }\end{array}$ & -0.35974 & 0.46576 & -0.772 & 0.440 \\
\hline Day & -0.10865 & 0.02294 & -4.736 & $<.0001^{*}$ \\
\hline
\end{tabular}

The two-way ANOVA confirmed significant differences in reaction time between treatments and individual experiments (Table 6). Only results from the heat and salinity treatments were analysed using the ANOVA as there were not enough values from the sediment and control treatments to perform the analysis. Post-hoc tests found that the mean reaction time of individuals exposed to the salinity treatment was slower than that of individuals exposed to the heat treatment. Individuals in experiments $2 \& 4$ had a slower reaction time than individuals in experiments $1 \& 3$ (Table 7, Figure 24). 
Table 6. Overview of results from two-way ANOVA for reaction time in tuatua. Statistically significant results $\mathrm{p}<0.05$ indicated by*.

\begin{tabular}{|l|l|l|l|l|}
\hline Source & df & $\begin{array}{l}\text { Sum of } \\
\text { Squares }\end{array}$ & F & $\mathrm{p}$ \\
\hline Experiment & 3 & 1.71 & 10.24 & $<.0001^{*}$ \\
\hline Treatment & 1 & 0.24 & 4.36 & $0.0384^{*}$ \\
\hline $\begin{array}{l}\text { Experiment* } \\
\text { Treatment }\end{array}$ & 3 & 0.1 & 0.61 & 0.61 \\
\hline
\end{tabular}

Table 7. Tukey test for differences among experiments for reaction time in tuatua

\begin{tabular}{|l|l|l|}
\hline Experiment & $\begin{array}{l}\text { Tukey } \\
\text { group }\end{array}$ & Least sq mean \\
\hline 1 & B & 0.505 \\
\hline 2 & A & 0.697 \\
\hline 3 & B & 0.5 \\
\hline 4 & A & 0.769 \\
\hline
\end{tabular}




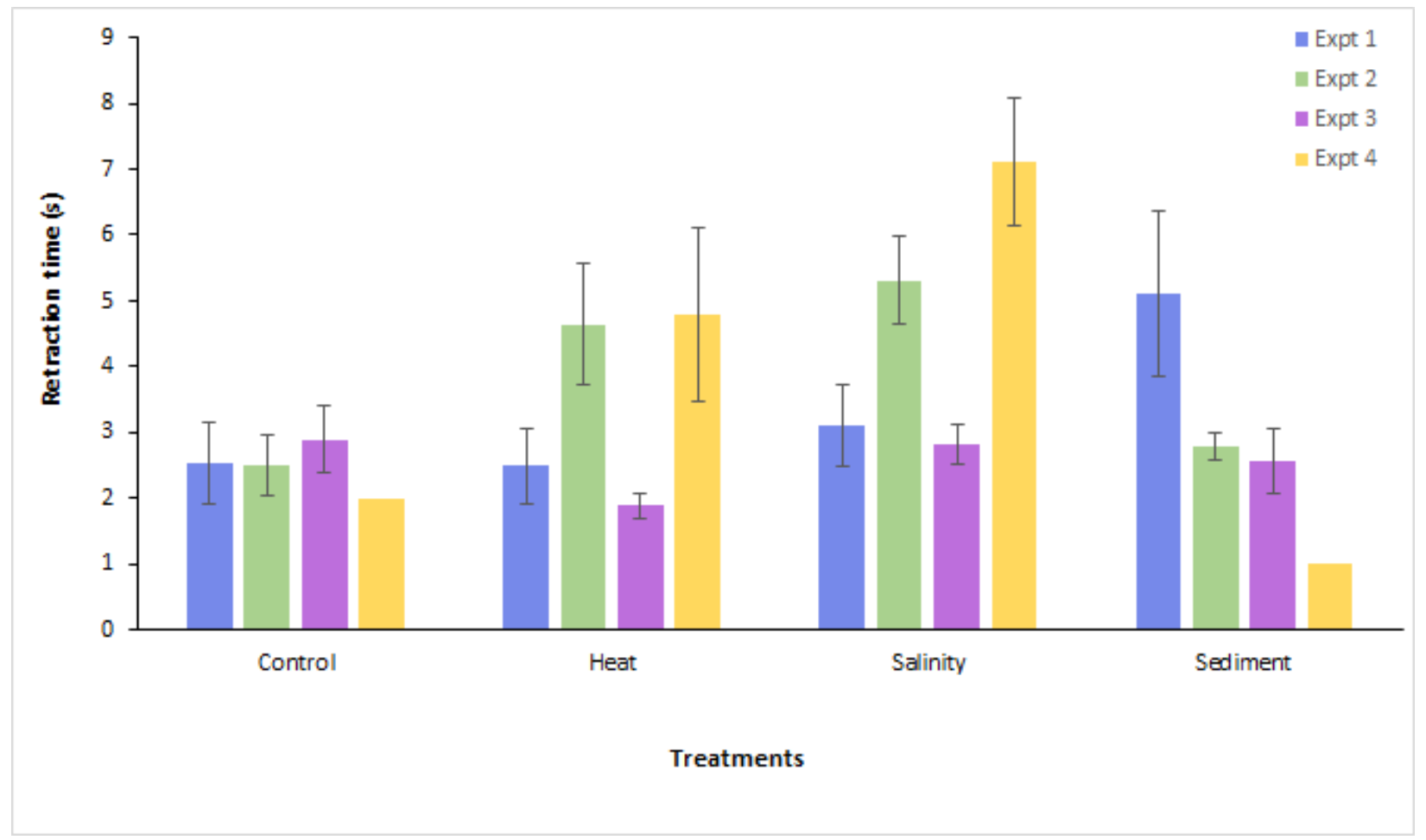

Figure 24. Mean reaction times in seconds (+/- 1 standard error) across treatments. Data was combined across days. Note that in experiment 4 the control and sediment treatments only had one value and therefore had no error. 


\section{Part 4: Analysis of treatment effects on histological and morphological categories}

Tuatua

\section{Histology}

There was no difference in traits across treatments for digestive glands $\left(X^{2}=21.86, d f=16, p=\right.$ 0.148), gonads $\left(X^{2}=6.03, d f=8, p\right.$-value $\left.=0.644\right)$, or gills $\left(X^{2}=15.81, d f=12, p=0.2\right)$. However, when combined across treatments but broken down by week, digestive glands $\left(X^{2}=30.82, d f=16\right.$, $\mathrm{p}=0.014)$ had significant changes in categories with increased exposure time. Gonad $\left(\mathrm{X}^{2}=9.94\right.$, $\mathrm{df}=8, \mathrm{p}$-value $=0.269)$ and gills $\left(\mathrm{X}^{2}=18.42, \mathrm{df}=12, \mathrm{p}=0.104\right)$ had no significant difference when analysed over time (weeks).

Dominant digestive gland category changed over the duration of experiments, with the number of individuals in category $\mathrm{C}$ steadily increasing as time progressed, and the number of individuals in category D steadily declining (Figure 25). The most significant change between weeks was between week 0 \& 4 (Fishers, p <.0001) and week $2 \& 4$ (Fishers, p=0.0017), where there was a major increase in the number of individuals that fit into category $\mathrm{C}$ and a decrease in individuals in category A \& D (Figure 25). The most significant shift in the number of individuals in a category happens between categories A \& C ( $\mathrm{p}=0.0004)$ and C \& D ( $\mathrm{p}=0.0002)$. Non-significant results for pairwise comparisons over time are in Appendix C, Table 2. 


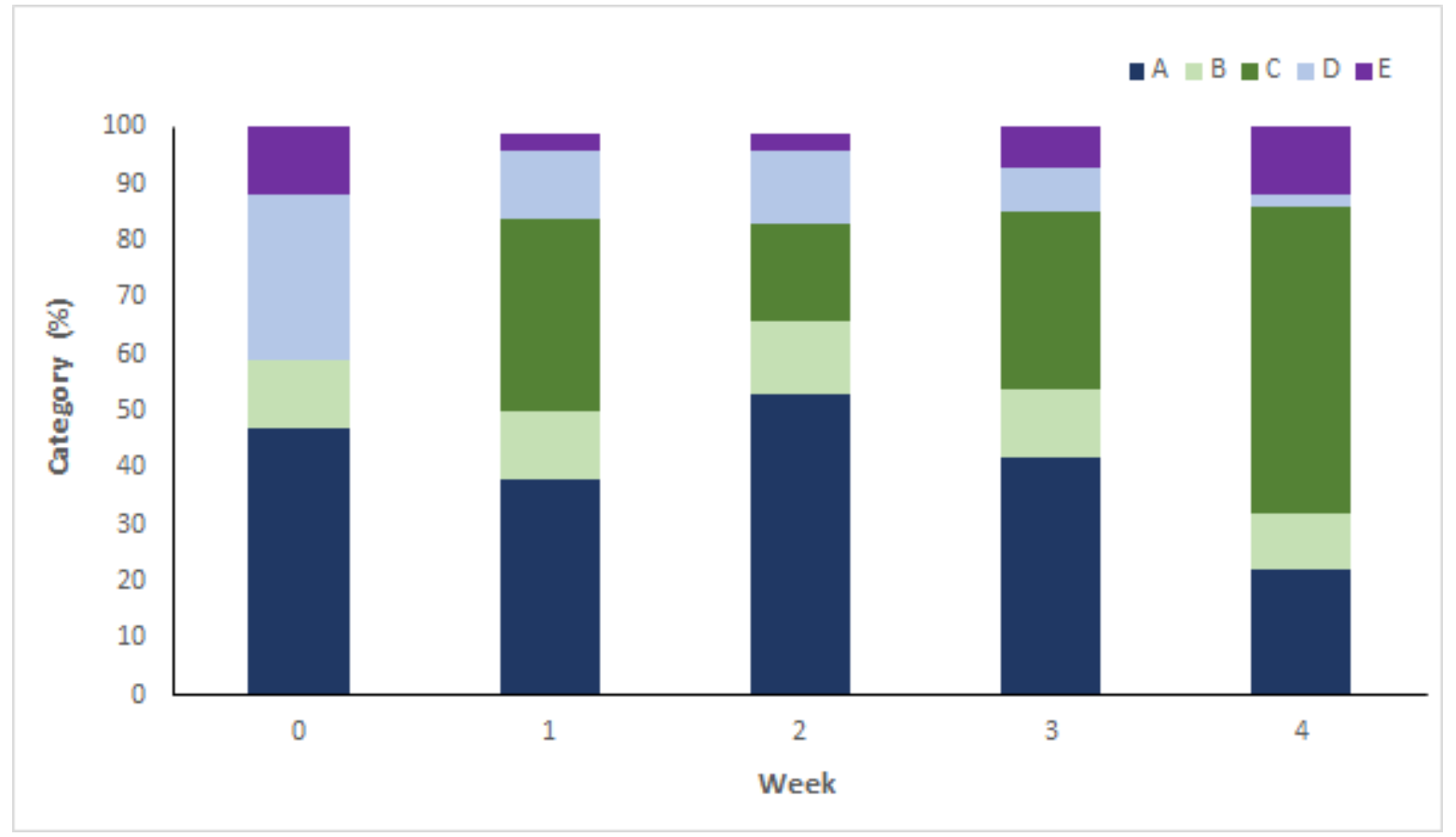

Figure 25. Digestive gland category changes over exposure time (weeks) combined over all treatments.

\section{Morphology vs treatment}

Gill erosion, gill colour, body colour, and body consistency all showed changes in dominant categories across treatments (Table 8). This was often because the heat treatment had a different dominant category compared to all other treatments. For gill erosion, the individuals subjected to heat and salinity treatments fell into significantly different categories when analysed. For gill colour, the baseline individuals and individuals subjected to heat the treatments were significantly different in category make up to one another, and for body colour and consistency, the individuals subjected to heat and control treatments were significantly different to each other (Table 9). 
Table 8. Morphological traits compared to treatments in tuatua. Test statistic is $\mathrm{X}^{2}$. Statistically significant results $\mathrm{p}<0.05$ indicated by*.

\begin{tabular}{|l|l|l|l|}
\hline & Test statistic & df & p val \\
\hline Gill erosion & 18.91 & 8 & $0.015^{*}$ \\
\hline Gill colour & 15.79 & 8 & $0.046^{*}$ \\
\hline Body colour & 17.6 & 8 & $0.025^{*}$ \\
\hline Body consistency & 16.39 & 8 & $0.037^{*}$ \\
\hline Red Marks & 11.26 & 8 & 0.185 \\
\hline
\end{tabular}

Table 9. All significant pairwise comparisons between treatments in morphological traits. Nonsignificant results for pairwise comparisons can be found in Appendix C Tables 3-6. Test statistic is $\mathrm{X}^{2}$. $\mathrm{p}$ values showing statistical significance indicated by*. Cut offs are variable due to bonferroni correction.

\begin{tabular}{|l|l|l|l|l|}
\hline $\begin{array}{l}\text { Morphological } \\
\text { indicator }\end{array}$ & $\begin{array}{l}\text { Treatment } \\
\text { s } \\
\text { compared }\end{array}$ & $\begin{array}{l}\text { Test } \\
\text { statistic }\end{array}$ & df & $\mathbf{p}$ \\
\hline Gill erosion & H,S & 11.235 & 2 & $0.0036^{*}$ \\
\hline Gill colour & B,H & Fisher's & & $0.003^{*}$ \\
\hline Body colour & C,H & 10.931 & 2 & $0.0042^{*}$ \\
\hline Body consistency & C,H & 9.8489 & 2 & $0.0073^{*}$ \\
\hline
\end{tabular}


In the gill erosion and gill colour traits, the biggest difference in the number of individuals in a category was between the baseline and treatments. In gill erosion, there were no individuals in category 3 in baseline individuals and the highest number of individuals in category 3 were in the heat treatment. Additionally, in gill erosion there was a significant difference between the heat treatment and the salinity treatment in the number of individuals in each category (Table 11, Figure. 26a). Gill colour was relatively uniform across all treatments including the control (Figure. 26b). Body colour and consistency followed similar patterns of, the highest number of individuals in category 1 in the baseline treatment followed by the control treatment; and the lowest number of individuals in category 1 in the salinity treatment. For body consistency and colour, the salinity treatment had the highest number of individuals in category 3 (Figure. 26c, 26d). There was a difference in the number of individuals in each category between the baseline and aquaria treatments in all traits. The number of individuals sampled from the ocean for immediate dissection (B) (5 per experiment) was only a third of the number of individuals in all treatments so the category disparities could be due to the lower sample size. 

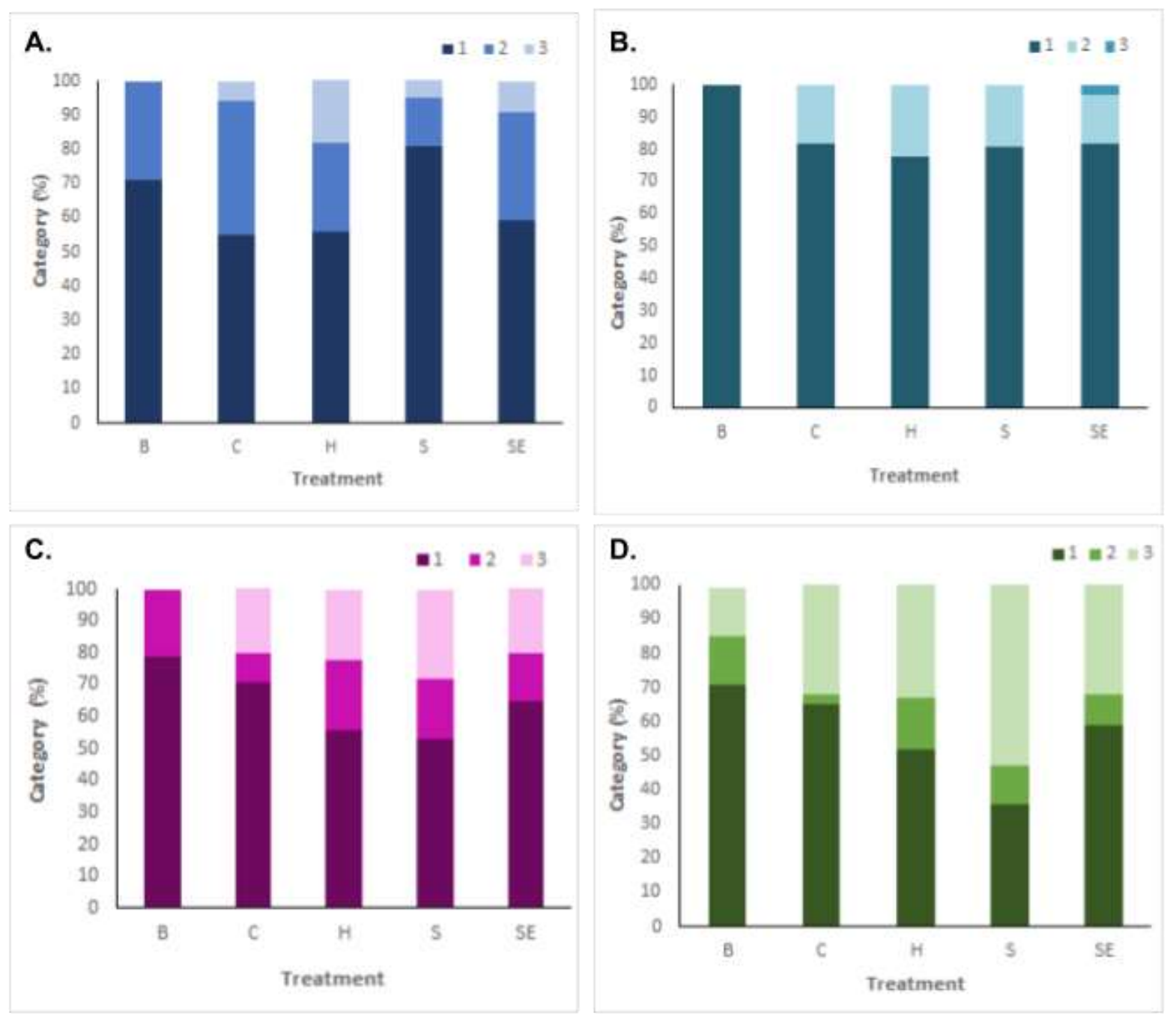

Figure 26. Morphological categories vs treatment where category is a percentage, and treatments are combined across all weeks. Where, $\mathrm{H}=$ heat treatment, $\mathrm{S}=$ salinity treatment, $\mathrm{Se}=$ sediment treatment, $\mathrm{C}=$ control, $\mathrm{B}=$ baseline.
A. Gill erosion vs treatment (Top left)
B. Gill colour vs treatment (Top right)
C. Body colour vs treatment (Bottom left)
D. Body consistency vs treatment (Bottom right) 


\section{Morphology vs week}

The number of individuals in the "red mark" categories did not vary according to treatment, however the number varied according to which week of the experiment individuals were sampled in. The number of individuals in the body consistency categories also varied according to the weeks of the experiment that the individuals were sampled in (Table 10).

Table 10. Tuatua traits compared to time of death (TOD). Test statistic is $\mathrm{X}^{2}$. Statistically significant results $\mathrm{p}<0.05$ indicated by*.

\begin{tabular}{|l|l|l|l|}
\hline & $\begin{array}{l}\text { Test } \\
\text { statistic }\end{array}$ & df & p val \\
\hline Gill erosion & 15.48 & 10 & 0.116 \\
\hline Gill colour & 11.4 & 10 & 0.327 \\
\hline Body colour & 12.54 & 10 & 0.251 \\
\hline Body consistency & 27.21 & 10 & $0.0024^{*}$ \\
\hline Red Marks & 18.55 & 10 & $0.0464^{*}$ \\
\hline
\end{tabular}

Individuals in the body consistency trait shifted between categories over weeks $0 \& 1$, and weeks 0 $\& 2$ (Table 11). For the body consistency traits, individuals shifted to a 50/50 split between category 1 and category 3 between weeks 0 and 1 . There was a significant difference between the number of individuals in categories 2 and 3 ( $p=0.0004)$ for the body consistency trait. Week 4 had the most similar composition of individuals in each category to week 0 (Figure 27). 


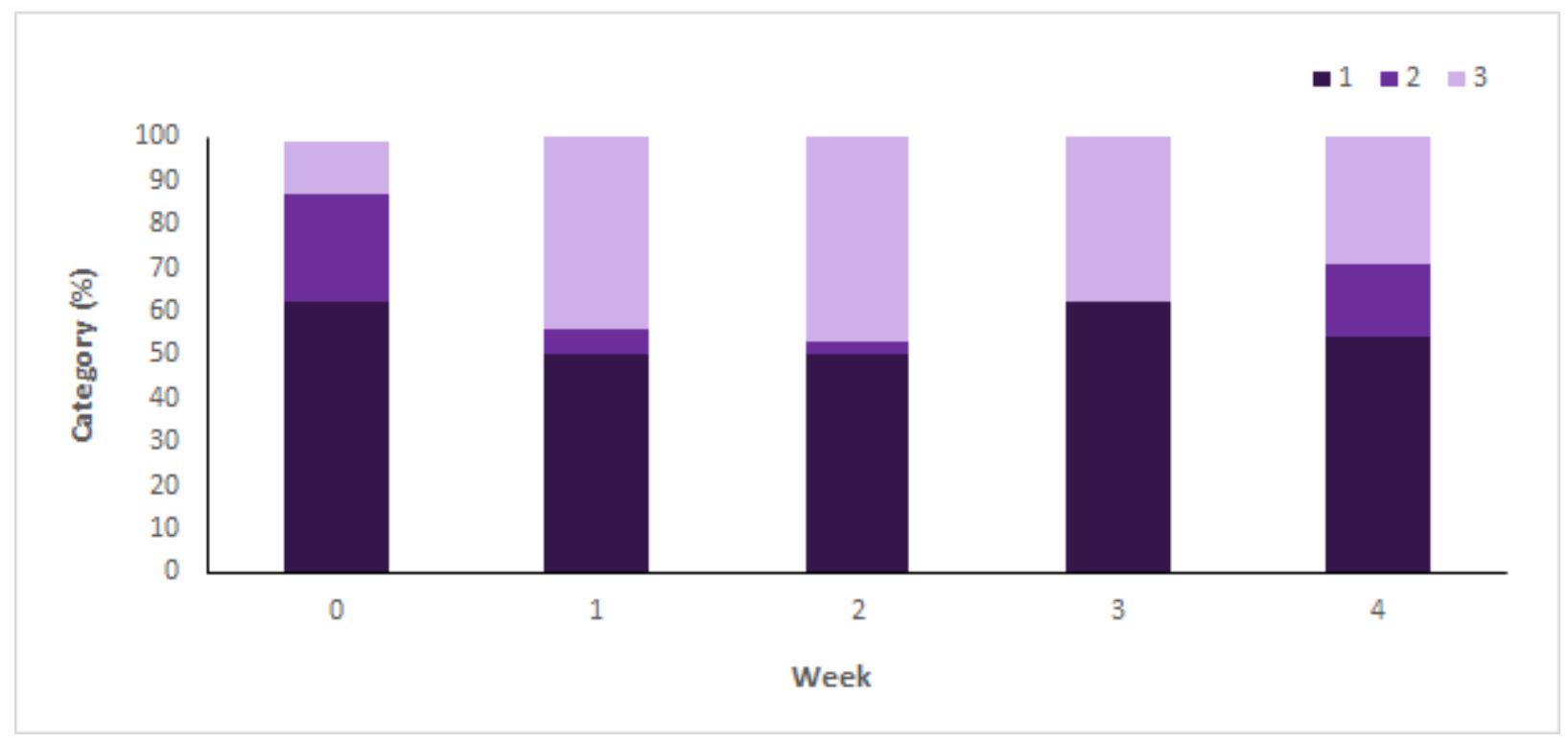

Figure 27. Changes in the percentage of individuals in each body consistency category over time (weeks) exposed to treatments.

The increase in the number of individuals in category 2 for body consistency in week 4 is influenced by increases in category 2 in week 4 in the salinity and sediment treatments (Figure 28S \& 28SE). The heat treatment resulted in a high number of individuals in category 2 for body consistency in week 0 , which steadily decreased over time (Figure $28 \mathrm{H}$ ). The control treatment had almost no individuals in category 2 for body consistency, with only one individual in category 2 at week 4 (Figure 28C). 

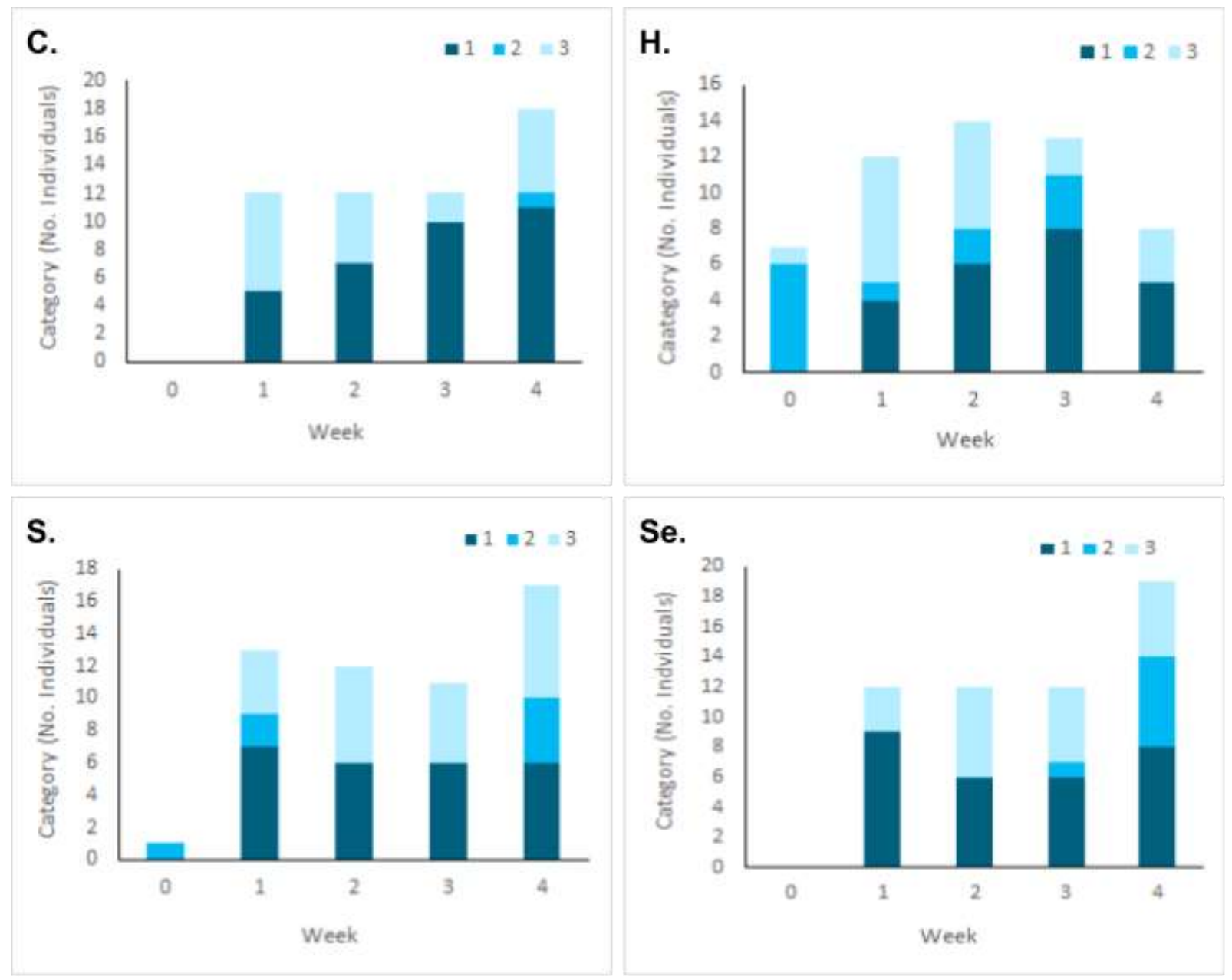

Figure 28. Changes in the number of individuals in each body consistency category over time (weeks) compared by treatment.

$\mathrm{C}=$ Control (Top left)

$\mathrm{H}=$ Heat (Top right)

$\mathrm{S}=$ Salinity (Bottom left)

$\mathrm{Se}=$ Sediment $($ Bottom right $)$ 
Table 11. All significant pairwise comparisons between categories within traits compared to time of death (TOD). $p$ values showing statistical significance indicated by*. Cut offs are variable due to bonferroni correction. Non-significant results for pairwise comparisons can be found in Appendix C, Tables 7 \& 8.

\begin{tabular}{|l|l|l|}
\hline $\begin{array}{l}\text { Morphological } \\
\text { indicator }\end{array}$ & $\begin{array}{l}\text { Weeks of } \\
\text { experiment }\end{array}$ & $\mathbf{p}$ \\
\hline Body consistency & 0,1 & $0.0009^{*}$ \\
\hline Body consistency & 0,2 & $0.0001^{*}$ \\
\hline Red Marks & 0,1 & $0.0026^{*}$ \\
\hline Red Marks & 0,2 & $0.0011^{*}$ \\
\hline Red Marks & 0,4 & $0.0022^{*}$ \\
\hline
\end{tabular}

The number of individuals in the categories for red marks differed significantly depending on which week the individuals were sampled in. In particular, week 0 had no individuals in category 3 for red marks, making it significantly different from weeks 1, 2 and 4 (Table 11). The biggest difference between categories was in category $1 \& 3(\mathrm{p}=0.0104)$, and this change happened after one week in aquaria (Figure 29).

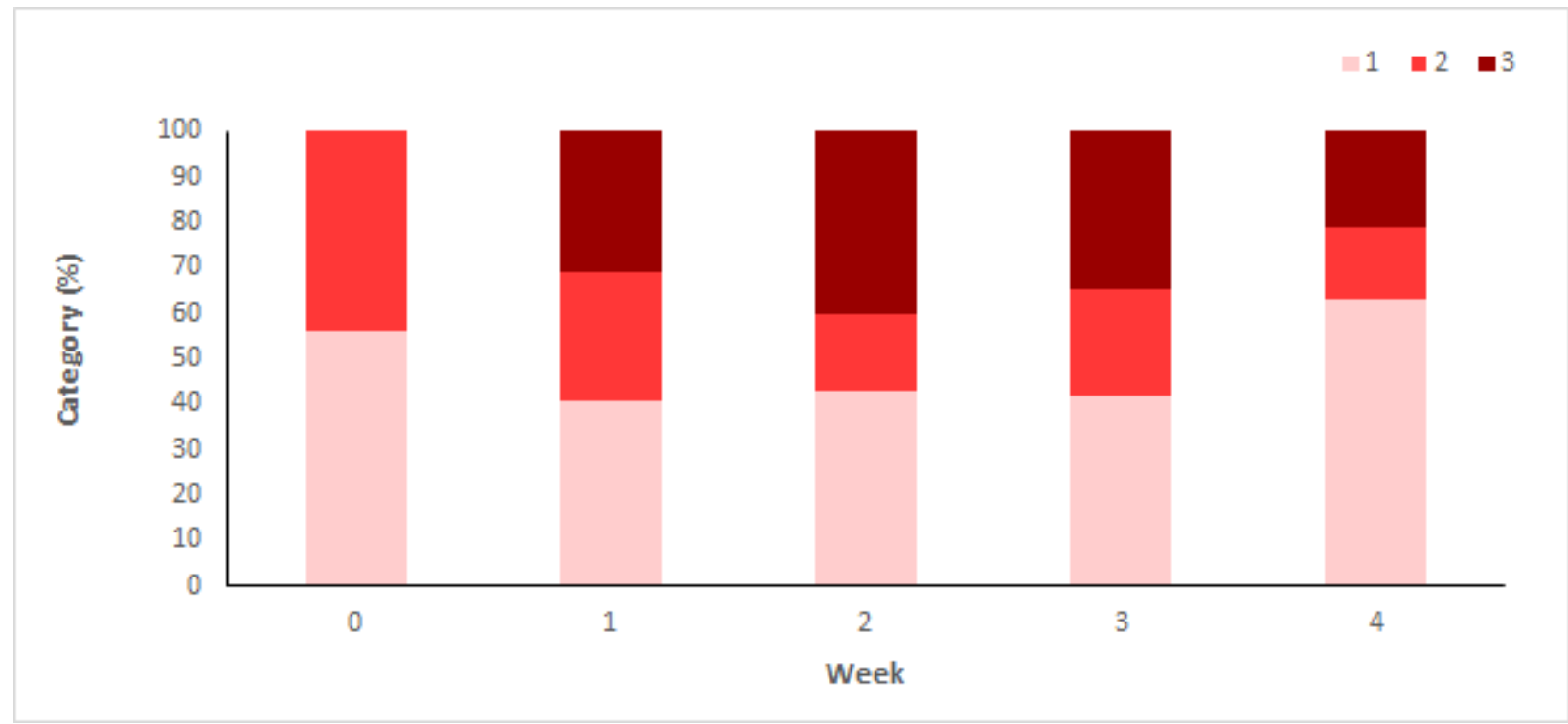

Figure 29. The percentage of individuals in each category for the red mark trait over time (weeks) exposed to treatments. 


\section{Cockles}

\section{Histology}

The number of individuals in histological traits assessed for cockles did not differ in dominant category across treatments: digestive gland $\left(X^{2}=24.24, \mathrm{df}=16, \mathrm{p}=0.084\right)$, gills $\left(\mathrm{X}^{2}=22.44, \mathrm{df}=-16\right.$, $\mathrm{p}=0.13)$, gonads $\left(\mathrm{X}^{2}=2.24, \mathrm{df}=4, \mathrm{p}\right.$-value $\left.=0.692\right)$ and foot edges $\left(\mathrm{X}^{2}=15.62, \mathrm{df}=20, \mathrm{p}=0.74\right)$. When broken down by week and combined across all treatments, digestive glands $\left(X^{2}=14.41, \mathrm{df}=15, \mathrm{p}\right.$ value $=0.495)$, gonads $\left(X^{2}=6.47, d f=5, p\right.$-value $\left.=0.263\right)$, and foot edges $\left(X^{2}=22.64, d f=20, p\right.$ value $=0.307$ ) still had no significant changes in the number of individuals in each category. When broken down by week and combined across all treatments, gill histology was found to have a significant change in dominant categories over time $\left(X^{2}=53.689, \mathrm{df}=20\right.$, $\mathrm{p}$-value $\left.<.0001\right)$.

Gill histology had significant differences between the number of individuals in categories A \& C (p $<.0001)$ and B \& C ( $p=0.0002)$ over time. There was a general decrease in the number of individuals in category $\mathrm{C}$ for gill histology over weeks and an increase in the number of individuals in category A and B for over weeks. The number of individuals in category D for gill histology fluctuated over time across all experiments (Figure. 30). Non-significant results for pairwise comparisons can be found in Appendix D, Table 9.

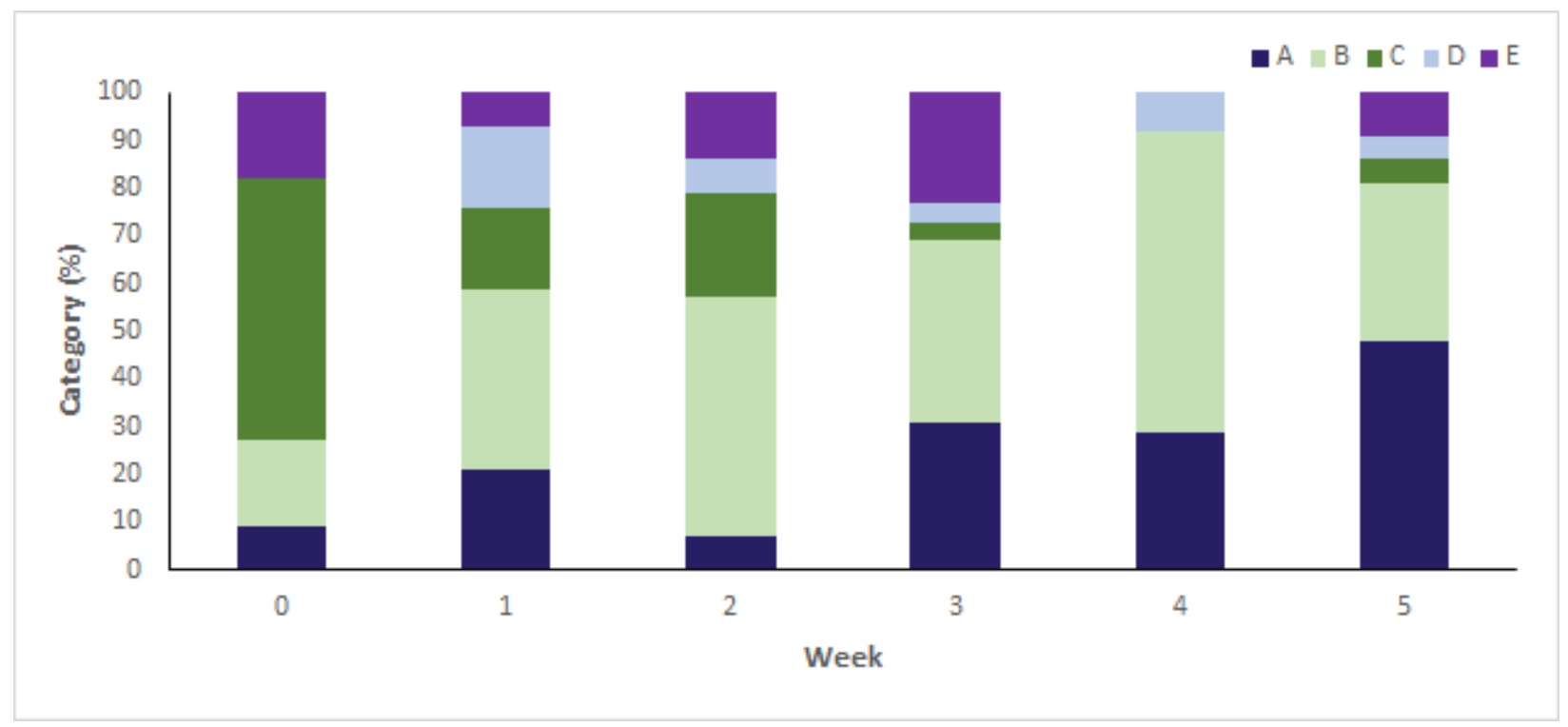

Figure 30. The percentage of cockles in gill histology categories over time (weeks) exposed to treatments. 


\section{Morphology}

The number of individuals in morphological traits assessed for cockle health were not significantly different across treatments: gill erosion $\left(X^{2}=7.25, \mathrm{df}=8, \mathrm{p}=0.51\right)$, gill colour $\left(\mathrm{X}^{2}=3.01, \mathrm{df}=4\right.$, $\mathrm{p}=0.556)$, body colour $\left(\mathrm{X}^{2}=4.26, \mathrm{df}=8, \mathrm{p}=0.833\right)$, and body consistency $\left(\mathrm{X}^{2}=1.23, \mathrm{df}=4, \mathrm{p}=0.873\right)$. However, when combined across treatments and compared over time, all morphological traits bar one were significant; gill erosion $\left(X^{2}=18.29, \mathrm{df}=8, \mathrm{p}\right.$-value $\left.=0.0191\right)$, gill colour $\left(\mathrm{X}^{2}=12.69, \mathrm{df}=4\right.$, $\mathrm{p}$-value $=0.0129)$, and body colour $\left(X^{2}=20.698, \mathrm{df}=8, \mathrm{p}\right.$-value $\left.=0.008\right)$ were significant. The only morphological trait that was not significant was body consistency $\left(X^{2}=2.53, \mathrm{df}=4, \mathrm{p}\right.$-value $\left.=0.639\right)$.

The number of individuals in gill colour categories changed each week. The number of individuals in category 1 increased until week 3, after which the number of individuals in category 1 began to decrease. The number of individuals in category 2 started and ended as the largest group, with the number of individuals in category 1 being the largest group in week 3 (p=0.0121) (Figure 31). The number of individuals in categories 1 and 2 of gill colour were significantly different between weeks $2 \& 4$ ( $\mathrm{p}=0.0008)$. Non-significant results for pairwise comparisons can be found in Appendix D, Table 10.

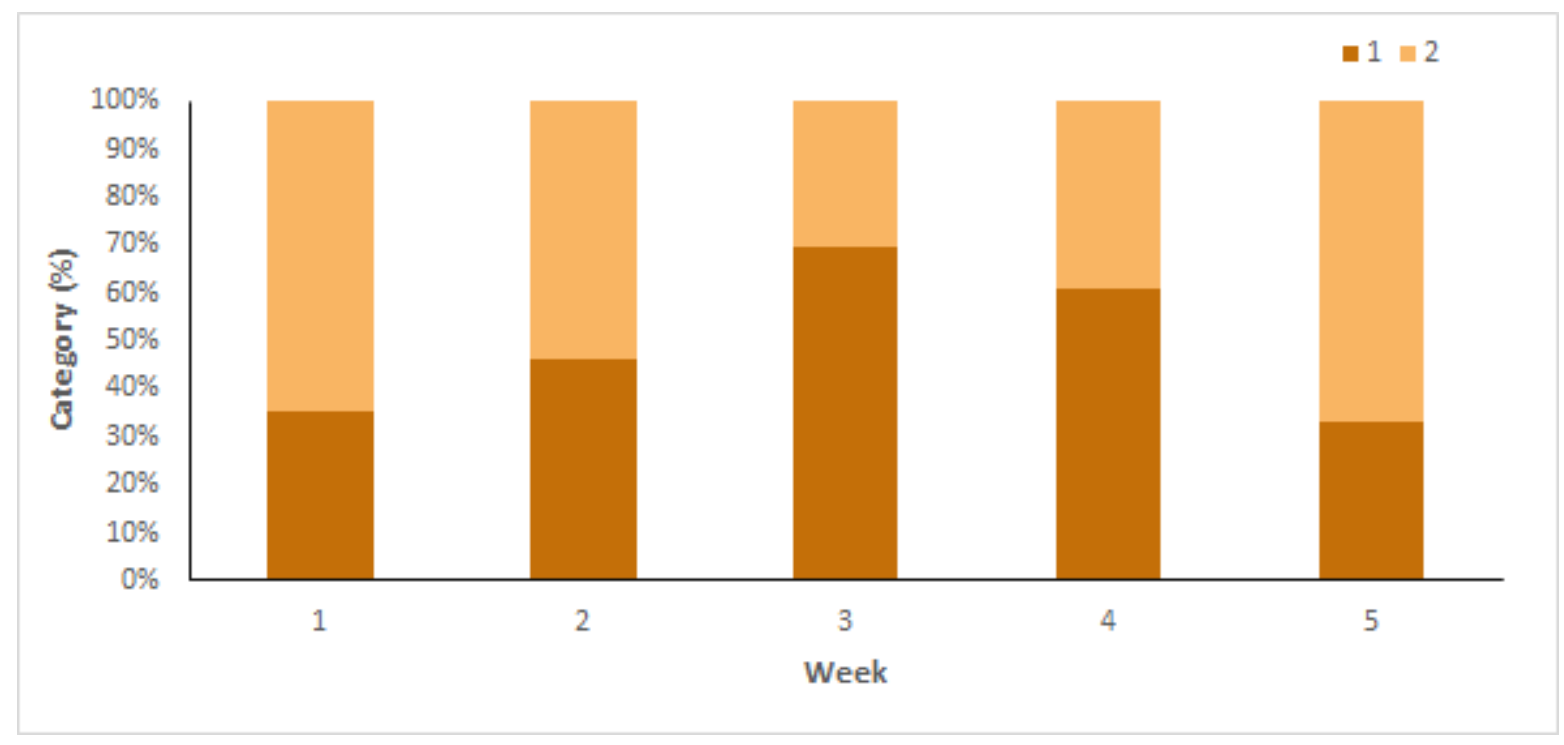

Figure 31. The percentage of cockles in categories for gill colour category over time (weeks) exposed to treatments. 
The number of individuals in categories 1, 2 and 3 for gill erosion was significantly different between weeks $2 \& 3(\mathrm{p}=0.0042), 3 \& 5(\mathrm{p}=0.0076)$ and $4 \& 5(\mathrm{p}=0.0028)$. In week 5 , the number of individuals in category 1 had the biggest increase and a large decrease in the number of individuals in category $2 \& 3$, while in weeks $3 \& 4$ the number of individuals in category 1 was at its lowest (Figure. 31). Non-significant results for pairwise comparisons can be found in Appendix D, Tables 11-12.

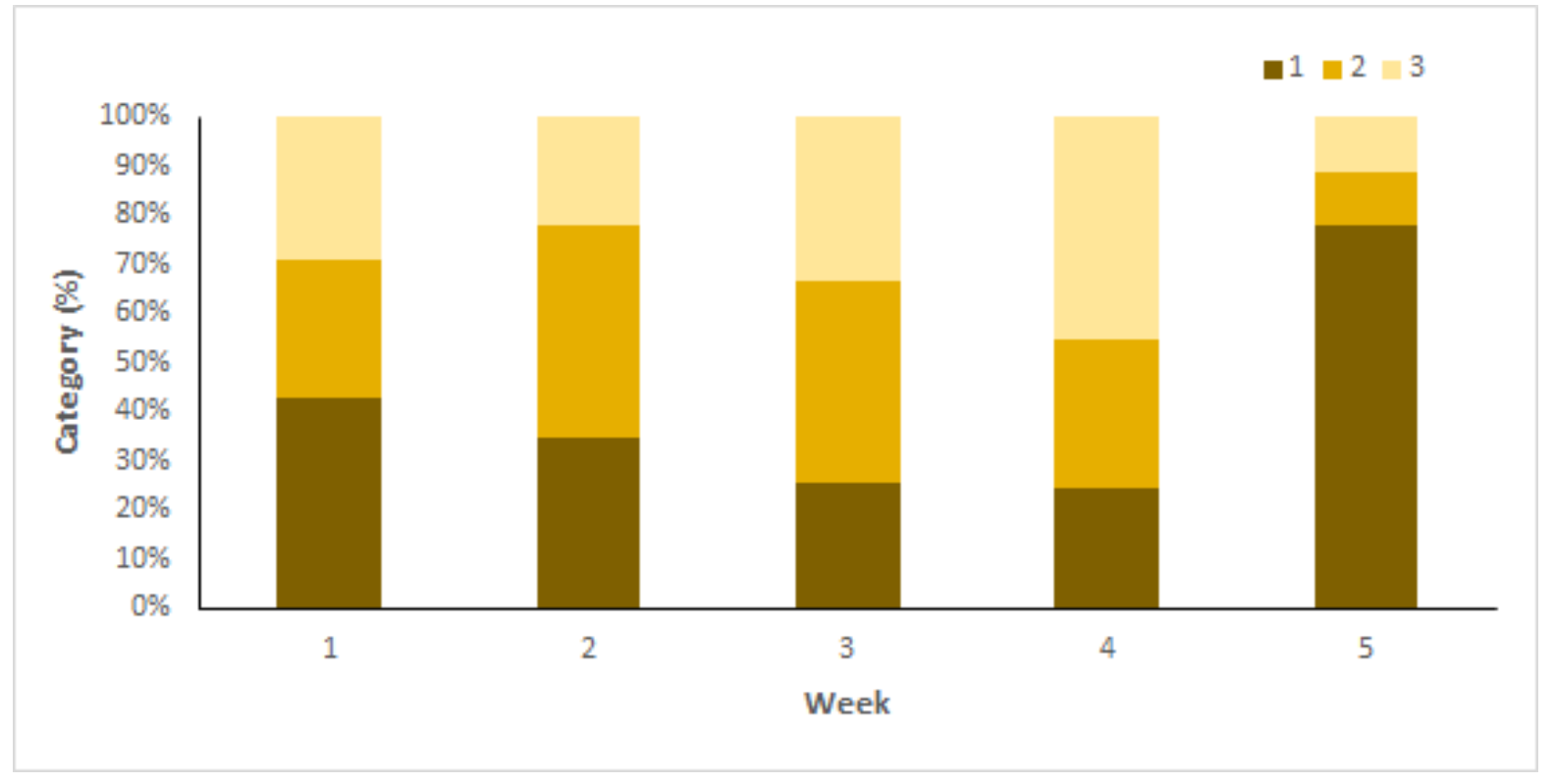

Figure 32. The percentage of cockles in categories for gill erosion over time (weeks) exposed to treatments. 
The number of individuals in the body colour categories 2 and 3 had the biggest variation over time $(p=0.0042)$. The number of individuals in category 2 shifting from the largest to the smallest group over time, and the number of individuals in category 3 shifting from the smallest to the largest group over time (with the exception of week 1). Weeks $2 \& 4$ had the biggest difference in category makeup, where the largest group in week 2 was category 2 and the smallest group was category 3 , and in week 4 the smallest group was category 2 and the largest group was category 3 ( $\mathrm{p}=0.0035$ )

(Figure. 33). Non-significant results for pairwise comparisons can be found in Appendix D, table 13.

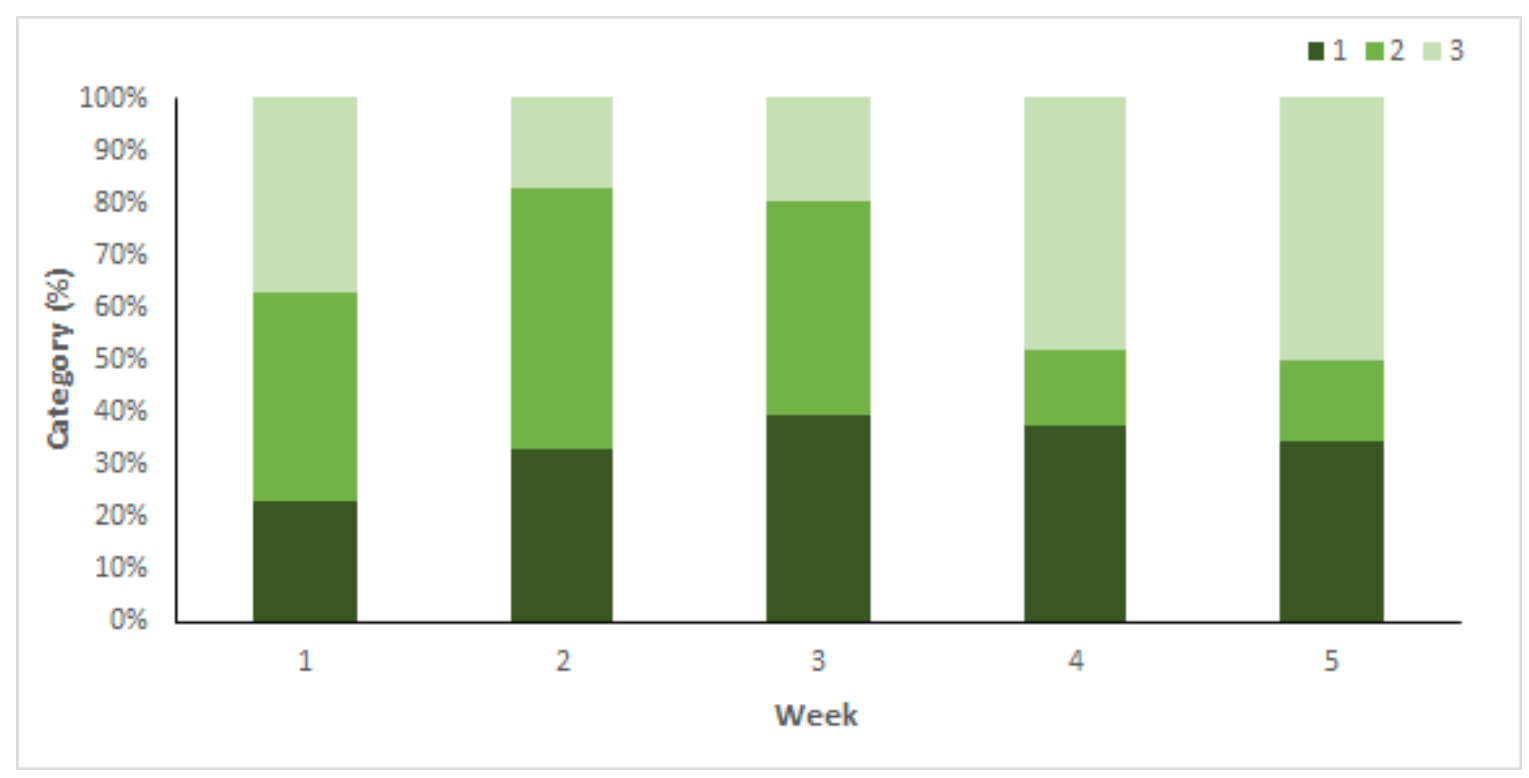

Figure 33. The percentage of cockles in categories for body colour over time (weeks) exposed to treatments. 


\section{Discussion:}

This study provides information on varying stress responses of two species of bivalve and helps to determine the difference between natural individual variation and signs of stress. Additionally, it assesses whether different stressors result in distinct stress responses. This is the first study to my knowledge to look at morphological, histological and behavioural signs of stress simultaneously in New Zealand bivalves, and greatly contributes to our understanding of these species and how they respond to environmental stressors. The environmental factors that caused stress responses for tuatua in this study were increased temperature and decreased salinity. This was expressed through a number of behavioural, morphological and histological stress markers. For cockles time exposed to treatment had the biggest effect on stress expression, while salinity had the biggest effect on mortality. Based on this study, stress expression changed based on stressor in tuatua but not in cockles, and stress markers largely differed between the two species.

\section{Mortality}

Global warming and changing environmental conditions can exceed species tolerances to heat, salinity and acidity, leading to Mass Mortality Events (MMEs) (Arafeh-Dalmau et al. 2019, Langenbuch \& Portner 2004, Ho et al. 2019). P. subtriangulata and A. stutchburyi, like many other infaunal bivalves are not able to leave their immediate environment, thus having robust mechanisms for tolerating stress, particularly thermal stress, is important for bivalves living a sedentary lifestyle to survive (Guerin et al. 2019). Because of this, mortality can be used as a measure of stress in sessile species (Hammond \& Hoffman 2010). For some species like corals, conditions outside their normal range can have near immediate mortality with devastating ecosystem effects (Eakin et al. 2010). Other species use their immune response to counteract the effects of the stressor, however, these responses are often not capable of combating long term stressors and can be detrimental over time (Rollo et al. 2006).

Throughout this research, $8 \%$ of $P$. subtriangulata died, and the highest mortality was consistently in the heat treatment followed by salinity and then sediment treatments. Death in the salinity and sediment treatments only occurred in experiment 4 . The low but consistent mortality rate in the heat treatment shows that temperature was a mild stressor for tuatua. As mortality only occurred in experiment 4 in the other treatments they were likely low stressors that could cause mortality 
when combined with other stress factors. However, the sediment treatment may not have had a stress effect as it had no significant stress makers across either species or experiment. Sequencing of the pacific oyster ( $C$. gigas) genome found that a large proportion of their genes are dedicated to stress response, particularly heat stress (Zhang et al. 2012). Though mobile, Atlantic cod (Gadus morhua) were also found to have a large number of thermal adaptive mechanisms during genome sequencing (Star et al. 2011). When under heat stress, organisms can undergo heat induced apoptosis. This is prevented by the expression of heat shock protein hsp70 and its homologues in cells (Mosser et al. 1997). Expansion of heat shock proteins occurred in the lineages of both the pearl oyster (Pinctada fucata) and the pacific oyster (Takeuchi et al. 2016). Tuatua suffered some mortality within the experiments but overall this is a low percentage of individuals. It is likely that similar to the 2 species of oyster, tuatua have expanded a wide number of genes to deal with different stressors including heat stress, however, heat shock proteins in tuatua may not be as developed as in other species.

The dates of the experiments were spread throughout the year, meaning differences between experiments could possibly be attributed to season. The majority of tuatua individuals died in experiment 4 which ran from mid-October to late November. Experiment 4 encompasses the second of two annual tuatua spawning periods (February to April and September to November) (Grant \& Creese 1995). Spawning can have an effect on the ability of individuals to respond to stress. Bivalves have a lowered metabolic activity, impaired lysosomal membrane stability and lowered immune response post spawning (Li et al. 2009a). This is often the cause of "summer mortality syndrome", a phenomenon that occurs because, during this time individuals have lowered thermal tolerance, and a lowered ability to isolate and clear pathogens (Li et al 2009b, Wendling \& Wegner 2013). Summer mortality syndrome may be applicable to tuatua based on the results of this spawning period, because decreased tolerance to temperature and salinity stress occurred in experiment 4 compared to the other experiments. The histological data supports this and illustrates ripe gonads coinciding with season. The largest number of individuals with ripe gonads occurred in experiment 4 , followed by experiment 3 and experiment 2 . However, there were fewer individuals overall in experiment 2 when compared to experiment 3 and 4 . Because of this, experiment 2 may not be representative of the overall tuatua population at this time and further investigation would be needed to confirm if ripe gonads correlate with season resulting in spawning mortality. 
In some bivalves, the ability to deal with stress post-spawning changes with size, and smaller individuals have quicker recovery periods (Song et al. 2007). However, tolerance to stressors did not change with size for either species during the course of this study. As age increases with size in both tuatua and cockles, stress tolerance is unlikely to be age related (Allam \& Espinosa 2016). Immunity against stressors may rely more on the evolution and expansion of the innate immune system, as is the case in Mediterranean mussels (Mytilus galloprovincialis) (Gerdol et al. 2011). However, it is also possible that the tuatua collected for this experiment did not represent the smaller size classes sufficiently enough to detect a size effect.

In contrast to tuatua, cockles had the highest mortality in the salinity treatments and in all treatments in experiment 1 . This included deaths of individuals from the control treatment. There was also high mortality in the pilot experiment that occurred immediately prior to experiment 1 (Appendix E, table 14). Cockles spawn from October to December and cockle mortality in this experiment is unrelated to spawning (Booth 1983). Experiment 4 ran through spawning season for cockles and there was no significant death from this experiment. Perrigault et al. (2012) found that immunity in the clam Mercenaria mercenaria was lowered by increases in salinity that made individuals more susceptible to parasite infections. If individuals in the pilot experiment and experiment 1 were already experiencing external stress, lowering salinity could have weakened cockle immunity. Increased stressors in the field may have been occurring during March to late May. The Pauatahanui inlet has high heavy metal concentration and variable environmental conditions (Blaschke et al. 2010). Increased stress in this environment could be due to higher than average heavy metal loads, or sudden temperature changes (Ford \& Chintala 2006).

For both species, initial exposure to stress appeared to cause a sharp decline in numbers, which then slowed. In tuatua, the majority of individuals died before the end of the second week, after which time mortality rates decreased. Cockles had the highest mortality rate at the end of week 1 , after which time the mortality rate steadily declined until the end of the experiment. The sudden addition of a stressor into the aquaria likely contributed to the mortality. For example, in the Japanese mud snail (Batillaria attramentaria) sudden drops in salinity caused mortality within the first 16 days, while long-term reductions in salinity did not cause mortality (Ho et al. 2019). In the common fruit fly (Drosophila melanogaster), early exposure to desiccating airflow caused an increase in mortality rate followed by a steady decline (Aziz et al. 1995). Different methods of tissue preservation can change mortality rate. In the Mediterranean fruit fly (Ceratitis capitata) higher 
lipids concentrations positively influenced tissue preservation after cold exposure and increased recovery (Pujol-Lereis et al. 2016). In the case of marine bivalves digestive gland lysosomes serve a similar purpose to lipids in Diptera and lysosome concentration may influence stress tolerance and mortality onset (Hole et al. 1992). Different levels of stressors can also change the onset of initial mortality. Exposure in the burrowing marine worm (Sipunculus nudus) to $3 \% \mathrm{CO}_{2}$ showed a rise in mortality after 35 days before decline in the mortality rate (Langenbuch \& Portner 2004). In tuatua and cockles, tissue reaction and intensity of stressors may predict the onset of an initial mortality rise and its severity. The initial high death rate seen in this experiment imitates the immune response in the bivalves Crassostrea virginica and Ruditapes philippinarum. Research has shown that after introduction of bacteria, it can take up to 14 days to clear the bacteria from the organism (Froelich \& Oliver 2013). The intensity level of stressors used in these experiments likely exceeds the threshold for mortality in tuatua and cockles at 2 weeks. Shock of the rapid change in environmental conditions likely contributed to mortality in the current experiments, and could be contributing to MMEs in the environment (Garrabou et al. 2009). Mortality caused by stressors is also influenced by a number of other factors such as food availability, parasites and pollutants (Khan et al. 2018, Zwen et al. 2011). In the present study, bivalves were deprived of fresh seawater for approximately 18 hours overnight as treatments ran. We do not know food availability in the raw water supply and it is possible food supply varied seasonally and may contribute to some of the mortality seen throughout experiments.

\section{Behavioural responses}

Across a number of different species when individuals are under stress there is a reduction in reaction time to stimuli, this is often due to impaired functioning (Montory et al. 2015, Haaker et al. 1992, Edelaar et al. 2003). For example, the fry of Skiffia multipunctata show reflex impairments including lethargy and gasping in response to sub-lethal concentrations of phosphate (Aneli et al. 2014). Davis et al. (2010) found fish response to stress could also include spontaneous activity, gag response and operculum closure when individuals are stressed with restraints, increased temperature or hypoxia. In abalone (Haliotis sp.), withering syndrome disrupts bodily processes causing a reduction in reaction time and mantle retraction (Haaker et al. 1992). 
Tuatua sit anchored in the sand with their foot extended (Morton \& Miller 1968). In this experiment, time taken to retract the foot back into the shell when removed from the water was measured to see if this was affected by stress, as it may be an easy indicator for assessing field populations suspected to be under environmental strain. No difference was found in retraction time between the control and sediment treatments, but individuals in the salinity treatment reacted far slower when removed from the sediment. Reduction of salinity can cause decreased movement in a number of marine species. In the gastropod (Crepipatella peruviana) salinities below 24ppt caused isolation of brooding chambers and caused adults to clamp to substrate and cease movement (Montory et al. 2015). As behavioural reaction is an immediate response, it is likely that the slower reaction observed in tuatua in the salinity treatment is indicative of lowered salinity causing a mild stress reaction. Mortality is a cumulative effect of body processes being overwhelmed by stress and causing mortality. In tuatua mortality only occurred in the salinity treatment in experiment 4 , it is possible that the salinity stress was having a low stress effect that was not lethal unless combined with other stressors. Ho et al. (2019) found that when suddenly introduced to lowered salinity of 3ppt, the Japanese mud snail (B. attramentaria) hermatised immediately and did not move, produce stool or react to being touched with a stimulus, before dying. As salinity was increased above 16ppt, individuals had higher movement and activity. In the common starfish (Asterias rubens) lowered salinity led to a reduction in feeding and the size of prey selected. However, A. rubens then began to acclimatize to the lowered salinity and feeding increased back to its original rate over time (Aguera 2015). Lowered salinities may not be lethal for bivalves if they are able to acclimatize, however, this ability will change between species and depending on the severity of the stressor. In the current experiments cockle and tuatua mortality decreased over time, and it is possible that individuals surviving in salinity treatments began to acclimatize despite constant stress treatment.

Temperature stress had an effect on tuatua mortality across all experiments and a small effect on behaviour. Infaunal species are highly affected by temperature changes. A study looking at heat wave effects on an ecosystem found that $86 \%$ of sessile species responded to the temperature change in some way while only $14 \%$ of free living species did. The authors found, abundances of the blue mussel (M. edulis) were reduced by almost half and abundances of the Baltic clam (Limecola balthica) were reduced by 35\%. However, some invertebrates were able to behaviourally thermoregulate and maintain stable population numbers or increase abundance (Pansch et el. 2018). A similar phenomena is observed in the mangrove snail (Littoraria scabra). In this gastropod, there is a relationship between body temperature and substrate. Individuals behaviourally thermoregulate through selection of areas with favourable substrate temperatures 
(Chapperon \& Seuront 2011). In invertebrates if behavioural thermoregulation is not possible, physiological processes work to accommodate environmental change. For example, an increase in ambient temperature also increased the respiration rate in the sea hare (Phyllaplysia taylori). The severity of the temperature variation $P$. taylori was exposed to dictated the rate of mortality (Tanner et al. 2019). The observations in this experiment are supported by the findings of previous studies that some intertidal species have the ability to behaviourally respond to temperature variations, while others must respond physiologically. In tuatua a clear behavioural link could not be observed between temperature and reaction time. It was also found that temperature stress could result in mortality for tuatua. This suggests the main mechanism for dealing with temperature stress in tuatua is physiological, or aquaria treatments were not suitable for behavioural responses in tuatua to occur.

In experiments 1 and 3 (autumn and early spring) reaction time was relatively uniform across all treatments, while in experiments 2 and 4 (winter and late spring) reaction time was much slower in individuals exposed to the salinity treatment and to a lesser extent in individuals exposed to the temperature treatment. The clear distinction in reaction times observed between experiments suggests that other factors may have affected the changes in reaction times. Changes in reaction times could be based on seasonal fluctuations. For example, some birds have seasonal response changes to environmental stress, including nest abandonment and aggressiveness (Wingfield \& Kitaysky 2002). In the present research, as raw seawater was used to supply the aquaria, the influx of food may have changed seasonally. The omnivorous zooplankton (Ochromonas $s p$ ), increases feeding seasonally with changing temperatures (Wilken et al. 2013). Another possibility is, feeding behaviour in tuatua and cockles could have alternated seasonally. Sgro et al. (2005) found feeding in two species of marine bivalve was affected negatively in some seasons when there were; low abundances of food in the water column, low qualities of food or high turbidity. Fluctuations seen in reaction time over seasons in the current study could be related to food availability and feeding behaviour or a combination of these factors. Other variables that could influence increased seasonal stress include changes in burial depth. The clam Macoma balthica changes burial depth seasonally, burying deeper in the winter to protect from storms and parasitism (Edelaar et al. 2003). A similar change in burial depth may occur in tuatua, noting that the sediment depth remained the same throughout all experiments. The inability to move vertically through the sediment column, coupled with the experimental treatment, may have caused the stress experienced by tuatua to change seasonally, which was observed through the changes in behavioural reactions. 
Reduction of foot retraction likely has negative effects on life processes of bivalves. For example it could reduce effectiveness of burrowing, as the foot is the main tool for movement. In the bivalve (Indoaustriella lamprelli) burrowing behaviour was inhibited when individuals were stressed with copper enrichment. Burrowing behaviour was reduced to complete inactivity and inhibited the individuals' ability for reburial depending on copper concentrations (Hutchins et al. 2009). In the freshwater clam Anodontites trapesialis, after exposure to cigarette butt leachates, burrowing was also significantly reduced (Montalvao et al. 2019). Research into how burial behaviour correlates with foot retraction would be an important next step in understanding the full extent of this behavioural stress response and how it negatively affects life processes of burrowing bivalves.

\section{Histological categories}

Histopathology in bivalves has been used in the past to find if there are cellular level changes in individuals that have been treated with chemicals, pesticides and pharmaceuticals (Pinto et al. 2019, Wu et al. 2019, Kadam et al. 2018). For example, histopathology has been used to assess and determine what healthy and unhealthy digestive glands in the Asian clam (Corbicula fluminea) look like when treated with Aluminum. Healthy glands are described as having a single layer of cells enclosing the digestive tubules and a ' $\mathrm{Y}$ ' shaped lumen, whereas unhealthy glands have a wide lumen and a thinner epithelial thickness as an inflammatory response (Wu et al. 2019). Mediterranean mussels (Mytilus galloprovincialis) contaminated with lanthanum showed infiltration of haemocytes into gills, loss of gill cilia, digestive gland atrophy and necrosis (Pinto et al. 2019). Another way histological damage can be expressed is through gonad alternation. In the sand clams (Gomphina veneriformis) the introduction of the pesticide Tributyltin (TBT) resulted in an increase in intersex gonads in both males and females (Park et al. 2012). Finally, gills can often show negative impacts of chemical pollution. The textile effluent methyl orange has been observed to infiltrate the gill structure and cause swelling and distortion through the gill lamellae in Lamellidens marginalis (Kadam et al. 2018). Similarly, a study found the introduction of imidacloprid caused swelling of gill epithelium, degeneration of digestive tubules and cell necrosis in Asian freshwater clams (Shan et al. 2020). As these examples illustrate, damage to different body structures by chemicals is well documented in histology. However, few studies have examined if and how these same patterns are expressed under different levels of environmental stress.

In this study, for tuatua, there appeared to be changes in the digestive gland associated with increasing time exposed to treatments, when combined over all experiments. Glycogen and lipid storage occur in digestive glands, thus fullness of tissue and size of lumen space can signal stress, 
especially in relation to food deprivation (Berthelin et al. 2000). The changes in digestive cells seen in tuatua may be due to a behavioral change in feeding patterns as individuals get stressed. This relationship has been observed for eastern oysters (Crassostrea virginica) and hard clams (Mercenaria mercenaria) when exposed to heat stress and increased carbon dioxide. Under these stressors feeding was lessened leading to decreases in tissue energy reserves and eventual mortality (Ivanina et al. 2013). In the current experiment, digestive cell categories in tuatua shifted from the majority of individuals occurring in the full gland and sparse gland categories (A \& D respectively) in week 0 , to majority of individuals occurring in the medium-full glands with high cellular infiltration category (C) in week 4. It is unexpected that Category D would be dominant early on as it was characterized by the biggest lumen space with high interstitial infiltration. These individuals might be easily or already stressed and die off before week 1 explaining the reduction of category D observed by week 2 . The other dominant category in week 1 , had the fullest digestive gland (category A). This category (A) steadily decreases in frequency as exposure to stressors continue and energy reserves are depleted. Category $\mathrm{C}$ and $\mathrm{E}$ grow in number over time and these categories are both characterised by wider lumen spaces and less full glands. This suggests tissue condition is worsening over time. Interestingly, category B remained stable throughout the experiments. Category B had full glands with infiltration of body tissue (likely haemocytes) into the digestive glands. The stability of this category could indicate category B is a transitory stage where the immune response is beginning to be expressed (Canes \& Pruzzo 2016).

In contrast to digestive glands there was no change in gill histology over exposure time in tuatua. This may be similar to histological stress expressions in the grooved carpet shell (Ruditapes decussatus). Costa et al. (2013) found 30 histological lesions were defined in gills and digestive glands showing inflammation, necrosis, and neoplastic diseases in response to environmental stressors. The digestive glands were significantly more damaged than the gills in the majority of individuals (Costa et al. 2013). Tuatua likely follow a similar response pattern where digestive glands show stress more intensely than gills.

Histologically, there was no change in cockle tissues in response to stress treatments or over exposure time, with the exception of changes to gills. This pattern in cockles mimics stress expression observed in the freshwater bivalve Unio tumidus. When under copper stress, U. tumidus increased antioxidant response in gills but did not significantly change morphology in digestive glands (Doytte et al. 1997). In the present study, gill histology in cockles initially had the most 
individuals in category $\mathrm{C}$, in week 0 . Category $\mathrm{C}$ was characterized by non-uniform gills with space between filaments, and cellular debris present in water tubules. This shifted over time to have the most individuals in category $A$ and $B$ in week 5 . These categories (A and B) were characterised by uniform well-articulated plicae, with compacted filaments. The pattern observed in gill change is the inverse of the expected order based on gill histology in stressed and unstressed sand clams (Gomphina veneriformis). In sand clams, the control individuals had uniform plicae and filaments with clear structure, and chemically treated individuals had broken filaments, cellular debris and gaps in plicae. Damage to gills in sand clams caused reduction in feeding and filtration rate (Park et al. 2012). This suggests that in my experiments, individuals may have started with gill damage, perhaps due to environmental stressors. Movement to aquaria could have removed cockles from external stressors in their ecosystem and allowed recovery.

Another tissue response explored in this study as a stress marker in bivalves was changes in the concentration of foot cells. The tissue at the foot edge of cockles, contains mucus cells (nuclei stained purple) within the foot muscle. No obvious concentration changes were observed in the mucus cells when exposed to stressors at these intensities, despite these cells having been hypothesized as a first level of defense in bivalve immunity (Ellis et al. 2011). While there was variation among individuals in concentration of mucus cells, this could not be concluded as an immune response and is more likely indicative of natural variation in the cockle population. Preliminary results from this experiment may indicate mucus cells do not have a role in immune response in cockles.

A possible external stressor that affects cockles are rickettsia like organisms (RLOs). In New Zealand RLOs have been associated with at least 6 shellfish mortality events. In Paphies ventricosa RLOs can give rise to gas bubble disease which causes bubbles to form on the gill filaments, and blisters to form on the outer valve surfaces of the organism (Ross et al. 2017). RLOs were present in both species of shellfish in this experiment. Presence of RLOs could be due to lowered immunity in stress treatments allowing opportunity for increased infection, individuals of the same species being kept in confined space allowing easy transfer of parasites, or random distribution of RLOs from the environment (Zwen et al. 2011). In this study issues in distinguishing RLOs from haemocytes in the slides hindered interpretation. Under expert examination, using the slides created in this study, investigating patterns of RLOs in different stress treatments could be an extremely valuable next step in beginning to understand MMEs associated with RLOs. 
There was no significant change in the gonad development in cockles or tuatua under environmental stress. Differences in the gonad tissue likely represented natural variation in gonad development due to normal reproductive cycles. In some bivalves, energy from food is prioritized for reproductive success, especially in times of food deprivation. Energy allocation can be at the cost of loss of body mass and impaired gonad recovery post spawning (Delgado \& Camacho 2005). However, in other bivalves, gonad reabsorption can be induced under environmental stress (Camacho-Mondragon et al. 2012). Li et al. (2009) used gonad reabsorption in oysters (Crassostrea gigas) as a measure of food deprivation stress. However, no notable change in gonads was found in this study.

It is important to note cockles may not have been under stress during the majority of these experiments. Overall, there was low cockle death and little changes in histological morphology. It is possible that cockles are highly resistant to mild environmental variation (Marsden 2004). If so, MMEs in cockles will only occur under combinations of stressors (e.g. disease, food limitation, and pollution), or under high intensity individual stressors. This knowledge lends to our understanding of predicting when and why cockle MMEs will occur. Further investigation should look into testing the tolerance of cockles under high intensity individual stressors and multiple stressors.

\section{Morphological categories}

In order to ensure survival in an ecosystem, some morphological characteristics change in response to environmental stressors. Change can either help the organism to acclimatize in response to a stressor or cause negative effects due to damage (Littler 1980, Dubilier 1995, Diner et al. 2015). Identifying and assessing damage due to stressors helps us understand the health of the species in the environment. For example, in the mummichog fish (Fundulus heteroclitus) individuals had fewer vertebrate and higher instances of vertebrae abnormalities when developed in higher temperatures, making them more vulnerable to predation (Mitten \& Koehn 1976). In response to elevated $\mathrm{CO}_{2}$ levels, larval sand dollars developed a narrow body shape and smaller stomachs impairing feeding ability (Chan et al. 2011). Additionally, cadmium exposure on brittle stars impacted their ability to recover from an injury by causing newly regenerated arms to be smaller, and contain more developing ossicles (Andrea et al. 1996). Negative effects of stress can also be internal, for example, M. galloprovincialis reduces the volume of muscle fibers after an introduction of bacteria negatively impacting a number of life functions within the individual (Parsi et al. 2009). In the literature, descriptions of unhealthy and healthy tissue are largely focused on cell level 
changes, however, this neglects tissue morphology changes visible to the naked eye (Shan et al. 2020). This study starts to help fill this gap by identifying variation in morphological tissue due to environmental stress treatments and distinguishing this from natural variation.

For tuatua, traits that showed significant change over time in assigned visual categories were body consistency and red marks. No individuals had red marks at the darkest level (Category 3) until after week 0 . Categorical make up of each week remained largely the same after week 0 over all experiments. Red marks in dissected tuatua appeared near digestive glands and stomach and likely represent part of the stomach (Personal obs). Under oxidative stress, multiple bivalves were found to experience increases in antioxidant enzymes, and high concentrations of these enzymes could be detected at the cellular level with cytoplasmic staining (Orbea et al. 2000). It is possible that the expression of antioxidant stress enzymes, or a mechanism similar to this, could be the cause of the "red marks" I observed. However, further investigation should be considered to determine the definitive cause of these marks in bivalves. Increase in intensity of red marks after starting the experiment could be a sign of stress in individuals or could be a signal of another environmental change.

Of all treatments, increased temperature had the biggest effect on morphology change of tuatua and had a significant effect on all categories (with the exception of red marks). In gill erosion, body colour and body consistency this effect of the heat treatment was shown through a reduction in the prevalence of clearly visible gills, pink body colour, and a somewhat watery body consistency (category 1) respectively; and an increase in gills that were barely visible, white or yellow body colour and body consistencies that were either extremely watery or dehydrated (categories 2 and 3) respectively. Additionally, the salinity treatment had fewer individuals with pink body colour and somewhat watery consistency (category 1) than in the baseline and control treatments. For gill erosion, body colour and body consistency the categories I defined could have some basis for defining healthy (1) from stressed (2 or 3) tuatua under heat and salinity stress. Although there were significant changes in gill colour in the scope of this study, it is unlikely to be a useful measure of stress as the composition was the same across all treatments and control (with the exception of the baseline). The lack of category variation in baseline tuatua could be explained by the lower number of tuatua sampled from the ocean (5 per experiment) not encompassing the full scope of normal morphological variation.

Body consistency had the biggest change from week 0 to 1 in tuatua where there was a drop in the number of individuals with watery body consistency (category 2) and an increase in the number of 
individuals with dehydrated body consistency (category 3) which continued until week 4 . Week 4 had an increase in the number of individuals with watery body consistency (category 2) in comparison to weeks 1-3. Body consistency was the only category that had significant change correlated to both treatment and exposure time. When separated by treatment, the large rise in individuals with watery body consistency (category 2) observed in week 4 occurred mainly in the salinity and sediment treatments. Few individuals in this category (2) were seen in the control treatment and a high number of individuals in the watery body category (2) occurred in week 0 of the heat treatment before slowly tapering off. Individuals in week 0 of the heat treatment died before dissection and were presumably stressed. As this is a high-stress treatment, a watery body consistency (category 2) dominates early on. With the lower stressors the watery body consistency was not observed until later in the experiment. Watery body consistency may be a sign of intense or cumulative stress. This also explains why this category (2) does not appear much in the control treatment. It is hard to attribute change in body consistency to a single stress cause, but this could be due to a change in water content, organs leaking fluid, or issues with osmotic balance (Lange 1970, Pierce \& Greenberg 1972, Eggermont et al. 2020).

Treatment did not have any effect on the number of individuals in different morphological levels in the cockles' categories. While there were differences in category make up this should be attributed to natural variation and not treatment. This is perhaps because cockles live in the estuarine environment and likely have higher tolerance to the environmental fluctuations than tuatua that live in the open coast (Marsden 2004). Variations of estuarine temperatures can be upward of $20^{\circ} \mathrm{C}$ while open coasts rarely vary more than $5^{\circ} \mathrm{C}$. When compared to similar coastal species, estuarine intertidal species consistently have higher tolerance to fluctuations in salinity, temperature and dissolved oxygen. This pattern is similar across taxa and climates (Madeira et al. 2012). Living in estuaries can be beneficial, for example, juvenile phases of European bass (Dicentrarchus labrax) have higher growth in estuaries than the open coast, with the exception of when there are heat waves (Vinagre et al. 2012). Additionally, estuarine species of phytoplankton tolerate lower salinities better than coastal species, though both have better tolerance than oceanic species (Brand 1984). However, as estuaries are more variable in abiotic features, they are expected to be highly affected by climatic change (Wetz \& Yoskowitz 2013). Because of this, it is reasonable to expect to see continually increasing cockle mortality events as environmental conditions change despite cockles having relatively high environmental tolerances. 
When broken down by week, all cockle morphological categories had time-related changes in the number of individuals in each level, with the exception of body consistency. In contrast to tuatua, body consistency was not significant as a stress measure for cockles. However, both body colour and gill colour could be useful stress markers for cockles. Colour change in different species can occur due to hormonal or $\mathrm{pH}$ change in response to stress, and therefore can be used as a stress marker. In Atlantic cod (Gadus morhua), pre-mortality stress is shown through fillet colour change and lowered muscle pH (Stein et al. 2005). In birds, melanisation colouration in feral pigeons (Columba livia domestica) changes as a response mechanism to increasing environmental stress through variation in hormone levels (Corbel et al. 2016). Additionally, the stony creek frog (Litoria wilcoxii) experiences a similar skin colour change in response to mild stress, also altering hormone levels (Kindermann et al. 2013). The principal behind this change can similarly be applicable for invertebrates. Body colour categories showed an increase in the number of individuals with pink bodies and yellow margins (category 2), which continued to increase until week 3 , after which there was a sharp decline in the number of individuals in category 2 . The translucent morphology (category 3) followed the opposite pattern to category 2. The number of individuals in the mild pink body category (1) remained relatively stable throughout the experiments.

Gill colour followed a similar pattern to body colour, with an increase in the number of individuals with pink gills until week 3 , and then a gradual decrease. Blue gills showed the inverse pattern. Under the experimental treatments, after 3 weeks the highest proportion of individuals with pink gills were observed. The pattern of increase until week 3, followed by a decrease is only observed in low numbered categories ( 1 or 2 ) of body and gill colour. It is possible that colour alteration in cockles is an overall body shift happening due to changing hormone levels in response to stress. Another possibility is that the increase and then decrease of individuals in different categories within traits could be a sign of attempted recovery in cockles, before eventual decline due to the persistence of stressors. Colour change categories in cockles followed the standard recovery pattern of decreasing and then increasing stress response. For example, when exposed to increased salinity, the copepod Tigriopus californicus first showed a decline in fitness before reaching a stable recovery despite the stressor remaining constant. When exposed to increased temperature, a similar fitness pattern occurred, however, after recovery decline could begin again in the temperature treatments (Hwang et al. 2016). The black sea cucumber (Holothuria forskali) follows a similar pattern of increasing antioxidant enzymes in response to oxidative stress before gradual recovery (Tonn et al. 2016). To fully understand the mechanism behind colour changes, research into antioxidant enzyme change and hormone change in relation to colour variation would be 
required. Despite our lack of understanding around the mechanism causing colour change, gill and body colour change in cockles are promising preliminary stress markers.

Over time, gill erosion followed a trend of the number of individuals with 'clearly defined gill margins' (category 1) steadily decreasing, the number of individuals with 'obscured margins' (category 2) staying stable and the number of individuals with 'barely visible' gills (category 3 ) increasing for the first 4 weeks. This is consistent with what could be expected from healthy tissue degrading with stress exposure, however, in week 5 there was a shift and 'clearly defined gill margins' (category 1) became the most dominant category of the whole experiment. Only experiment 2 and 3 ran to week 5 and both placed the overwhelming majority of individuals in category 1 . There is no clear explanation for this because there was no significant death in either of these experiments, and cockles were chosen randomly for dissection. It is possible the increase of individuals in category 1 was a random occurrence due to the sample size in week 5 being lower overall than previous weeks.

In cockles, the number of individuals in each gill category changed in relation to stress exposure, and gill damage could be a good indicator of stress under low levels of environmental change. Gill structure and function is important for food uptake and selection in filter feeders and variation in gill and palp morphology can be great between and within bivalve species (Medler \& Silverman 2001). Additionally, gill morphology can change depending on food availability and juvenile growth environment (Compton et al. 2008, Drent et al. 2004). Alterations of gills can impair life processes of organisms and alter feeding functionality (Beniger et al. 1992). Tissues within gills are also important in osmoregulation and are the site of oxidative stress in bivalves (Haque et al. 2019). Gill damage caused by stress has the potential to impede several key life processes in bivalves. Narrowing down the cause of different types of gill damage and how morphology is altered in response to stress would aid in understanding of how functionality is impeded by changes in gill morphology. 


\section{Implications and further research}

This is the first research of its kind among these two bivalves. While it may not be easily generalizable due to its limitations, it does provide robust pilot data for further work in this area. For example future investigations could look at interactions between stressors, or stress markers of one extreme stressor. This work highlights the differences in stress responses between species and illustrates the need for more research.

Tuatua and cockles appear to be relatively robust in response to long term exposure to individual stressors based on the results of this study. The treatments in this experiment were applied on average for 18 hours, 5 nights a week for 4 weeks. The frequency of stressor application is standard compared to other long-term studies looking at environmental stress. Short term studies tended to run for 4-48 hours, while long-term experiments could run from 5 days to 3 months and the acclimation period for these studies could be up to 3 weeks (Ellis et al. 2002, Wendling \& Wegner 2013, Chapparo et al. 2009, Lockwood \& Somero 2011). The intensity of stressors in previous studies could also be variable. Salinity stress treatments ranged from 10-24ppt, sediment stress treatments used concentrations from $100 \mathrm{mg} / \mathrm{L}$ and sublethal temperature treatments ranged from 32-37 ${ }^{\circ} \mathrm{C}$ (Cheng et al. 2020, Li et al. 2007, Pechenik et al. 2000, Wang et al. 2008, Cranford \& Gordon 1992, Smit et al. 2002). However, these studies have relatively high rates of mortality, and tend to have constant application of stressors. In the current experiment the salinity treatment ranged from 9-12ppt, the sediment treatment had concentrations of $8 \mathrm{~g} / \mathrm{L}$, and the temperature treatment was $10^{\circ} \mathrm{C}$ above ambient seawater temperature $\left(20-27^{\circ} \mathrm{C}\right)$. These intensities were similar to previous literature and were much higher than naturally occurring levels of these stressors at both sites. Otaki River opens to the sea just south of the main beach and water temperature throughout the year ranges from $12-20^{\circ} \mathrm{C}$. Pauatahanui and Ration Streams are the source of $80 \%$ of sediment run-off into Pauatahanui inlet and water temperature at this site varies from $10-17^{\circ} \mathrm{C}$ (Surf forecast, 2019). Both sites have a freshwater input, but there is little data around sedimentation at either location. As there was low mortality across all experiments despite the high intensities of stressors, both tuatua and cockles likely have high resistance to singular changes in temperature, and salinity in their natural environment. It is difficult to make conclusions about sediment tolerance without better data on sediment input into these ecosystems.

The results of this study could mean MMEs are likely to be a result of multiple stressors occurring within a system (e.g. stress and disease). This contributes to our understanding of why and when MMEs may occur. It is possible that during the high cockle mortality event from March to May 
another stressor was occurring in the environment and contributed to the mortality seen in the pilot experiment and experiment 1. Past this event, the level of stressors for cockles may have been too low to have a significant impact accounting for the lack of cockle stress signs. In future cockle MMEs, time of year should be noted to investigate if the March-May time period is significant and what other correlating factors could be contributing to lowered cockle immunity. Additional experiments could also be carried out to investigate stressor thresholds for mortality in tuatua and cockles.

Recognising how damage manifests can aid in understanding the health of organisms and the environment (Mosser et al. 1997, Dallares et al. 2018). Bivalves can be used as environmental indicator species because of their sensitivity to pollutants, isotopes present in their shell growth, and their ability to accumulate microorganisms (Almeida et al. 2007, Bemis \& Geary 1996, Dore \& Lees 1995). For example, Dallares et al. (2018) looked at 3 different bivalve species living in the same system and assessed biochemical markers and histopathology to evaluate pesticide pollution. Sub-optimal health was found across all 3 species and was used to confirm presence of a stress input into the environment. Understanding different mechanisms of how bivalves express stress across species can also further our understanding of ecosystem health. Though tuatua and cockles do not reside in the same ecosystem, sampling and health assessments could help understand wider environmental perturbations.

In terms of susceptibility to different environmental stressors, tuatua had the highest sensitivity to the heat treatment, while cockles had the highest sensitivity to the salinity treatment. Despite suspended sediment being considered an important stressor for sessile filter feeders, it had the lowest effect of all stressors tested in these experiments (Bell et al. 2015). This could be because tuatua and bivalves are adapted to fine sediment input, or the concentration at which clay was added to aquaria in this experiment was too low to produce a stress effect (Ilan \& Abelson 1995). Tuatua and cockles reacted to sediment differently throughout the experiments. Cockles were relatively unresponsive to the weekly addition of sediment while tuatua processed sediment out into mucus bound faeces and pseudofaeces (Newell 2004, Personal obs). This reduced the amount of clay in the water column of aquaria over time and suggests tuatua have some defense against fine sediment input, at this level with minimal negative effects. However, in experiment 4 where tuatua were the most stressed, some mortality occurred within sediment treatments. Processing fine sediment likely has a low energetic cost on tuatua that may be detrimental when coupled with other stressors. Researching bivalve response to sediment input across a range of particle sizes and 
concentrations is needed to understand how New Zealand bivalves tolerate and react to external sediment input.

The cellular mechanisms behind visual markers of stress are a missing piece of the puzzle in understanding stress response in tuatua and cockles. Further research into different gene expression in response to stressors could help isolate mechanisms involved in cell regulation and immune response in New Zealand bivalves (Bertrand et al. 2012). For example, after exposure to salinity stress, the mussels M. galloprovincialis and Mytilus trossulus had 117 genes that showed a significant change and 12 genes that were associated with species specific responses to salinity. Forty-five of the 117 genes that were expressed when exposed to salinity stress also changed in response to heat stress (Lockwood \& Somero 2011). Heat shock protein 90 (HSP90) and its homologues can help predict how different species will respond to thermal stressors (Cheng et al. 2020). Based on the results of this study, we would expect to see higher concentrations of heat shock proteins, and stress associated gene expression in cockles. Tuatua may exhibit lower overall gene expression but higher salinity specific gene response. It would be interesting to see if there are any shared genes expressed in response to stress across tuatua and cockles. Comparing changes in gene expression to changes in stress markers in both species will help further understanding about the immune system in tuatua and cockles and help to confirm when they are experiencing stress.

The signs used to detect stress in both cockles and tuatua were only partially successful and need further research to confirm if they can be considered suitable stress markers. It is possible that morphological and histological markers are subtle and species-specific, creating difficulty in detecting them. More work is needed to find and confirm these markers. Cell expression changes in response to heat and salinity stress in tuatua and cockles can be further studied using the slides produced in this set of experiments. The cataloging of these slides can also serve as a measure for how these shellfish change in cell morphology over time, and how their response to increasing heat, decreasing salinity, and addition of fine sediment changes over time. These slides also capture a snapshot of the year 2019 and give an idea of what parasite loads, and environmental conditions (when looked at baseline individuals) were like in each of these two systems. They are invaluable in furthering our understanding of these bivalves and ecosystems. 
Understanding shellfish health also has human implications. The ocean and its taonga (treasures) are of central importance to Maori culture, as seen through expression in myths and legends (Ruddle 1995, Paulin 2007). The connection with the ocean is of spiritual, intellectual and social importance. Protecting these environments and adapting human behaviors to fit into the surrounding ecosystem is core to traditional beliefs and essential for sustaining these ecosystems (Wellington Regional Council 1998, Memon \& Cullen 1992). The shellfish studied in this experiment are also traditionally harvested for consumption. Ingestion of unhealthy shellfish can have devastating human health impacts. For example, an assessment of 121 market-ready oysters in Vietnam showed $81 \%$ of samples were found to be contaminated with norovirus (Suffredini et al. 2020). Largely this occurs at safe consumption levels, but in cases can cause mass shellfish poisoning events (Pilotto et al. 2019). The largest ever shellfish poisoning event was in Shanghai and involved 300,000 people contracting Hepatitis A and 47 deaths within 2 months (Chiang \& Chuang 2003, Xu et al. 1992). Shellfish poisoning events are steadily increasing worldwide. Being able to assess shellfish health by looking at the reaction time when removed from sediment and the dissection morphology, allows a way for local populations to avoid harvest of shellfish during times of high stress. This is beneficial to shellfish population numbers and human health.

\section{Conclusions}

Stress can be exhibited in broadly similar ways across a range of marine organisms including fish, gastropods and bivalves (Stein et al. 2005, Montory et al. 2015, Park et al. 2012). Despite this, there is also a huge amount of variation in response mechanisms even within the bivalve class. This study further confirmed this variation showing that despite the similarities in body morphology, there can be highly different responses to stress across cockles and tuatua.

The creation of visual indices to compare morphology and histology of different tissue types under different environmental stressors, though needing further development, is a novel achievement and has not been attempted in these species before. Though many of the categories did not appear to change in relation to stressors, there is still value in better understanding the individual variation in both morphological and histological states between individuals within a species. Understanding how the keystone bivalves $A$. strutchburyi and $P$. subtriangulata express stress is of importance to species health, sustainability, ecosystem health, and human health. 
Overall, stress tolerance in this study was higher in the cockles than in the tuatua. Across all experiments fewer cockles died, indicating cockles have higher tolerance to variations in heat and salinity. Summer spawning mortality had no effect on cockles in this experiment but had a significant effect on tuatua. This study suggests that tuatua may be most vulnerable during spawning periods that coincide with rapid change in environmental conditions. During these times tuatua may be vulnerable to MMEs, and care should be taken around harvesting. In cockles, changing environmental conditions with periods of lowered salinity should be closely monitored as this is likely to be when vulnerability is highest. In histology, more change was associated with time spent exposed to stressors than specific treatment. In order to detect cellular stress in tuatua and cockles, the time exposed may be more important than the stressor itself, however, this is also dependent on the stressor and its intensity. Identifying the normal categorical make up within different tissue traits in a population is extremely valuable. If the proportion of individuals in a trait category is different to the expected proportion, this could give insight as to whether stressors are present in an ecosystem, and how long they have been present for.

This study identifies heat and salinity as stressors in P. subtriangulata and A. stutchburyi with increased heat acting as a high stressor and lowered salinity acting as a low stressor. There was a possible seasonal component to expression of stress in both species that exacerbated the effects of both these treatments. Cumulative exposure over time also intensified the stressor effect. The shock of initial introduction to the stress treatment had the most visible response in mortality, morphology and histology. This was particularly notable in gills in cockles and body consistency and digestive glands in tuatua. Slow reaction time when removed from sediment should be further explored as a possible tool to identify tuatua stress especially, in mild stress situations. Being aware of stress markers contributes to our understanding of when tuatua and cockles are stressed and can help to predict and prevent MMEs in these and other bivalves in the future. 


\section{$\underline{\text { References: }}$}

Adkins, S. C., Marsden, I. D., \& Pirker, J. G. (2014). Variation in Population Structure and Density of Austrovenus stutchburyi (Veneridae) from Canterbury, New Zealand. Journal of Shellfish Research, 33(2), 343-354. https://doi.org/10.2983/035.033.0204

Agüera, A., Schellekens, T., Jansen, J. M., \& Smaal, A. C. (2015). Effects of osmotic stress on predation behaviour of Asterias rubens. Journal of Sea Research, 99, 9-16. https://doi.org/10.1016/j.seares.2015.01.003

Ajonina, P. U., Ajonina, G. N., Usongo, L., Mekongo, F., \& Ayissi, I. (2005). Gender roles and economics of exploitation, processing and marketing of bivalves and impacts on forest resources in the Sanaga Delta region of Douala-Edea Wildlife Reserve, Cameroon. International Journal of Sustainable Development and World Ecology, 12(2), 161-172. https://doi.org/10.1080/13504500509469627

Al-Homadhi, E. S. (2009). Improving Local Bentonite Performance for Drilling Fluids Applications. Journal of King Saud University - Engineering Sciences, 21(1), 45-52. https://doi.org/10.1016/S1018-3639(18)30522-1

Allam, D. Raftos, Immune responses to infectious diseases in bivalves. Journal of invertebrate pathology 131 (2015) 121-136.

Allam, B., \& Pales Espinosa, E. (2016). Bivalve immunity and response to infections: Are we looking at the right place? Fish and Shellfish Immunology, 53, 4-12. https://doi.org/10.1016/j.fsi.2016.03.037

Aneli, R. J. R., Alejandra, D. L. S. B., Lilia, F. F. A., \& Gabriel, G. O. (2014). Lethal and sub-lethal toxicity of sodio phosphate dibasic and effects in gills and behaviour of fry on the goodeid fish Skiffia multipunctata. Hidrobiologica, 24(3), 207-214.

Arafeh-Dalmau, N., Montaño-Moctezuma, G., Martinez, J. A., Beas-Luna, R., Schoeman, D. S., \& Torres-Moye, G. (2019). Extreme Marine Heatwaves alter kelp forest community near its equatorward distribution limit. Frontiers in Marine Science, 6, 1-18. https://doi.org/10.3389/fmars.2019.00499 
Atmar, R. L., Metcalf, T. G., Neill, F. H., \& Estes, M. K. (1993). Detection of enteric viruses in oysters by using the polymerase chain reaction. Applied and Environmental Microbiology, 59(2), 631-635. https://doi.org/10.1128/aem.59.2.631-635.1993

Aziz A., K., Liang, X., \& James W., C. (1995). Stress experiments as a means of investigating agespecific mortality in Drosophila melanogaster. Experimental Gerontology, 30(2), 177-184. https://doi.org/10.1016/0531-5565(94)00058-1

Babirat, C., Mouritsen, K. N., \& Poulin, R. (2004). Equal partnership : two trematode species, not one, manipulate the burrowing behaviour of the New Zealand cockle , Austrovenus stutchburyi. Journal of Helminthology, 195-199. https://doi.org/10.1079/JOH2003231

Bell, J. J., McGrath, E., Biggerstaff, A., Bates, T., Bennett, H., Marlow, J., \& Shaffer, M. (2015). Sediment impacts on marine sponges. Marine Pollution Bulletin, 94(1-2), 5-13. https://doi.org/10.1016/j.marpolbul.2015.03.030

Bemis, B. E. Geary, D. H. (1996). The Usefulness of Bivalve Stable Isotope Profiles as Environmental Indicators: Data from the Eastern Pacific Ocean and the South Caribbean Sea. Research Reports, 11, 328-339.

Bengtsson, B. E., Bengtsson, A., \& Himberg, M. (1985). Fish deformities and pollution in some Swedish waters. Ambio, 14(1), 32-35. https://doi.org/10.2307/4313095

Beninger, P. G., Ward, E., Macdonald, B. A., Thompson, R. J., Biologie, D. De, Sciences, F. Brunswick, N. (1992). Gill function and particle transport in Placopecten magellanicus (Mollusca: Bivalvia) as revealed using video endoscopy. Marine Biology, 114, 281-288.

Berthelin, C., Kellner, K., \& Mathieu, M. (2000). Storage metabolism in the Pacific oyster (Crassostrea gigas) in relation to summer mortalities and reproductive cycle (West Coast of France). Comparative Biochemistry and Physiology - B Biochemistry and Molecular Biology, 125(3), 359-369. https://doi.org/10.1016/S0305-0491(99)00187-X

Blaschke, Paul M. Woods, J. Forsyth, F. (2010). The Porirua Harbour and its catchment / report for Porirua City Council \& Wellington City Council. Ministry for Prime Industries (MPI).

Boettcher, K. J., Barber, B. J., \& Singer, J. T. (2000). Additional Evidence that Juvenile Oyster Disease Is Caused by a Member of the Roseobacter Group and Colonization of 
Nonaffected Animals by Stappia stellulata-Like Strains. Applied and Environmental Microbiology, 66(9), 3924-3930.

Booth, J. D. (1983). Studies on twelve common bivalve larvae, with notes on bivalve spawning seasons in New Zealand. New Zealand Journal of Marine and Freshwater Research, 17(3), 231-265. https://doi.org/10.1080/00288330.1983.9516001

Brahma, N., \& Gupta, A. (2020). Acute toxicity of lead in fresh water bivalves Lamellidens jenkinsianus obesa and Parreysia (Parreysia) corrugata with evaluation of sub-lethal effects on acetylcholinesterase and catalase activity, lipid peroxidation, and behavior. Ecotoxicology and Environmental Safety, 189. https://doi.org/10.1016/j.ecoenv.2019.109939

Brand, L. E. (1984). The salinity tolerance of forty-six marine phytoplankton isolates. Estuarine, Coastal and Shelf Science, 18(5), 543-556. https://doi.org/10.1016/02727714(84)90089-1

Camacho-Mondragó N, M. A., Arellano-Martínez, M., \& Ceballos-Vázquez, B. P. (2012). Particular features of gonadal maturation and size at first maturity in Atrina maura (Bivalvia: Pinnidae). Scientia Marina, 76(3), 539-548. https://doi.org/10.3989/scimar.03522.05A

Canesi, L., \& Pruzzo, C. (2016). Specificity of Innate Immunity in Bivalves: A Lesson from Bacteria. In Lessons in Immunity: From Single-cell Organisms to Mammals. https://doi.org/10.1016/B978-0-12-803252-7.00006-0

Cao, L., Damborenea, C., Penchaszadeh, P. E., \& Darrigran, G. (2017). Gonadal cycle of Corbicula fluminea (Bivalvia: Corbiculidae) in Pampean streams (Southern Neotropical Region). PLoS ONE, 12(10), 1-16. https://doi.org/10.1371/journal.pone.0186850

Cervello, M., Arizza, V., Cammarata, M., Matranga, V., Parrinello, N. (1996) Properties of sea urchin coelomocytes agglutinins. Italian J. Zool. 63, 353-356.

Chan, K. Y. K., Grünbaum, D., \& O’Donnell, M. J. (2011). Effects of ocean-acidification-induced morphological changes on larval swimming and feeding. Journal of Experimental Biology, 214(22), 3857-3867. https://doi.org/10.1242/jeb.054809 
Chang PS, Lo CF, Wang YC, Kou GH (1996) Identification of white spot syndrome associated baculovirus (WSSV) target organs in shrimp, Penaeus monodon, by in situ hybridization. Dis Aquat Org 27:131-139

Chaparro, O. R., Segura, C. J., Montory, J. A., Navarro, J. M., \& Pechenik, J. A. (2009). Brood chamber isolation during salinity stress in two estuarine mollusc species: From a protective nursery to a dangerous prison. Marine Ecology Progress Series, 374, 145-155. https://doi.org/10.3354/meps07777

Chapperon, C., \& Seuront, L. (2011). Behavioral thermoregulation in a tropical gastropod: Links to climate change scenarios. Global Change Biology, 17(4), 1740-1749. https://doi.org/10.1111/j.1365-2486.2010.02356.x

Cheng, D., Liu, H., Zhang, H., Tan, K., Ye, T., Ma, H., ... Zheng, H. (2020). Effects of thermal stress on mortality and HSP90 expression levels in the noble scallops Chlamys nobilis with different total carotenoid content. Cell Stress and Chaperones, 25(1), 105-117. https://doi.org/10.1007/s12192-019-01052-5

Chiang, S. R., \& Chuang, Y. C. (2003). Vibrio vulnificus infection: Clinical manifestations, pathogenesis, and antimicrobial therapy. Journal of Microbiology, Immunology and Infection, 36(2), 81-88.

Chuang, Yin Ching. Yuan, Chung-Yin. Liu, Cheng-Yi. Lan, Chi-Kin. Huang, Amy, H.-M. (1992). Vibrio vulnificus Infection in Taiwan : Report of 28 Cases and Review of Clinical Manifestations and Treatment. Clinical Infectious Diseases, 15(2), 271-276.

Anon. Surf forecast. Retrieved from: https://www.surf-forecast.com/breaks/OtakiBeach/seatemp

Compton, T. J., Kentie, R., Storey, A. W., Veltheim, I., Pearson, G. B., \& Piersma, T. (2008). Carbon isotope signatures reveal that diet is related to the relative sizes of the gills and palps in bivalves. Journal of Experimental Marine Biology and Ecology, 361(2), 104-110. https://doi.org/10.1016/j.jembe.2008.03.011

Corbel, H., Legros, A., Haussy, C., Jacquin, L., Gasparini, J., Karimi, B., \& Frantz, A. (2016). Stress response varies with plumage colour and local habitat in feral pigeons. Journal of Ornithology, 157(3), 825-837. https://doi.org/10.1007/s10336-016-1331-9 
Costa, P. M., Carreira, S., Costa, M. H., \& Caeiro, S. (2013). Development of histopathological indices in a commercial marine bivalve (Ruditapes decussatus) to determine environmental quality. Aquatic Toxicology, 126(2013), 442-454.

https://doi.org/10.1016/j.aquatox.2012.08.013

Covault, J. A., Craddock, W. H., Romans, B. W., Fildani, A., \& Gosai, M. (2013). Spatial and temporal variations in landscape evolution: Historic and longer-term sediment flux through global catchments. Journal of Geology, 121(1), 35-56.

https://doi.org/10.1086/668680

Cranfield, H. J. Michael, K. P. Dunn, A. (2002). The distribution, abundance and size of tuatua (Paphies donacina) on New Brighton Beach, Christchurch in 2001. Ministry of Fisheries.

Cranfield, H. J., Dunn, A., Doonan, I. J., \& Michael, K. P. (2005). Bonamia exitiosa epizootic in Ostrea chilensis from Foveaux Strait, southern New Zealand between 1986 and 1992. ICES Journal of Marine Science, 62(1), 3-13. https://doi.org/10.1016/j.icesjms.2004.06.021

Cranford, P. J., \& Jr, D. C. G. (1992). The influence of dilute clay suspensions on sea scallop (Placopecten Magellanicus) feeding activity and tissue growth. Netherlands Journal of Sea Research, 30, 107-120.

Cresswell, W. (2008). Non-lethal effects of predation in birds. Ibis, 150(1), 3-17. https://doi.org/10.1111/j.1474-919X.2007.00793.x

Dallarés, S., Carrasco, N., Álvarez-Muñoz, D., Rambla-Alegre, M., \& Solé, M. (2018). Multibiomarker biomonitoring approach using three bivalve species in the Ebro Delta (Catalonia, Spain). Environmental Science and Pollution Research, 25(36), 36745-36758. https://doi.org/10.1007/s11356-018-3614-6

D’Andrea, A. F., Stancyk, S. E., \& Chandler, G. T. (1996). Sub-lethal effects of cadmium on arm regeneration in the burrowing brittlestar, Microphiopholis gracillima. Ecotoxicology, 5(2), 115-133. https://doi.org/10.1007/BF00119050

Davis, M. W. (2010). Fish stress and mortality can be predicted using reflex impairment. Fish and Fisheries, 11(1), 1-11. https://doi.org/10.1111/j.1467-2979.2009.00331.x 
Degremont L (2011) Evidence of herpesvirus (OsHV-1) resistance in juvenile Crassostrea gigas selected for high resistance to the summer mortality phenomenon. Aquaculture 317:9495

Delgado, M., \& Camacho, A. P. (2005). Histological study of the gonadal development of Ruditapes decussatus (L.) (Mollusca: Bivalvia) and its relationship with available food. Scientia Marina, 69(1), 87-97. https://doi.org/10.3989/scimar.2005.69n187

Department of Conservation, \& Ministry of Fisheries. (2011). Coastal marine habitats and marine protected areas in the New Zealand Territorial Sea: a broad scale gap analysis. In Volume 1. Report and Appendices 1 to 6 (Vol. 1).

Diedrich, A. (2007). The impacts of tourism on coral reef conservation awareness and support in coastal communities in Belize. Coral Reefs, 26(4), 985-996. https://doi.org/10.1007/s00338-007-0224-z

Diner, R. E., Benner, I., Passow, U., Komada, T., Carpenter, E. J., \& Stillman, J. H. (2015). Negative effects of ocean acidification on calcification vary within the coccolithophore genus Calcidiscus. Marine Biology, 162(6), 1287-1305. https://doi.org/10.1007/s00227-0152669-x

Doney, S. C., Ruckelshaus, M., Emmett Duffy, J., Barry, J. P., Chan, F., English, C. A., ... Talley, L. D. (2012). Climate Change Impacts on Marine Ecosystems. Annual Review of Marine Science, 4(1), 11-37. https://doi.org/10.1146/annurev-marine-041911-111611

Dore, W. J., \& Lees, D. N. (1995). Behavior of Escherichia coli and male-specific bacteriophage in environmentally contaminated bivalve molluscs before and after deputation. Applied and Environmental Microbiology, 61(8), 2830-2834. https://doi.org/10.1128/aem.61.8.2830-2834.1995

Doyotte, A., Cossu, C., Jacquin, M. C., Babut, M., \& Vasseur, P. (1997). Antioxidant enzymes, glutathione and lipid peroxidation as relevant biomarkers of experimental or field exposure in the gills and the digestive gland of the freshwater bivalve Unio tumidus. Aquatic Toxicology, 39(2), 93-110. https://doi.org/10.1016/S0166-445X(97)00024-6 
Drent, J., Luttikhuizen, P. C., \& Piersma, T. (2004). Morphological dynamics in the foraging apparatus of a deposit feeding marine bivalve: Phenotypic plasticity and heritable effects. Functional Ecology, 18(3), 349-356. https://doi.org/10.1111/j.0269-8463.2004.00839.x

Dubilier, N. Giere, O. Grieshaber, M. K. (1995). Morphological and Ecophysiological adaptations of the Marine Oligochaete Tubificoides benedii to Sulfidic Sediments. American Zoology, $35,163-173$.

Eakin, C. M., Morgan, J. A., Heron, S. F., Smith, T. B., Liu, G., Alvarez-Filip, L., ... Yusuf, Y. (2010). Caribbean corals in crisis: Record thermal stress, bleaching, and mortality in 2005. PLoS ONE, 5(11). https://doi.org/10.1371/journal.pone.0013969

Edelaar, P., Drent, J., \& De Goeij, P. (2003). A double test of the parasite manipulation hypothesis in a burrowing bivalve. Oecologia, 134(1), 66-71. https://doi.org/10.1007/s00442-002-1038-x

Eggermont, M., Cornillie, P., Dierick, M., Adriaens, D., Nevejan, N., Bossier, P., ... Declercq, A. M. (2020). The blue mussel inside: 3D visualization and description of the vascular-related anatomy of Mytilus edulis to unravel hemolymph extraction. Scientific Reports, 10(1), 116. https://doi.org/10.1038/s41598-020-62933-9

Ellis, J., Cummings, V., Hewitt, J., Thrush, S., \& Norkko, A. (2002). Determining effects of suspended sediment on condition of a suspension feeding bivalve (Atrina zelandica): Results of a survey, a laboratory experiment and a field transplant experiment. Journal of Experimental Marine Biology and Ecology, 267(2), 147-174. https://doi.org/10.1016/S0022-0981(01)00355-0

Ellis, R. P., Parry, H., Spicer, J. I., Hutchinson, T. H., Pipe, R. K., \& Widdicombe, S. (2011). Immunological function in marine invertebrates: Responses to environmental perturbation. Fish and Shellfish Immunology, 30(6), 1209-1222. https://doi.org/10.1016/j.fsi.2011.03.017

Ereskovsky, A., Ozerov, D. A., Pantyulin, A. N., \& Tzetlin, A. B. (2019). Mass mortality event of White Sea sponges as the result of high temperature in summer 2018. Polar Biology, 42(12), 2313-2318. https://doi.org/10.1007/s00300-019-02606-0 
Fey, S. B., Siepielski, A. M., Nusslé, S., Cervantes-Yoshida, K., Hwan, J. L., Huber, E. R., ... Carlson, S. M. (2015). Recent shifts in the occurrence, cause, and magnitude of animal mass mortality events. Proceedings of the National Academy of Sciences of the United States of America, 112(4), 1083-1088. https://doi.org/10.1073/pnas.1414894112

Finlay, B. B., \& McFadden, G. (2006). Anti-immunology: Evasion of the host immune system by bacterial and viral pathogens. Cell, 124(4), 767-782.

https://doi.org/10.1016/j.cell.2006.01.034

Flegel, T.W., Lightner, D.V., Lo, C.F., Owens, L., 2008. Shrimp disease control: past, present and future. In: Bondad-Reantaso, M.G., Mohan, C.V., Crumlish, M., Subasinghe, R.P. (Eds.), Diseases in Asian Aquaculture VI. Fish Health Section. Asian Fisheries Society, Manila, Philippines, pp. 355-378

Ford, S. E., \& Chintala, M. M. (2006). Northward expansion of a marine parasite: Testing the role of temperature adaptation. Journal of Experimental Marine Biology and Ecology, 339(2), 226-235. https://doi.org/10.1016/j.jembe.2006.08.004

Franco, C. F., Santos, R., \& Coelho, A. V. (2011). Proteome characterization of sea star coelomocytes - The innate immune effector cells of echinoderms. Proteomics, 11, 35873592. https://doi.org/10.1002/pmic.201000745

Froelich, B., \& Oliver, J. D. (2013). The Interactions of Vibrio vulnificus and the Oyster Crassostrea virginica. Microbial Ecology, 65(4), 807-816. https://doi.org/10.1007/s00248-012-0162-3

Fryer, S. E., \& Bayne, C. J. (1996). Host-parasite interactions in molluscs. Progress in Molecular and Subcellular Biology, 15,131-153. https://doi.org/10.1007/978-3-642-79735-4_7

Garrabou, J., Coma, R., Bensoussan, N., Bally, M., Chevaldonné, P., Cigliano, M., ... Cerrano, C. (2009). Mass mortality in Northwestern Mediterranean rocky benthic communities: Effects of the 2003 heat wave. Global Change Biology, 15(5), 1090-1103. https://doi.org/10.1111/j.1365-2486.2008.01823.x

Genard, B. Moraga, D. Pernet, F. Boudry, P., \& Réjean, T. (2012). Expression of candidate genes related to metabolism, immunity and cellular stress during massive mortality in the American oyster Crassostrea virginica larvae in relation to biochemical and physiological parameters. Gene, 499(1), 70-75. 
Gerdol, M., Manfrin, C., De Moro, G., Figueras, A., Novoa, B., Venier, P., \& Pallavicini, A. (2011). The C1q domain containing proteins of the Mediterranean mussel Mytilus galloprovincialis: A widespread and diverse family of immune-related molecules. Developmental and Comparative Immunology, 35(6), 635-643. https://doi.org/10.1016/j.dci.2011.01.018

Grant, C. M., Hooker, S. H., Babcock, R. C., \& Creese, R. G. (2016). Synchronous spawning and reproductive incompatibility of two bivalve species: Paphies subtriangulata and Paphies australis Synchronous Spawning and Reproductive Incompatibility of Two Bivalve Species : Paphies subtriangulata and Paphies australis. The Veliger, (April 1998).

Guerin, M. N., Weinstein, D. J., \& Bracht, J. R. (2019). Stress Adapted Mollusca and Nematoda Exhibit Convergent Expanded Hsp70 and AIG1 Gene Families. Journal of Molecular Evolution, 87(9-10), 289-297. https://doi.org/10.1007/s00239-019-09900-9

Haaker, P. L., D. O. Parker, H. Togstad, D. V. Richards, G. E. Davis, and C. S. Friedman. 1992. Mass mortality and withering syndrome in black abalone Haliotis cracherodii, in California. Pages 214-224 in S. A. Shephard, M. J. Tegner, and S. A. Guzman del pro, editors. Abalone of the world. Blackwell Scientific Publications, Oxford, UK.

Hammond, L. T. M., \& Hofmann, G. E. (2010). Thermal tolerance of Strongylocentrotus purpuratus early life history stages: Mortality, stress-induced gene expression and biogeographic patterns. Marine Biology, 157(12), 2677-2687. https://doi.org/10.1007/s00227-010-1528-z

Harvell, C. D., Kim, K., Burkholder, J. M., Colwell, R. R., Epstein, P. R., Grimes, D. J., ... Vasta, G. R. (1999). Emerging Marine Diseases - Climate Links and Anthropogenic Factors. Marine Ecology, 285(September), 1505-1511.

Hewitt, J. E., Thrush, S. F., Cummings, V. J., \& Pridmore, R. D. (1996). Matching patterns with processes : predicting the effect of size and mobility on the spatial distributions of the bivalves Macomona liliana and Austrovenus stutchburyi. Marine Ecology Progress Series, $135,57-67$.

Hewson, I., Button, J. B., Gudenkauf, B. M., Miner, B., Newton, A. L., Gaydos, J. K., ... Lahner, L. (2014). Densovirus associated with sea-star wasting disease and mass mortality. PNAS, 111(48), 17278-17283. https://doi.org/10.1073/pnas.1416625111 
Ho, P. T., Rhee, H., Kim, J., Seo, C., Park, J. K., Young, C. R., \& Won, Y. J. (2019). Impacts of salt stress on locomotor and transcriptomic responses in the intertidal gastropod Batillaria attramentaria. Biological Bulletin, 236(3), 224-241. https://doi.org/10.1086/703186

Hole, L. M., Moore, M. N., \& Bellamy, D. (1992). Age-related differences in the recovery of lysosomes from stress-induced pathological reactions in marine mussels. Marine Environmental Research, 34(1-4), 75-80. https://doi.org/10.1016/01411136(92)90086-2

Hooker, S. H. (1997). Larval and post-larval development of the New Zealand Pipi, (Paphies australis) bivalvia. Bulletin of Marine Science, 61(2), 225-240.

Hutchins, C. M., Teasdale, P. R., Lee, S. Y., \& Simpson, S. L. (2009). Influence of sediment metal spiking procedures on copper bioavailability and toxicity in the estuarine bivalve indoaustriella lamprelli. Environmental Toxicology and Chemistry, 28(9), 1885-1892. https://doi.org/10.1897/08-469.1

Hwang, A. S., Pritchard, V. L., \& Edmands, S. (2016). Recovery from hybrid breakdown in a marine invertebrate is faster, stronger and more repeatable under environmental stress. Journal of Evolutionary Biology, 29(9), 1793-1803. https://doi.org/10.1111/jeb.12913

Ilan, M., \& Abelson, A. (1995). The life of a sponge in a sandy lagoon. Biological Bulletin, 189(3), 363-369. https://doi.org/10.2307/1542154

Islam, M. N., \& Hossain, M. A. (2013). Mortality Rate of Fish Seeds (Labeo rohita) During Traditional Transportation System in the Northwest Bangladesh. Journal of Scientific Research, 5(2), 383-392. https://doi.org/10.3329/jsr.v5i2.10572

Ivanina, A. V., Dickinson, G. H., Matoo, O. B., Bagwe, R., Dickinson, A., Beniash, E., \& Sokolova, I. M. (2013). Interactive effects of elevated temperature and CO2 levels on energy metabolism and biomineralization of marine bivalves Crassostrea virginica and Mercenaria mercenaria. Comparative Biochemistry and Physiology - A Molecular and Integrative Physiology, 166(1), 101-111. https://doi.org/10.1016/j.cbpa.2013.05.016 
Jemaa, M., Morin, N., Cavelier, P., Cau, J., Strub, J. M., \& Delsert, C. (2014). Adult somatic progenitor cells and hematopoiesis in oysters. Journal of Experimental Biology, 217(17), 3067-3077. https://doi.org/10.1242/jeb.106575

Jones, E., Francis, M., Paterson, C., \& Morrison, M. (2015). Habitats of particular significance for fisheries management : identification of threats and stressors to rig nursery areas New Zealand Aquatic Environment and Biodiversity Report No. 150. Ministry for Prime Industries (MPI).

Jones, G. P., McCormick, M. I., Srinivasan, M., \& Eagle, J. V. (2004). Coral decline threatens fish biodiversity in marine reserves. Proceedings of the National Academy of Sciences of the United States of America, 101(21), 8251-8253. https://doi.org/10.1073/pnas.0401277101

Jones, H. F. E., Pilditch, C. A., Bruesewitz, D. A., \& Lohrer, A. M. (2011). Sedimentary environment influences the effect of an infaunal suspension feeding bivalve on estuarine ecosystem function. PLoS ONE, 6(10). https://doi.org/10.1371/journal.pone.0027065

Jordan, T. E., Whigham, D. F., Hofmockel, K. H., \& Pittek, M. A. (2003). Nutrient and Sediment Removal by a Restored Wetland Receiving Agricultural Runoff. Journal of Environment Quality, 32(4), 1534. https://doi.org/10.2134/jeq2003.1534

Jørgensen, C. B. (1996). Bivalve filter feeding revisited. Marine Ecology Progress Series, 142(13), 287-302. https://doi.org/10.3354/meps142287

Kadam, S. K., Chandanshive, V. V., Rane, N. R., Patil, S. M., Gholave, A. R., Khandare, R. V., ... Govindwar, S. P. (2018). Phytobeds with Fimbristylis dichotoma and Ammannia baccifera for treatment of real textile effluent: An in situ treatment, anatomical studies and toxicity evaluation. Environmental Research, 160(September), 1-11. https://doi.org/10.1016/j.envres.2017.09.009

Keeling, S. E., Brosnahan, C. L., Williams, R., Gias, E., Hannah, M., Bueno, R., ... Johnston, C. (2014). New Zealand juvenile oyster mortality associated with ostreid herpesvirus 1 - an opportunistic longitudinal study. Diseases of Aquatic Organisms, 109, 231-239. https://doi.org/10.3354/dao02735 
Kennicutt, M. C., Keeney-Kennicutt, W. L., Bresley, B. J., \& Fenner, F. (1982). The use of pyrolysis and barium distributions to assess the areal extent of drilling fluids in surficial marine sediments. Environmental Geology, 4(3-4), 239-249. https://doi.org/10.1007/BF02380517

Khan, B., Adeleye, A. S., Burgess, R. M., Smolowitz, R., Russo, S. M., \& Ho, K. T. (2019). A 72-h exposure study with eastern oysters (Crassostrea virginica) and the nanomaterial graphene oxide. Environmental Toxicology and Chemistry, 38(4), 820-830. https://doi.org/10.1002/etc.4367

Kindermann, C., Narayan, E. J., Wild, F., Wild, C. H., \& Hero, J. M. (2013). The effect of stress and stress hormones on dynamic colour-change in a sexually dichromatic Australian frog. Comparative Biochemistry and Physiology - A Molecular and Integrative Physiology, 165(2), 223-227. https://doi.org/10.1016/j.cbpa.2013.03.011

Kristensen, E., Penha-Lopes, G., Delefosse, M., Valdemarsen, T., Quintana, C. O., \& Banta, G. T. (2012). What is bioturbation? The need for a precise definition for fauna in aquatic sciences. Marine Ecology Progress Series, 446, 285-302. https://doi.org/10.3354/meps09506

Kryger, J., \& Riisgård, H. U. (1988). Filtration rate capacities in 6 species of European freshwater bivalves. Oecologia, 77(1), 34-38. https://doi.org/10.1007/BF00380921

Lange, R. (1970). Isosmotic intracellular regulation and euryhalinity in marine bivalves. Journal of Experimental Marine Biology and Ecology, 5(2), 170-179. https://doi.org/10.1016/0022-0981(70)90015-8

Langenbuch, M., \& Pörtner, H. O. (2004). High sensitivity to chronically elevated CO 2 levels in a eurybathic marine sipunculid. Aquatic Toxicology, 70(1), 55-61. https://doi.org/10.1016/j.aquatox.2004.07.006

Lau, Y. T., Sussman, L., Pales Espinosa, E., Katalay, S., \& Allam, B. (2017). Characterization of hemocytes from different body fluids of the eastern oyster Crassostrea virginica. Fish and Shellfish Immunology, 71, 372-379. https://doi.org/10.1016/j.fsi.2017.10.025 
Lessios, H. A. (2005). Diadema antillarum populations in Panama twenty years following mass mortality. Coral Reefs, 125-127. https://doi.org/10.1007/s00338-004-0443-5

Li, Y., Qin, J. G., Abbott, C. A., Li, X., \& Benkendorff, K. (2007). Synergistic impacts of heat shock and spawning on the physiology and immune health of Crassostrea gigas: An explanation for summer mortality in Pacific oysters. American Journal of Physiology - Regulatory Integrative and Comparative Physiology, 293(6), 2353-2362. https://doi.org/10.1152/ajpregu.00463.2007

Li, Y., Qin, J. G., Li, X., \& Benkendorff, K. (2009). Spawning-dependent stress response to food deprivation in Pacific oyster Crassostrea gigas. Aquaculture, 286(3-4), 309-317. https://doi.org/10.1016/j.aquaculture.2008.09.035

Li, Y., Qin, J. G., Li, X., \& Benkendorff, K. (2009). Spawning-dependent stress responses in pacific oysters Crassostrea gigas: A simulated bacterial challenge in oysters. Aquaculture, 293(3-4), 164-171. https://doi.org/10.1016/j.aquaculture.2009.04.044

Lockwood, B. L., \& Somero, G. N. (2011). Transcriptomic responses to salinity stress in invasive and native blue mussels (genus Mytilus). Molecular Ecology, 20(3), 517-529. https://doi.org/10.1111/j.1365-294X.2010.04973.x

MacDiarmid, A., McKenzie, A., Sturman, J., Beaumont, J., Mikaloff-Fletcher, S., \& Dunne, J. (2012). Assessment of anthropogenic threats to New Zealand marine habitats. In New Zealand Aquatic Environment and Biodiversity Report.

Madeira, D., Narciso, L., Cabral, H. N., \& Vinagre, C. (2012). Thermal tolerance and potential impacts of climate change on coastal and estuarine organisms. Journal of Sea Research, 70, 32-41. https://doi.org/10.1016/j.seares.2012.03.002

Marsden, I. D. (2004). Effects of reduced salinity and seston availability on growth of the New Zealand little-neck clam Austrovenus stutchburyi. Marine Ecology Progress Series, 266, 151-171.

Matsuzaki, S. I. S., Usio, N., Takamura, N., \& Washitani, I. (2007). Effects of common carp on nutrient dynamics and littoral community composition: Roles of excretion and bioturbation. Fundamental and Applied Limnology, 168(1), 27-38. https://doi.org/10.1127/1863-9135/2007/0168-0027 
McElwain, A., \& Bullard, S. A. (2014). Histological Atlas of Freshwater Mussels (Bivalvia, Unionidae): Villosa nebulosa (Ambleminae: Lampsilini), Fusconaia cerina (Ambleminae: Pleurobemini) and Strophitus connasaugaensis (Unioninae: Anodontini) . Malacologia, 57(1), 99-239. https://doi.org/10.4002/040.057.0104

McEwen, B. S. (2013). Allostasis and allostatic load: Implications for neuropsychopharmacology. The Science of Mental Health: Stress and the Brain, 9(99), 2-18.

Medler, S., \& Silverman, H. (2001). Muscular alteration of gill geometry in vitro: Implications for bivalve pumping processes. Biological Bulletin, 200(1), 77-86. https://doi.org/10.2307/1543087

Memon, P, A. Cullen, R. (1992). Fishery Policies and their Impact on the New Zealand Maori. Marine Resource Economics, 7, 153-167. https://doi.org/10.20595/jjbf.19.0_3

Menge, B. A., Cerny-chipman, E. B., Johnson, A., Sullivan, J., Gravem, S., \& Chan, F. (2016). Sea Star Wasting Disease in the Keystone Predator Pisaster ochraceus in Oregon : Insights into Differential Population Impacts, Recovery, Predation Rate, and Temperature Effects from Long-Term Research. PLoS ONE, 11(5), 1-28. https://doi.org/10.6085/AA/publication

Michael, K. P. Forman, J. Hulston, D. Fu, D. (2012). New Zealand Fisheries Assessment Report 2013 / 38. In Ministry for Prime Industries (MPI).

Miner, C. M., Burnaford, J. L., Ambrose, R. F., Antrim, L., Bohlmann, H., Blanchette, C. A., ... Raimondi, P. T. (2018). Large-scale impacts of sea star wasting disease ( SSWD) on intertidal sea stars and implications for recovery. PLoS ONE, 13(3), 1-21. https://doi.org/10.6085/AA/marine

Mitton, J, B. Koehn, K. R. (1976). Morphological Adaptation to Thermal Stress in a Marine Fish, Fundulus heteroclitus. Biological Bulletin, 151(3), 548-559.

Ministry for Primary Industries (2015a). NZ Marine Pest ID Guide. In Biosecurity New Zealand. Ministry for Primary Industries (2015b). Proposed closures to the recreational harvesting of cockle and pipi at Ngunguru and Whangateau. Ministry for Prime Industries (MPI), (October), 21. 
Ministry for Primary Industries (2019). New Zealand Marine Pest ID Guide. Biosecurity New Zealand, Wellington. 32pp

Montalvão, M. F., Chagas, T. Q., Gabriela da Silva Alvarez, T., Mesak, C., Pereira da Costa Araújo, A., Gomes, A. R., ... Malafaia, G. (2019). Cigarette butt leachate as a risk factor to the health of freshwater bivalve. Chemosphere, 234, 379-387.

https://doi.org/10.1016/j.chemosphere.2019.06.100

Montory, J. A., Pechenik, J. A., Diederich, C. M., \& Chaparro, O. R. (2014). Effects of low salinity on adult behavior and larval performance in the intertidal gastropod Crepipatella peruviana (Calyptraeidae). PLoS ONE, 9(7). https://doi.org/10.1371/journal.pone.0103820

Moore, J. D., Robbins, T. T., Friedman, C. S., Moore, J. D., Robbins, T. T., \& Withering, C. S. F. (2000). Withering Syndrome in Farmed Red Abalone Haliotis rufescens: Thermal Induction and Association with a Gastrointestinal Rickettsiales- like Prokaryote Withering Syndrome in Farmed Red Abalone Haliotis rufescens. Journal of Aquatic Animal Health, 12, 26-34. https://doi.org/10.1577/1548-8667(2000)012<0026

Moritsch, M. M., \& Raimondi, P. T. (2018). Reduction and recovery of keystone predation pressure after related mass mortality. Ecology and Evolution, (February), 3952-3964. https://doi.org/10.1002/ece3.3953

Morton, J., and M. Miller. 1968. The New Zealand seashore. Collins, London. 638 pp

Moser, J. R., Galván, D. A., Mendoza, F., Encinas, T., Coronado, D. E., Portillo, G., ... Hernández, J. (2012). Water temperature in fluencies viral load and detection of White Spot Syndrome Virus ( WSSV ) in Litopenaeus vannamei and wild crustaceans. Aquaculture, 326-329, 914. https://doi.org/10.1016/j.aquaculture.2011.10.033

Mosser, D. D., Caron, A. W., Bourget, L., Denis-Larose, C., \& Massie, B. (1997). Role of the human heat shock protein hsp70 in protection against stress-induced apoptosis. Molecular and Cellular Biology, 17(9), 5317-5327. https://doi.org/10.1128/mcb.17.9.5317

Mouritsen, K. N. (2014). The parasite-induced surfacing behaviour in the cockle Austrovenus stutchburyi : a test of an alternative hypothesis and identification of potential mechanisms. Parasitology. https://doi.org/10.1017/S0031182002001427 
Mouritsen, K. N., \& Poulin, R. (2003). Parasite-induced trophic facilitation exploited by a nonhost predator: A manipulator's nightmare. International Journal for Parasitology, 33(10), 1043-1050. https://doi.org/10.1016/S0020-7519(03)00178-4

Mouritsen, K. N., \& Poulin, R. (2003). The risk of being at the top : foot-cropping in the New Zealand cockle Austrovenus stutchburyi. Journal of the Marine Biology Association of the United Kingdom, 497-498.

Musumeci, G. (2014). Past, present and future: overview on histology and histopathology. Journal of Histology and Histopathology, 1(1), 5. https://doi.org/10.7243/2055-091x-1-5

Mydlarz, L. D., Jones, L. E., \& Harvell, C. D. (2006). Innate Immunity, Environmental Drivers, and Disease Ecology of Marine and Freshwater Invertebrates. Annu. Rev. Ecol. Evol. Syst., 37, 251-290. https://doi.org/10.1146/annurev.ecolsys.37.091305.110103

Nakano, H., Koube, H., Umezawa, S., Momoyama, K., Hiraoka, M., Inouye, K., Oseko, N., 1994. Mass mortalities of cultured kuruma shrimp, Penaeus japonicus, in Japan in 1993: epizootiological survey and infection trials. Fish Pathol. 29, 135- 139

Newell, R. I. E. (2004). Ecosystem Influences of Natural and Cultivated Populations of Suspension-Feeding Bivalve Molluscs: A Review. Journal of Shellfish Research, 23(1), 5161.

Newell, R I E. Koch, E. W. (2004). Modelling Seagrass Density and Distribution in Response to Changes in Turbidity Stemming from Bivalve Filtration and Seagrass Sediment Stabilization. Estuaries and Coasts, 27(5), 793-806.

Niamul Haque, M., Eom, H. J., Nam, S. E., Shin, Y. K., \& Rhee, J. S. (2019). Chlorothalonil induces oxidative stress and reduces enzymatic activities of $\mathrm{Na}+/ \mathrm{K}+-$ ATPase and acetylcholinesterase in gill tissues of marine bivalves. PLOS ONE, 14(4), 1-17. https://doi.org/10.1371/journal.pone.0214236

Norkko A, Thrush SF, Hewitt JE, Cummings VJ, Norkko J, Ellis JI, Funnell GA, Schultz D, MacDonald I. (2002). Smothering of estuarine sandflats by terrigenous clay: the role of wind-wave disturbance and bioturbation in site-dependent macrofaunal recovery. Marine Ecology Progress Series. 234:23-42. 
Norman, R. Brosnahan, C. Fischer, J. Frazer, J. Johnston, C. Jones, C. Jones, B. Keeling, S. Pande, A. Pulford, D. Rawdon, T. Williams, R. (2013). Salmon Mortality Investigation. Ministry for Prime Industries (MPI).

Orbea, A., Dariush Fahimi, H., \& Cajaraville, M. P. (2000). Immunolocalization of four antioxidant enzymes in digestive glands of molluscs and crustaceans and fish liver. Histochemistry and Cell Biology, 114(5), 393-404. https://doi.org/10.1007/s004180000207

Ottaviani, E. Franceschi, C. (1995). The Neuroimmunology of stress from invertebrates to man. Progress in Neurobiology, 48, 421-440.

Pansch, C., Scotti, M., Barboza, F. R., Al-Janabi, B., Brakel, J., Briski, E., ... Wahl, M. (2018). Heat waves and their significance for a temperate benthic community: A near-natural experimental approach. Global Change Biology, 24(9), 4357-4367. https://doi.org/10.1111/gcb.14282

Parisi, M. G., Maisano, M., Cappello, T., Oliva, S., Mauceri, A., Toubiana, M., \& Cammarata, M. (2019). Responses of marine mussel Mytilus galloprovincialis (Bivalvia: Mytilidae) after infection with the pathogen Vibrio splendidus. Comparative Biochemistry and Physiology Part - C: Toxicology and Pharmacology, 221, 1-9. https://doi.org/10.1016/j.cbpc.2019.03.005

Park, K., Kim, R., Park, J. J., Shin, H. C., Lee, J. S., Cho, H. S., ... Kwak, I. S. (2012). Eco-toxicological evaluation of tributyltin toxicity to the equilateral venus clam, Gomphina veneriformis (Bivalvia: Veneridae). Fish and Shellfish Immunology, 32(3), 426-433. https://doi.org/10.1016/j.fsi.2011.11.031

Patterson, K. L., Porter, J. W., Ritchie, K. B., Polson, S. W., Mueller, E., Peters, E. C., ... Smith, G. W. (2002). The etiology of white pox, a lethal disease of the Caribbean elkhorn coral , Acropora palmata. PNAS, 99(13), 8725-8730.

Paulin, C. D. (2007). Perspectives of Mäori fishing history and techniques. Ngä ähua me ngä püräkau me ngä hangarau ika o te Mäori The Mäori fishery. Tuhinga, 18, 11-47.

Paul-Pont, I., Evans, O., Dhand, N. K., Rubio, A., Coad, P., \& Whittington, R. J. (2014). Descriptive epidemiology of mass mortality due to Ostreid herpesvirus-1 (OsHV-1) in commercially 
farmed Pacific oysters (Crassostrea gigas) in the Hawkesbury River estuary, Australia. Aquaculture, 422-423(December 2013), 146-159. https://doi.org/10.1016/j.aquaculture.2013.12.009

Pechenik, J. A., Gleason, T., Daniels, D., \& Champlin, D. (2001). Influence of larval exposure to salinity and cadmium stress on juvenile performance of two marine invertebrates (Capitella sp. I and Crepidula fornicata). Journal of Experimental Marine Biology and Ecology, 264(1), 101-114. https://doi.org/10.1016/S0022-0981(01)00313-6

Perrigault, M. Dahl, S, F. Espinosa, E. Allam, B. (2012). Effects of salinity on hard clam (Mercenaria mercenaria) defence parameters and QPX disease dynamics. Journal of Invertebrate Pathology, 110, 73-82. https://doi.org/10.1016/j.jip.2012.02.0004

Petes, L. E., Menge, B. A., \& Murphy, G. D. (2007). Environmental stress decreases survival, growth, and reproduction in New Zealand mussels. Journal of Experimental Marine Biology and Ecology, 351(1-2), 83-91. https://doi.org/10.1016/j.jembe.2007.06.025

Pierce, S. K., Jr., \& Greenberg, M. J. (1972). The nature of cellular volume regulation in marine bivalves. Journal of Experimental Biology, 57(3), 681-692.

Pilotto, M. R., Souza, D. S. M., \& Barardi, C. R. M. (2019). Viral uptake and stability in Crassostrea gigas oysters during depuration, storage and steaming. Marine Pollution Bulletin, 149, 110524. https://doi.org/10.1016/j.marpolbul.2019.110524

Pinto, J., Costa, M., Leite, C., Borges, C., Coppola, F., Henriques, B., ... Freitas, R. (2019). Ecotoxicological effects of lanthanum in Mytilus galloprovincialis: Biochemical and histopathological impacts. Aquatic Toxicology, 211(March), 181-192. https://doi.org/10.1016/j.aquatox.2019.03.017

Poulin, R., \& Mouritsen, K. N. (2006). Climate change, parasitism and the structure of intertidal ecosystems. Journal of Helminthology, 183-191. https://doi.org/10.1079/JOH2006341

Pruzzo, C., Gallo, G., \& Canesi, L. (2005). Mini-review Persistence of vibrios in marine bivalves : the role of interactions with haemolymph components. Environmental Microbiology, 7, 761-772. https://doi.org/10.1111/j.1462-2920.2005.00792.x 
Pujol-Lereis, L. M., Fagali, N. S., Rabossi, A., Catalá, Á., \& Quesada-Allué, L. A. (2016). Chill-coma recovery time, age and sex determine lipid profiles in Ceratitis capitata tissues. Journal of Insect Physiology, 87, 53-62. https://doi.org/10.1016/j.jinsphys.2016.02.002

Redfearn, P. (1987). Larval shell development of the northern tuatua, Paphies subtriangulata (Bivalvia, Mesodesmatidae ). NZ Journal of Marine and Freshwater Research, 8330. https://doi.org/10.1080/00288330.1987.9516201

Richardson, J. R., Aldridge, A. E., \& Smith, P. J. (1982). Analyses of tuatua populations - Paphies subtriangulata and Paphies donacina. New Zealand Journal of Zoology, 9(2), 231-237. https://doi.org/10.1080/03014223.1982.10423851

Ritchie, K.B. (2006). Regulation of microbial populations by coral surface mucus and mucusassociated bacteria. Marine Ecology Progress Series 322:1-14.

Rollo, A., Sulpizio, R., Nardi, M., Silvi, S., Orpianesi, C., Caggiano, M., ... Carnevali, O. (2006). Live microbial feed supplement in aquaculture for improvement of stress tolerance. Fish Physiology and Biochemistry, 32(2), 167-177. https://doi.org/10.1007/s10695-0060009-2

Ross, P. M. (2017). First detection of gas bubble disease and Rickettsia -like organisms in Paphies ventricosa, a New Zealand surf clam. Journal of Fish Diseases, (June), 187-190. https://doi.org/10.1111/jfd.12684

Ross, P. M., Knox, M. A., Smith, S., Smith, H., Williams, J., \& Hogg, I. D. (2018). Historical translocations by Māori may explain the distribution and genetic structure of a threatened surf clam in Aotearoa (New Zealand). Scientific Reports, 8(1), 1-8. https://doi.org/10.1038/s41598-018-35564-4

Rowley, A. F., \& Powell, A. (2007). Invertebrate Immune Systems-Specific, Quasi-Specific, or Nonspecific? The Journal of Immunology, 179(11), 7209-7214. https://doi.org/10.4049/jimmunol.179.11.7209

Ruddle, K. (1995). The Role of Validated Local Knowledge in the Restoration of Fisheries Property Rights: The Example of New Zealand Maori. Property Rights in a Social and Ecological Context: Part 2, Case Studies Ad Design Applications, pp. 111-120. 
Sandwell, D. R., Pilditch, C. A., \& Lohrer, A. M. (2009). Density dependent effects of an infaunal suspension-feeding bivalve (Austrovenus stutchburyi) on sandflat nutrient fluxes and microphytobenthic productivity. Journal of Experimental Marine Biology and Ecology, 373(1), 16-25. https://doi.org/10.1016/j.jembe.2009.02.015

Scheibling, R. E., \& Hennigar, A. W. (1997). Recurrent outbreaks of disease in sea urchins Strongylocentrotus droebachiensis in Nova Scotia : evidence for a link with large-scale meteorologic and oceanographic events. Marine Ecology Progress Series, 152, 155-165.

Sgro, L., Munari, C., Angonese, A., Basso, S., \& Mistri, M. (2005). Functional responses and scope for growth of two non-indigenous bivalve species in the sacca di goro (northern adriatic sea, italy). Italian Journal of Zoology, 72(3), 235-239.

https://doi.org/10.1080/11250000509356677

Shan, Y., Yan, S., Hong, X., Zha, J., \& Qin, J. (2020). Effect of imidacloprid on the behavior, antioxidant system, multixenobiotic resistance, and histopathology of Asian freshwater clams (Corbicula fluminea). Aquatic Toxicology, 218, 105333. https://doi.org/10.1016/j.aquatox.2019.105333

Shirakashi, S., \& El-Matbouli, M. (2009). Myxobolus cerebralis (Myxozoa), the causative agent of whirling disease, reduces fecundity and feeding activity of Tubifex tubifex (Oligochaeta). Parasitology, 136(6), 603-613. https://doi.org/10.1017/S0031182009005721

Smaal, A. C., Ferreira, J. G., Grant, J., Petersen, J. K., \& Strand, Ø. (2018). Goods and services of marine bivalves. Goods and Services of Marine Bivalves, 591. https://doi.org/10.1007/978-3-319-96776-9

Smit, M. G. D., Holthaus, K. I. E., Trannum, H. C., Neff, J. M., Kjeilen-Eilertsen, G., Jak, R. G., ... Hendriks, A. J. (2008). Species sensitivity distributions for suspended clays, sediment burial, and grain size change in the marine environment. Environmental Toxicology and Chemistry, 27(4), 1006-1012. https://doi.org/10.1897/07-339.1

Smith, P. J., Macarthur, G. J., \& Michael, K. P. (2010). Regional variation in electromorph frequencies in the tuatua, Paphies subtriangulata, around New Zealand. NZ Journal of Marine and Freshwater Research, 8330. https://doi.org/10.1080/00288330.1989.9516337 
Song, L., Li, X., Clarke, S., Wang, T., \& Bott, K. (2007). The Application of Neutral Red Retention Assay to Evaluate the Differences in Stress Responses to Sexual Maturation and Spawning Between Different Sizes of Pacific Oyster, Crassostrea Gigas (Thunberg). Journal of Shellfish Research, 26(2), 493-499. https://doi.org/10.2983/07308000(2007)26[493:taonrr]2.0.co;2

Sousa, R., Gutiérrez, J. L., \& Aldridge, D. C. (2009). Non-indigenous invasive bivalves as ecosystem engineers. Biological Invasions, 11(10), 2367-2385. https://doi.org/10.1007/s10530-009-9422-7

Star, B., Nederbragt, A. J., Jentoft, S., Grimholt, U., Malmstrøm, M., Gregers, T. F., ... Jakobsen, K. S. (2011). The genome sequence of Atlantic cod reveals a unique immune system. Nature, 477(7363), 207-210. https://doi.org/10.1038/nature10342

Stien, L. H., Hirmas, E., Bjørnevik, M., Karlsen, Ø., Nortvedt, R., Rørå, A. M. B., ... Kiessling, A. (2005). The effects of stress and storage temperature on the colour and texture of prerigor filleted farmed cod (Gadus morhua L.). Aquaculture Research, 36(12), 1197-1206. https://doi.org/10.1111/j.1365-2109.2005.01339.x

Strayer, D. L., Caraco, N. F., Cole, J. J., Findlay, S., \& Pace, M. L. (1999). Transformation of freshwater ecosystems by bivalves: A case study of zebra mussels in the Hudson River. BioScience, 49(1), 19-27. https://doi.org/10.2307/1313490

Studer, A., \& Poulin, R. (2013). Differential effects of temperature variability on the transmission of a marine parasite. Marine Biology, 160(10), 2763-2773. https://doi.org/10.1007/s00227-013-2269-6

Suffredini, E., Le, Q. H., Di Pasquale, S., Pham, T. D., Vicenza, T., Losardo, M., ... De Medici, D. (2020). Occurrence and molecular characterization of enteric viruses in bivalve shellfish marketed in Vietnam. Food Control, 108. https://doi.org/10.1016/j.foodcont.2019.106828

Swales, A., Bentley, S. J., McGlone, M. S., Ovenden, R., Hermanspahn, N., Budd, R., ... Okey, M. J. (2005). Pauatahanui inlet: effects of historical catchment landcover changes on inlet sedimentation. NIWA Client Report: HAM2004-149. 
Takeuchi, T., Koyanagi, R., Gyoja, F., Kanda, M., Hisata, K., Fujie, M., ... Kawashima, T. (2016). Bivalve-specific gene expansion in the pearl oyster genome: implications of adaptation to a sessile lifestyle. Zoological Letters, 2(1), 1-13. https://doi.org/10.1186/s40851-0160039-2

Tanner, R. L., Faye, L. E., \& Stillman, J. H. (2019). Temperature and salinity sensitivity of respiration, grazing, and defecation rates in the estuarine eelgrass sea hare, Phyllaplysia taylori. Marine Biology, 166(8), 1-12. https://doi.org/10.1007/s00227-019-3559-4

Thibodeaux, L. J. Bierman, V. J. (2003). The Bioturbation-Driven Chemical release process. In Environmental science and technology (Vol. 253).

Thieltges, D. W. Rick, J. (2006). Effect of temperature on emergence, survival and infectivity of cercariae of the marine trematode Renicola roscovita (Digenea: Renicolidae). Diseases of Aquatic Organisms, 73, 63-68. https://doi.org/10.3354/dao073063

Thiyagarajan, V., Pechenik, J. A., Gosselin, L. A., \& Qian, P. Y. (2007). Juvenile growth in barnacles: Combined effect of delayed metamorphosis and sub-lethal exposure of cyprids to low-salinity stress. Marine Ecology Progress Series, 344, 173-184. https://doi.org/10.3354/meps06931

Thrush, S. F., Hewitt, J. E., Cummings, V. J., Ellis, J. I., Hatton, C., Lohrer, A., \& Norkko, A. (2004). Muddy waters: Elevating sediment input to coastal and estuarine habitats. Frontiers in Ecology and the Environment, 2(6), 299-306. https://doi.org/10.1890/15409295(2004)002[0299:MWESIT]2.0.CO;2

Tokarskyy, O., Marshall, D. L., Dillon, J., \& Andrews, L. S. (2019). Long-term depuration of crassostrea virginica oysters at different salinities and temperatures changes vibrio vulnificus counts and microbiological profile. Journal of Food Protection, 82(1), 22-29. https://doi.org/10.4315/0362-028X.JFP-18-225

Tonn, N., Novais, S. C., Silva, C. S. E., Morais, H. A., Correia, J. P. S., \& Lemos, M. F. L. (2016). Stress responses of the sea cucumber Holothuria forskali during aquaculture handling and transportation. Marine Biology Research, 12(9), 948-957. https://doi.org/10.1080/17451000.2016.1218030 
Trombini, C., Hampel, M., \& Blasco, J. (2019). Assessing the effect of human pharmaceuticals (carbamazepine, diclofenac and ibuprofen) on the marine clam Ruditapes philippinarum: An integrative and multibiomarker approach. Aquatic Toxicology, 208(July 2018), 146156. https://doi.org/10.1016/j.aquatox.2019.01.004

Vaughn, C. C., \& Hakenkamp, C. C. (2001). The functional role of burrowing bivalves in freshwater ecosystems. Freshwater Biology, 46(11), 1431-1446. https://doi.org/10.1046/j.1365-2427.2001.00771.x

Vinagre, C., Narciso, L., Cabral, H. N., Costa, M. J., \& Rosa, R. (2012). Coastal versus estuarine nursery grounds: Effect of differential temperature and heat waves on juvenile seabass, Dicentrarchus labrax. Estuarine, Coastal and Shelf Science, 109, 133-137. https://doi.org/10.1016/j.ecss.2012.05.029

Wang, F., Yang, H., Gao, F., \& Liu, G. (2008). Effects of acute temperature or salinity stress on the immune response in sea cucumber, Apostichopus japonicus. Comparative Biochemistry and Physiology - A Molecular and Integrative Physiology, 151(4), 491-498. https://doi.org/10.1016/j.cbpa.2008.06.024

Wang, J., Zhang, G., Fang, X., Guo, X., Li, L., Luo, R., ... Wang, J. (2012). The oyster genome reveals stress adaptation and complexity of shell formation. Nature, 490(7418), 49-54. https://doi.org/10.1038/nature11413

Wanick, R., Mermelstein, C., Andrade, I. R., Santelli, R. E., Paranhos, R. P. R., \& Coutinho, C. C. (2017). Distinct histomorphology for growth arrest and digitate outgrowth in cultivated Haliclona sp. (Porifera: Demospongiae). Journal of Morphology, 278(12), 1682-1688. https://doi.org/10.1002/jmor.20741

Wells, S. R., Wing, L. C., Smith, A. M., \& Smith, I. W. G. (2019). Historical changes in bivalve growth rates indicate ecological consequences of human occupation in estuaries. Aquatic Conservation: Marine and Freshwater Ecosystems, 29(9), 1452-1465. https://doi.org/10.1002/aqc.3039

Wen, J., Anantheswaran, R. C., \& Knabel, S. J. (2009). Changes in barotolerance, thermotolerance, and cellular morphology throughout the life cycle of Listeria 
monocytogenes. Applied and Environmental Microbiology, 75(6), 1581-1588.

https://doi.org/10.1128/AEM.01942-08

Wendling, C. C., \& Wegner, K. M. (2013). Relative contribution of reproductive investment, thermal stress and Vibrio infection to summer mortality phenomena in Pacific oysters. Aquaculture, 412-413, 88-96. https://doi.org/10.1016/j.aquaculture.2013.07.009

Wetz, M. S., \& Yoskowitz, D. W. (2013). An “extreme" future for estuaries? Effects of extreme climatic events on estuarine water quality and ecology. Marine Pollution Bulletin, 69(1-2), 7-18. https://doi.org/10.1016/j.marpolbul.2013.01.020

Wilken, S., Huisman, J., Naus-Wiezer, S., \& Van Donk, E. (2013). Mixotrophic organisms become more heterotrophic with rising temperature. Ecology Letters, 16(2), 225-233. https://doi.org/10.1111/ele.12033

Wingfield, John. C. Kitaysky, A. S. (2002). Endocrine Responses to Unpredictable Environmental Events : Stress or Anti-Stress Hormones? Integrative and Comparative Biology, 42(3), 600-609.

Wijsman J.W.M., Troost K., Fang J., Roncarati A. (2019) Global Production of Marine Bivalves. Trends and Challenges. In: Smaal A., Ferreira J., Grant J., Petersen J., Strand Ø. (eds) Goods and Services of Marine Bivalves. Springer, Cham. https://doi.org/10.1007/978-3-31996776-9_2

Woodin, S. A., Wethey, D. S., Olabarria, C., Vázquez, E., Domínguez, R., Macho, G., \& Peteiro, L. (2020). Behavioral responses of three venerid bivalves to fluctuating salinity stress. Journal of Experimental Marine Biology and Ecology, 522(November 2019), 151256. https://doi.org/10.1016/j.jembe.2019.151256

Wootton, E. C., Dyrynda, E. A., \& Ratcliffe, N. A. (2003). Bivalve immunity: Comparisons between the marine mussel (Mytilus edulis), the edible cockle (Cerastoderma edule) and the razor-shell (Ensis siliqua). Fish and Shellfish Immunology, 15(3), 195-210. https://doi.org/10.1016/S1050-4648(02)00161-4

Wu, Y., Gu, E., Li, H., Tian, C., \& Feng, C. (2019). Oxidative stress and histological changes in: Corbicula fluminea exposed to nano-Al13 and monomeric Al coagulants. Environmental Science: Nano, 6(9), 2736-2748. https://doi.org/10.1039/c9en00320g 
Xu, Z. Y., Li, Z. H., Wang, J. X., Xiao, Z. P., \& Dong, D. X. (1992). Ecology and prevention of a shellfish-associated hepatitis A epidemic in Shanghai, China. Vaccine, 10(SUPPL. 1), 1988-1989. https://doi.org/10.1016/0264-410X(92)90547-W

Yakovis, E., \& Artemieva, A. (2017). Cockles, barnacles and ascidians compose a subtidal facilitation cascade with multiple hierarchical levels of foundation species. Scientific Reports, 7(February), 1-11. https://doi.org/10.1038/s41598-017-00260-2

Yamada, H., \& Kayama, M. (1987). Liberation of nitrogenous compounds from bottom sediments and effect of bioturbation by small bivalve, Theora lata (Hinds). Estuarine, Coastal and Shelf Science, 24(4), 539-555. https://doi.org/10.1016/02727714(87)90133-8

You, X., Su, Y., Mao, Y., Liu, M., Wang, J., Zhang, M., \& Wu, C. (2010). Effect of high water temperature on mortality, immune response and viral replication of WSSV infected Marsupenaeus japonicus juveniles and adults. Aquaculture, 305(1-4), 133-137. https://doi.org/10.1016/j.aquaculture.2010.04.024

Zhu, Z., Xu, T., He, Z., Wu, X., Wu, L., Meng, Q., \& Huang, J. (2012). Rickettsia-like organism infection associated with mass mortalities of blood clam, Tegillarca granosa, in the Yueqing Bay in China. Acta Oceanologica Sinica, 31(1), 106-115.

https://doi.org/10.1007/s13131-012-0182-3 


\section{Appendices:}

\section{Appendix A:}

\section{Davidson's fixative:}

strong formalin (37\%) ---------------500 mL

Alcohol ------------------------------ 750 mL

Glacial acetic acid ------------------- $250 \mathrm{~mL}$

Tap water --------------------------- 750 mL

Eosin: enough to color

Mix well and store at room temperature.

1\% Acid Alcohol Solution:

Hydrochloric acid --------------- $10 \mathrm{ml}$

70\% ethanol -------------------- $1000 \mathrm{ml}$

Mix well and store at room temperature.

Differentiate 30 second to 2 minutes after hematoxylin overstain.

50 um paraffin sections require 2 minutes differentiation

Eosin Y Solution:

Eosin Y Stock Solution (1\%):

Eosin Y ---------------------------------- $10 \mathrm{~g}$

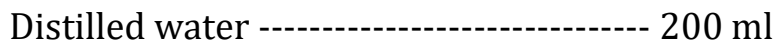

95\% Ethanol ------------------ $800 \mathrm{ml}$

Mix to dissolve and store at room temperature.

Eosin Y Working Solution (0.25\%):

Eosin Y stock solution ----------------- $250 \mathrm{ml}$

80\% Ethanol ------------------------------ $750 \mathrm{ml}$

Glacial acetic acid (concentrated) ----- $5 \mathrm{ml}$

Mix well and store at room temperature.

\section{Scott's tap water:}

Sodium bicarbonate ----------------------------- $2 \mathrm{~g}$

Magnesium sulphate ----------------------------- $20 \mathrm{~g}$

Deionised water-------------------------------- 1 litre

Dissolve the salts in the water. Store stock solutions at room temperature. 


\section{Appendix B:}

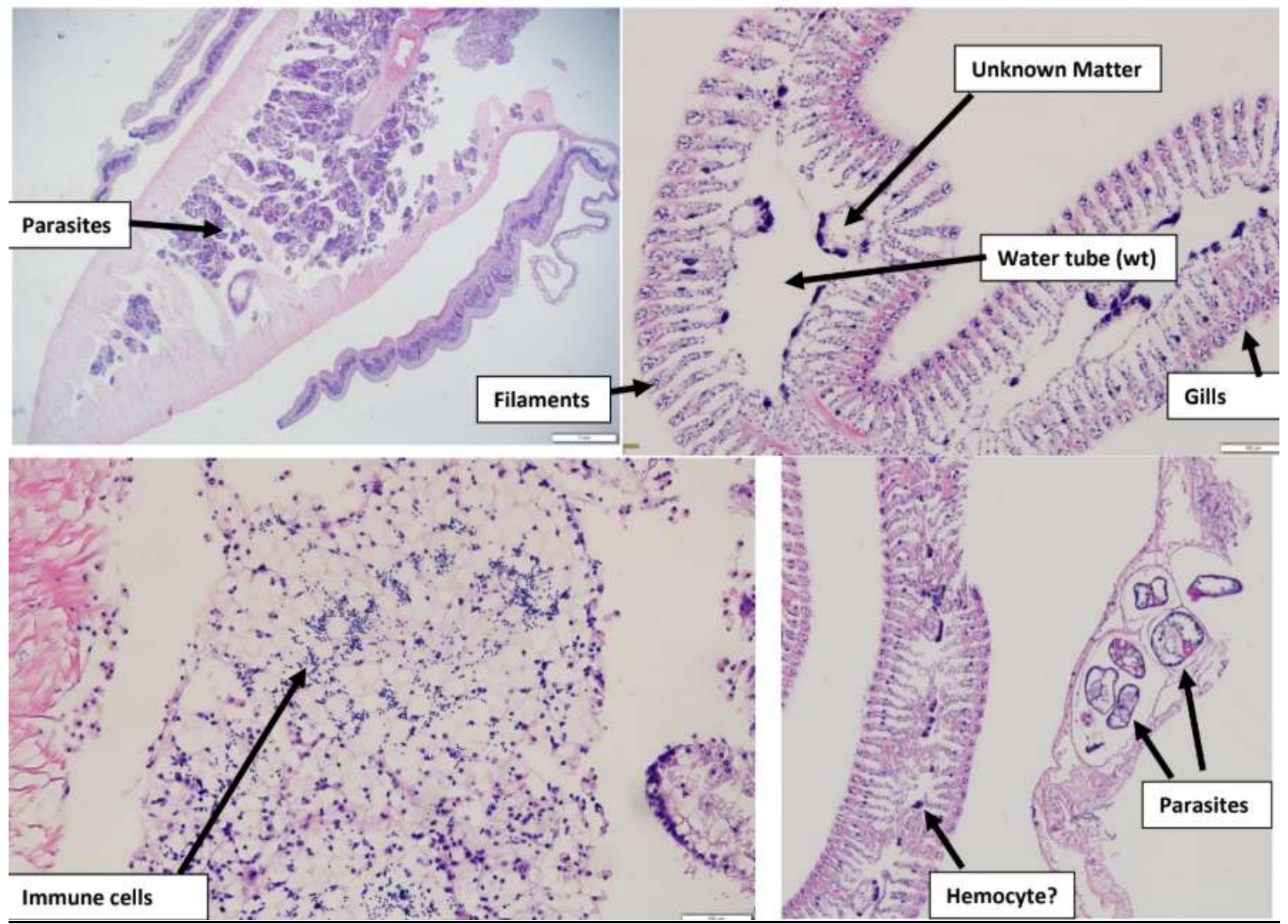

Figure 1. Labelled picture of tuatua slides from MPI catalogue. 


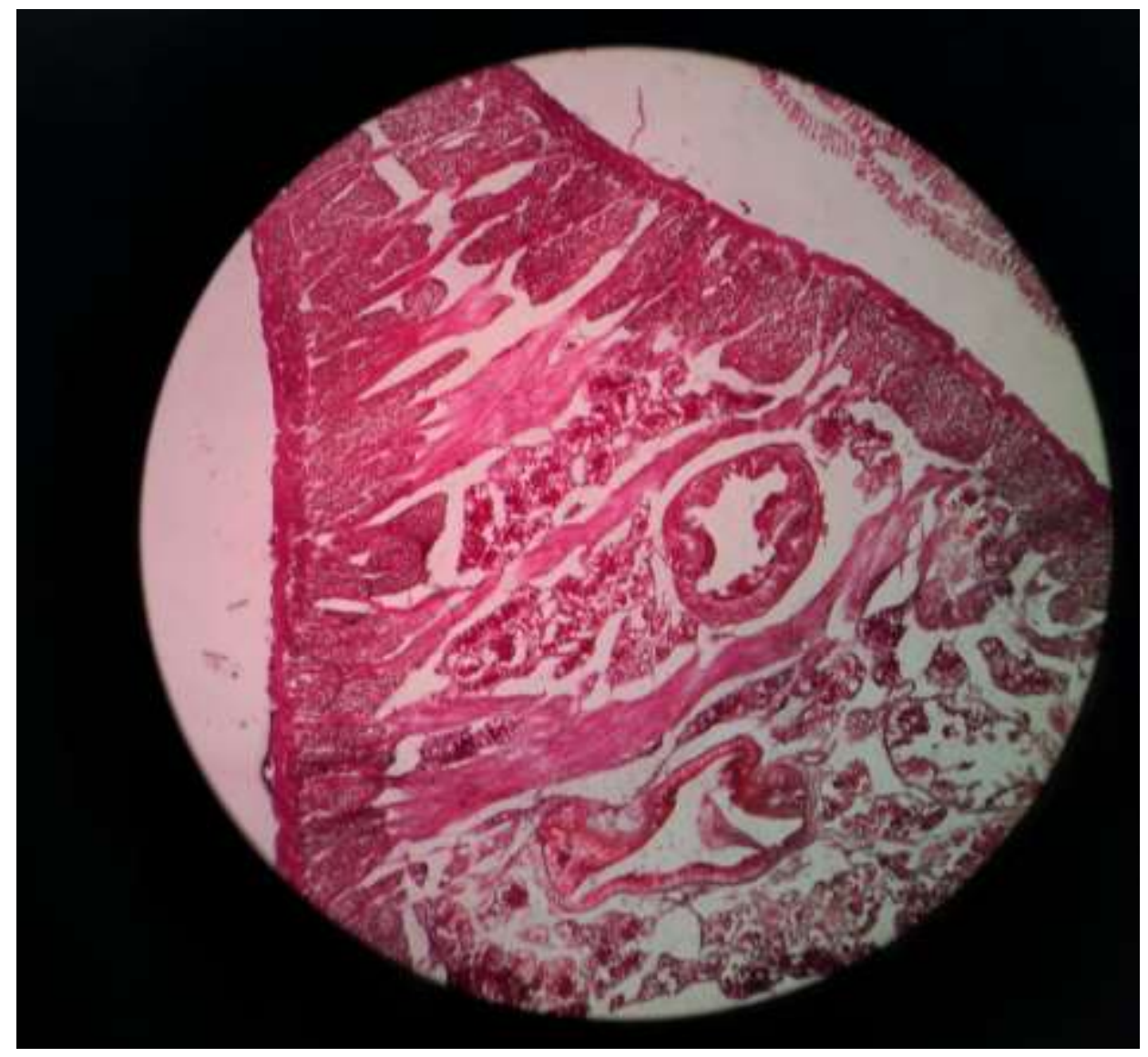

Figure 2. Example of failed histology slides. Image is obscured due to thickness in sectioning, difficulty in staining and tissue falling off slides. 


\section{Appendix C:}

Table 1: Natural death $v$ treatment in cockles. $p$ values from fisher's test.

\begin{tabular}{|l|l|}
\hline Treatment & p Val (4dp) \\
\hline C, H & 0.3613 \\
\hline C, S & 1 \\
\hline C, SE & 1 \\
\hline H, S & 1 \\
\hline H, SE & 0.4958 \\
\hline S, SE & 0.2443 \\
\hline
\end{tabular}

Table 2: Differences of digestive gland of tuatua over weeks. $p$ values from fisher's test.

\begin{tabular}{|l|l|}
\hline Weeks compared & $\mathrm{p}$ Val \\
\hline 0,1 & 0.02434 \\
\hline 0,2 & 0.2312 \\
\hline 0,3 & 0.0479 \\
\hline 0,4 & $<.0001^{* *}$ \\
\hline 1,2 & 0.569 \\
\hline 1,3 & 0.9325 \\
\hline 1,4 & 0.1201 \\
\hline 2,3 & 0.6732 \\
\hline 2,4 & $0.001731^{* *}$ \\
\hline 3,4 & 0.2327 \\
\hline
\end{tabular}


Table 3: Differences of gill erosion of tuatua over treatments

\begin{tabular}{|l|l|l|l|}
\hline Treatment compared & Chi squared & df & p Val \\
\hline B,C & Fisher's & & 0.1222 \\
\hline B,H & Fisher's & & 0.02458 \\
\hline B,S & Fisher's & & 0.2993 \\
\hline B,SE & Fisher's & & 0.2869 \\
\hline C,H & 1.986 & 2 & 0.3705 \\
\hline C,S & 7.8917 & 2 & 0.01933 \\
\hline C,SE & 0.40389 & 2 & 0.8171 \\
\hline H,S & 11.235 & 2 & $0.003634^{* *}$ \\
\hline H,SE & 2.9983 & 2 & 0.2233 \\
\hline S,SE & 4.8687 & 2 & 0.0876 \\
\hline
\end{tabular}

Table 4: Differences of gill colour of tuatua over treatments

\begin{tabular}{|l|l|}
\hline Treatment compared & p Val \\
\hline B,C & 0.2146 \\
\hline B,H & $0.002973^{* *}$ \\
\hline B,S & 0.02376 \\
\hline B,SE & 0.05722 \\
\hline C,H & 0.04926 \\
\hline C,S & 0.3733 \\
\hline C,SE & 0.8772 \\
\hline H,S & 0.3945 \\
\hline H,SE & 0.1387 \\
\hline S,SE & 0.7586 \\
\hline
\end{tabular}


Table 5: Differences of body colour of tuatua over treatments

\begin{tabular}{|l|l|l|l|}
\hline Treatment compared & Chi Squared & df & p Val \\
\hline B,C & Fisher's & & 0.06483 \\
\hline B,H & Fisher's & & 0.0151 \\
\hline B,S & Fisher's & & 0.01983 \\
\hline B,SE & Fisher's & & 0.05569 \\
\hline C,H & 10.931 & 2 & $0.004231^{* *}$ \\
\hline C,S & 5.2345 & 2 & 0.073 \\
\hline C,SE & 2.4764 & 2 & 0.2899 \\
\hline H,S & 1.7823 & 2 & 0.4102 \\
\hline H,SE & 3.4011 & 2 & 0.1826 \\
\hline S,SE & 0.66211 & 2 & 0.7182 \\
\hline
\end{tabular}

Table 6: Differences of body consistency of tuatua over treatments

\begin{tabular}{|l|l|l|l|}
\hline $\begin{array}{l}\text { Treatment } \\
\text { compared }\end{array}$ & Chi squared & df & p Val \\
\hline B,C & Fisher's & & 0.05341 \\
\hline B,H & Fisher's & & 0.04 \\
\hline B,S & Fisher's & & 0.03178 \\
\hline B,SE & Fisher's & & 0.09298 \\
\hline C,H & 9.8489 & 2 & $0.007267^{* *}$ \\
\hline C,S & Fisher's & & 0.1526 \\
\hline C,SE & Fisher's & & 0.2824 \\
\hline H,S & 2.1556 & 2 & 0.3403 \\
\hline H,SE & 2.5333 & 2 & 0.2818 \\
\hline
\end{tabular}




\begin{tabular}{|l|l|l|l|}
\hline S,SE & 0.44983 & 2 & 0.7986 \\
\hline
\end{tabular}

Table 7: Differences of body consistency of tuatua over weeks

\begin{tabular}{|l|l|l|l|}
\hline Weeks compared & Chi Squared & $\mathrm{df}$ & $\mathrm{p}$ Val \\
\hline 0,1 & Fisher's & & $0.0008947^{* *}$ \\
\hline 0,2 & Fisher's & & $0.0001384^{* *}$ \\
\hline 0,3 & Fisher's & & 0.01526 \\
\hline 0,4 & 5.839 & 2 & 0.05396 \\
\hline 1,2 & Fisher's & & 0.8966 \\
\hline 1,3 & Fisher's & & 0.3497 \\
\hline 1,4 & 3.5522 & 2 & 0.1693 \\
\hline 2,3 & Fisher's & & 0.1795 \\
\hline 2,4 & 5.5543 & 2 & 0.06222 \\
\hline 3,4 & 2.9323 & 2 & 0.2308 \\
\hline
\end{tabular}

Table 8: Differences of red marks of tuatua over weeks

\begin{tabular}{|l|l|l|l|}
\hline Weeks compared & Chi Squared & $\mathrm{df}$ & $\mathrm{p}$ Val \\
\hline 0,1 & Fisher's & & $0.002629^{* *}$ \\
\hline 0,2 & 13.697 & 2 & $0.001061^{* *}$ \\
\hline 0,3 & Fisher's & & 0.005312 \\
\hline 0,4 & Fisher's & & $0.002213^{* *}$ \\
\hline 1,2 & 1.1984 & 2 & 0.5493 \\
\hline 1,3 & 1.8329 & 2 & 0.3999 \\
\hline 1,4 & 3.4169 & 2 & 0.1811 \\
\hline
\end{tabular}




\begin{tabular}{|l|l|l|l|}
\hline 2,3 & 2.055 & 2 & 0.3579 \\
\hline 2,4 & 3.1649 & 2 & 0.2055 \\
\hline 3,4 & 0.18142 & 2 & 0.9133 \\
\hline
\end{tabular}




\section{Appendix D:}

Table 9: Differences of gills of cockles over weeks pooled over treatments. p values from fisher's test.

\begin{tabular}{|l|l|}
\hline Weeks compared & p Val \\
\hline 0,1 & 0.07988 \\
\hline 0,2 & 0.1908 \\
\hline 0,3 & 0.008008 \\
\hline 0,4 & $3.462 \mathrm{e}-06^{* *}$ \\
\hline 0,5 & 0.006617 \\
\hline 1,2 & 0.389 \\
\hline 1,3 & 0.1308 \\
\hline 1,4 & 0.01385 \\
\hline 1,5 & 0.2191 \\
\hline 2,3 & 0.06497 \\
\hline 2,4 & $0.0007661^{* *}$ \\
\hline 2,5 & 0.01518 \\
\hline 3,4 & 0.0092 \\
\hline 3,5 & 0.73 \\
\hline 4,5 & 0.04019 \\
\hline
\end{tabular}


Table 10: Differences of gill colour of cockles over weeks. p values from fisher's test.

\begin{tabular}{|l|l|}
\hline Weeks compared & $\mathrm{p}$ Val \\
\hline 1,2 & 0.4081 \\
\hline 1,3 & 0.01113 \\
\hline 1,4 & 0.02214 \\
\hline 1,5 & 1 \\
\hline 2,3 & 0.1447 \\
\hline 2,4 & 0.2971 \\
\hline 2,5 & 0.475 \\
\hline 3,4 & 0.704 \\
\hline 3,5 & 0.02777 \\
\hline 4,5 & 0.05907 \\
\hline
\end{tabular}

Table 11: Differences of gill colour of cockles over treatments

\begin{tabular}{|l|l|}
\hline Categories compared & $\mathrm{p}$ Val \\
\hline 1,2 & 0.01211 \\
\hline
\end{tabular}

Table 12: Differences of gill erosion of cockles over weeks. $p$ values from fisher's test.

\begin{tabular}{|l|l|}
\hline Weeks compared & $\mathrm{p}$ Val \\
\hline 1,2 & 0.3952 \\
\hline 1,3 & 0.207 \\
\hline 1,4 & 0.09907 \\
\hline 1,5 & 0.1881 \\
\hline 2,3 & $0.004207^{* *}$ \\
\hline
\end{tabular}




\begin{tabular}{|l|l|}
\hline 2,4 & 0.1318 \\
\hline 2,5 & 0.02961 \\
\hline 3,4 & 0.5428 \\
\hline 3,5 & $0.007565^{* *}$ \\
\hline 4,5 & $0.002789^{* *}$ \\
\hline
\end{tabular}

Table 13: Differences of body colour of cockles over weeks. p values from fisher's test.

\begin{tabular}{|l|l|}
\hline Weeks compared & p Val \\
\hline 1,2 & 0.04714 \\
\hline 1,3 & 0.03558 \\
\hline 1,4 & 0.07952 \\
\hline 1,5 & 0.4471 \\
\hline 2,3 & 0.7869 \\
\hline 2,4 & $0.003525^{* *}$ \\
\hline 2,5 & 0.03483 \\
\hline 3,4 & 0.01153 \\
\hline 3,5 & 0.05521 \\
\hline 4,5 & 0.9184 \\
\hline
\end{tabular}




\section{Appendix E:}

The pilot experiment occurred from the 19th of March to the 12th of April. Each treatment was tested at 3 different levels with no replicates. The temperature treatment was tested at $\mathrm{HH}=32^{\circ} \mathrm{C}, \mathrm{HM}=26^{\circ} \mathrm{C}$, and $\mathrm{HL}=20^{\circ} \mathrm{C}$. The salinity treatment was tested at $\mathrm{SH}=20 \mathrm{ppt}, \mathrm{SM}=15 \mathrm{ppt}$, $\mathrm{SL}=10 \mathrm{ppt}$. Finally, the sediment treatment was tested at $\mathrm{SEH}=80 \mathrm{~g}, \mathrm{SEM}=40 \mathrm{~g}$, and SEL=25g. At the end of each week individuals were dissected and observed for morphological changes. Initially, sediment was added at the beginning of the experiment and stirred daily, but this became lesser over the course of 5 weeks and was adjusted to be topped up weekly after the pilot experiments. Mortality was relatively low for the pilot and all treatments were used at their highest intensity level for the final experiments. Mortality seen over the course of this experiment is laid out in the table below.

Table 14: Mortality in pilot experiment. Where TOD= time of death by date, and week = time of death in relation to weekly dissections.

\begin{tabular}{|l|r|l|l|}
\hline Species & \multicolumn{1}{|l|}{ TOD } & Treatment & Week \\
\hline Cockle & $3 / 20 / 2019$ & SL & Week 0 \\
\hline Cockle & $3 / 20 / 2019$ & SL & Week 0 \\
\hline Cockle & $3 / 21 / 2019$ & SL & Week 0 \\
\hline Cockle & $3 / 21 / 2019$ & SL & Week 0 \\
\hline Cockle & $3 / 24 / 2019$ & SEH & Week 0 \\
\hline Cockle & $3 / 24 / 2019$ & SH & Week 0 \\
\hline Cockle & $3 / 24 / 2019$ & SEL & Week 0 \\
\hline Cockle & $3 / 28 / 2019$ & HH & Week 1 \\
\hline Cockle & $4 / 1 / 2019$ & SEL & Week 1 \\
\hline Cockle & $4 / 2 / 2019$ & HH & Week 2 \\
\hline Cockle & $4 / 3 / 2019$ & HM & Week 2 \\
\hline Cockle & $4 / 4 / 2019$ & SM & Week 2 \\
\hline Cockle & $4 / 9 / 2019$ & HH & Week 3 \\
\hline Cockles & $4 / 11 / 2019$ & SEH & Week 3 \\
\hline Tuatua & $2 / 4 / 2019$ & HH & Week 1 \\
\hline Tuatua & $7 / 4 / 2019$ & HH & Week 2 \\
\hline
\end{tabular}

